

\author{
PISA
}

\title{
¡Vamos a leer un cuento! \\ El papel de los papás y las mamás en la educación
}

Edición en español a cargo de Morelos Torres Aguilar

y Abel Rubén Hernández Ulloa
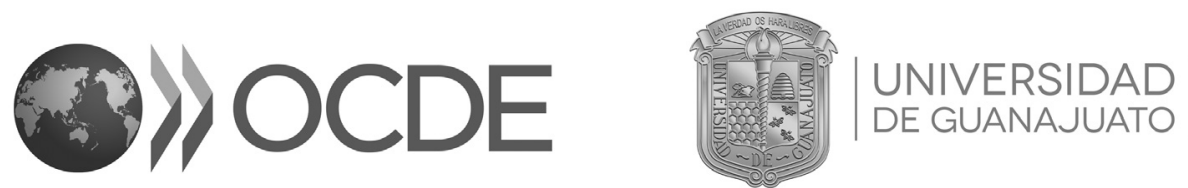

La calidad de la traducción y su correspondencia con la lengua original de la obra son responsabilidad de la Universidad de Guanajuato. En caso de discrepancias entre esta traducción al español y la versión original en inglés, sólo la versión original se considerará válida. 


\section{Universidad de Guanajuato}

Dr. José Manuel Cabrera Sixto

Rector General

Dr. Luis Felipe Guerrero Agripino

Rector del Campus Guanajuato

Dr. Javier Corona Fernández

Director de la División de Ciencias Sociales y Humanidades

Mtro. Luis Jesús Ibarra Manrique

Director del Departamento de Educación

Anel González Ontiveros

Coordinadora del Cuerpo Académico Configuraciones Formativas

Traducción por miembros del Cuerpo Académico Configuraciones Formativas

Dr. Abel Rubén Hernández Ulloa (Coordinador de la Traducción)

Dra. Luz María Muñoz de Cote

Dra. Sylvia Catherina van Dijk Kocherthaler

Originalmente publicado en Inglés y Francés bajo los títulos: PISA. Let's Read Them a Story! The Parent Factor in Educatión/PISA. Lisez-leur une histoire! Le facteur parental dans l'education.

() 2012 OCDE. Todos los derechos reservados.

(c) 2014 Universidad de Guanajuato para esta edición en español.

Lascurain de Retana \# 5, Zona Centro

C.P. 36000 , Guanajuato, Gto. México

Diseño para la presente edición en español: Joaquín Meza

Formación: Blanca L. Sánchez

Fotografía: Shutterstock

ISBN versión electrónica: 978-607-441-290-1

ISBN versión impresa: 978-607-441-292-5

Esta publicación no puede ser reproducida, ni total ni parcialmente, en ninguna forma ni por ningún medio, sin el permiso previo, por escrito, de los editores. 


\section{Prefacio}

La educación empieza en el hogar. Con la primera palabra que un padre o una madre expresa a su hijo o hija, le abre paso al mundo del lenguaje y le lleva al camino de la exploración y el descubrimiento. Cuando la escuela formal comienza, muchos padres creen que su papel como educadores ha terminado. Pero la educación es una responsabilidad compartida de padres y madres, maestras y maestros, escuelas e instituciones en la economía y en la sociedad. Nuevos descubrimientos de PISA muestran que la participación activa de los padres en la educación de sus hijos es fundamental para su éxito a lo largo de su vida escolar, y más allá de ella.

Los resultados de PISA también ofrecen alivio a las madres y a los padres que se preocupan por no tener tiempo, o el conocimiento académico requerido para ayudar a sus hijas e hijos a tener éxito en la escuela. Muchos tipos de apoyo parental, que se asocian a mejores resultados de los estudiantes en PISA, requieren en realidad de poco tiempo, y de un conocimiento no especializado. Lo que cuenta es el interés genuino, y un compromiso activo.

Este reporte, ¡Vamos a leer un cuento! El papel de los papás y las mamás en la educación, busca determinar en qué medida y de qué manera se relaciona la participación de los padres y las madres con la destreza lectora, y el disfrute de la lectura. $Y$ dado que las destrezas lectoras son una herramienta esencial para la comprensión del mundo, este reporte también examina si los estudiantes cuyos papás y mamás se involucraron más en su educación, están mejor equipados para aprender a lo largo de sus vidas.

¡Vamos a leer un cuento! no documenta solamente los resultados y análisis de PISA, sino que también ofrece a las madres, a los padres, a los educadores y a los funcionarios públicos que toman decisiones políticas, sugerencias sobre cómo mejorar la participación de las madres y los padres, y describe los tipos de actividades que se asocian más estrechamente con el mejor desempeño lector. Provee de abundantes ejemplos de programas que promueven formas efectivas para la participación de los padres alrededor del mundo. Y lo más importante: el reporte muestra a los padres que nunca es demasiado temprano -y nunca demasiado tarde- para involucrarse en la educación de sus hijas e hijos. ¡Estar involucrados es la mejor inversión que los padres pueden hacer para el futuro de la siguiente generación!

\section{Angel Gurría \\ Secretario General de la OCDE}





\section{Prefacio a la versión en español}

Compartir la lectura es uno de los actos más esenciales para el desarrollo del ser humano y de la cultura. Compartir las experiencias que han vivido papás y mamás de diversas culturas, al leer para sus hijos e hijas y junto con ellos, es un acto que nos habla de generosidad intergeneracional, y también de solidaridad global. En nuestra tarea de heredar mejores posibilidades para el desarrollo humano de las siguientes generaciones, necesitamos ampliar los horizontes de acción, con el fin de disminuir las diferencias en la construcción de las capacidades elementales para el ejercicio de la libertad. Este reporte especial del Programa para la Evaluación Internacional de los Estudiantes (PISA, por sus siglas en inglés), presenta experiencias y resultados de acciones y programas que escuelas, comunidades, organizaciones no gubernamentales, empresas privadas y gobiernos, han instrumentado en favor de la participación de los padres en la educación, y para el fomento a la lectura de sus niñas y niños. Asimismo, se da ejemplo de acciones específicas que los padres han realizado para participar de manera fundamental en la educación de sus hijos. Este reporte muestra cómo esas acciones han dado frutos positivos, que se expresan en mejores resultados en el logro académico evaluado por PISA. El texto es una invitación a la comunidad académica para que reflexione sobre la profundidad de la tarea evaluativa desde el contexto internacional; y es también una propuesta para dimensionar la búsqueda de modelos efectivos de interacción a diferentes niveles regionales y organizacionales, rasgo que caracteriza a los trabajos de la Organización para la Cooperación y el Desarrollo Económicos (OCDE).

La versión en español de este reporte es el primer fruto de la unión de esfuerzos entre la OCDE y la Universidad de Guanajuato. Se refrenda en este trabajo el compromiso de ambas instituciones para reducir la distancia entre la academia y el desarrollo social, colaboración inaugural que manifiesta el anhelo de incidir, propositivamente, en la generación de mejores políticas públicas para mejorar la calidad de vida. En este mismo sentido propositivo, el equipo de traducción ha considerado fundamental el hecho de manifestarse a favor de la equidad de género a lo largo del texto. Por esta razón se hace referencia, siempre que sea posible, tanto a mamás como a papás, tanto a hijos como a hijas, tanto a niños como a niñas, cuando en el original en inglés se implicaba a ambos. Sólo hemos evitado las reiteraciones excesivas, por ejemplo cuando se repite la expresión "padres y madres" varias veces en un mismo párrafo, o bien en el caso de los adjetivos, que califican por igual a hombres y mujeres. También hemos utilizado, en lo posible, un género neutro. Con esta acción anhelamos contribuir para que en un futuro próximo se puedan reducir en otros espacios las enormes desigualdades de género que aún prevalecen.

Confiamos en que este trabajo sirva a la comunidad hispanoparlante internacional, e inspirados en la figura de Cervantes y su Quijote, quien ha sido adoptado como símbolo de la ciudad de Guanajuato, queremos invitarlos a su lectura con alegría: ¡Vamos a leer un cuento!

\section{Abel Rubén Hernández Ulloa Departamento de Educación de la Universidad de Guanajuato Coordinador del equipo de traducción}





\section{Agradecimientos}

Este reporte fue bosquejado por Marilyn Achiron, Francesca Borgonovi y Guillermo Montt. Marika Boiron, Olivia De Backer, Elizabeth Del Bourgo, Juliet Evans, Giannina Rech y Elisabeth Villoutreix proveyeron los insumos editoriales y administrativos para el reporte. Francesco Avvisati, María del Carmen Huerta, Nathan Driskell, Irena Koźmińska, Esther Serok, Steven Sheldon, Helen Westmoreland y Lynne Whitney ofrecieron valiosas contribuciones en varios estadios del reporte. El desarrollo del reporte fue dirigido por el Cuerpo Directivo de PISA, presidido por Lorna Bertrand (Reino Unido). 



\section{Contenido}

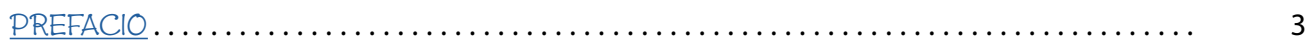

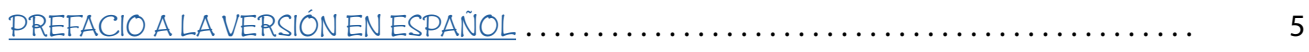

AGRADECIMIENTOS $\ldots \ldots \ldots \ldots \ldots \ldots \ldots \ldots \ldots \ldots \ldots \ldots \ldots \ldots \ldots \ldots \ldots \ldots \ldots \ldots \ldots \ldots \ldots \ldots \ldots \ldots$

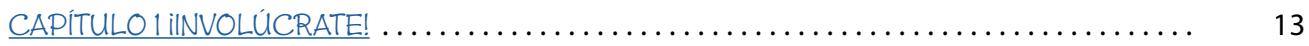

CAPITULO 2 LEE A TUS HIJOS UN CUENTO $\ldots \ldots \ldots \ldots \ldots \ldots \ldots \ldots \ldots \ldots \ldots \ldots \ldots \ldots \ldots \ldots \ldots \ldots$

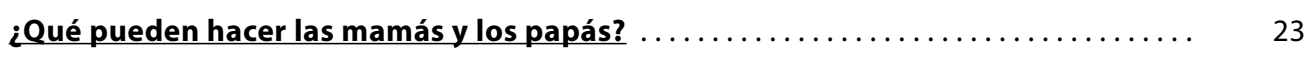

¿Qué pueden hacer las maestras y los maestros? $\ldots \ldots \ldots \ldots \ldots \ldots \ldots \ldots \ldots \ldots$

CAPÍTULO 3 HABLA CON TUS HIJOS SOBRE EL MUNDO QUE LES RODEA............ 29

¿Qué pueden hacer las mamás y los papás? $\ldots \ldots \ldots \ldots \ldots \ldots \ldots \ldots \ldots \ldots \ldots \ldots$

¿Qué pueden hacer las maestras y los maestros? $\ldots \ldots \ldots \ldots \ldots \ldots \ldots \ldots \ldots$

CAPITULO 4 INVOLÚCRATE EN LA ESCUELA PORQUE QUIERES,

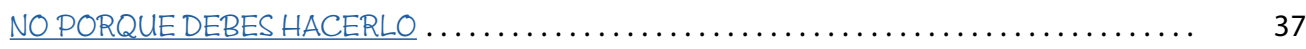

¿Qué pueden hacer las mamás y los papás? $\ldots \ldots \ldots \ldots \ldots \ldots \ldots \ldots \ldots \ldots \ldots \ldots$

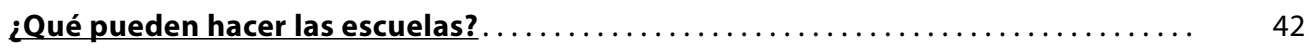

¿Qué pueden hacer los sistemas educativos? $\ldots \ldots \ldots \ldots \ldots \ldots \ldots \ldots \ldots \ldots$

CAPITTULO 5 MUESTRA A TUS HIJOS QUE TÚ TAMBIÉN VALORAS LA LECTURA ......... 49

¿Qué pueden hacer las mamás y los papás? $\ldots \ldots \ldots \ldots \ldots \ldots \ldots \ldots \ldots \ldots \ldots \ldots \ldots \ldots$

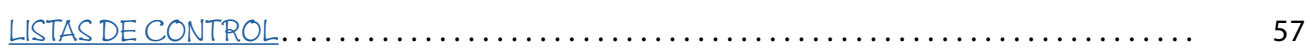

INFORMACIÓN EN CUADROS SOBRE LA PARTICIPACIÓN DE LAS MAMÁS

YLOS PAPAS EN LA LECTURA $\ldots \ldots \ldots \ldots \ldots \ldots \ldots \ldots \ldots \ldots \ldots \ldots \ldots \ldots \ldots \ldots \ldots \ldots \ldots \ldots \ldots \ldots$ 


\section{RECUADROS}

Recuadro 1.1 ¿De qué manera beneficia a los estudiantes la participación de las

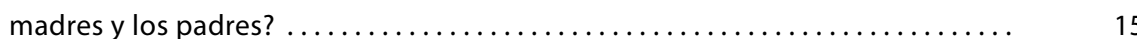

Recuadro 1.2 El Programa para la Evaluación Internacional de los Estudiantes (PISA) ....... 16

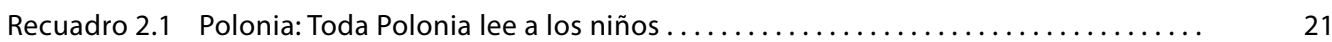

Recuadro 2.2 Reino Unido: Inicio en los libros (Bookstart) ........................ 21

Recuadro 2.3 Suecia: Las For Mej, Pappa .............................. 22

Recuadro 2.4 Rumania: Programa Nacional Parental en Educación de la Niñez Temprana ... 26

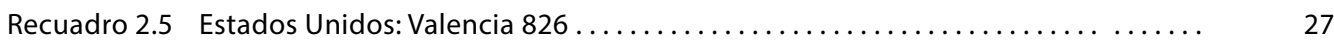

Recuadro 3.1 Alrededor del mundo: el enfoque Reggio Emilia . . . . . . . . . . . . 30

Recuadro 3.2 Israel: La familia como educador.......................... 32

Recuadro 4.1 El reconocimiento legal de las madres y lospadres como socios en Irlanda 38

Recuadro 4.2 Estados Unidos: La zona infantil de Harlem . . . . . . . . . . . . . . . . 41

Recuadro 4.3 Estados Unidos: La red nacional de escuelas asociadas . . . . . . . .... 41

Recuadro 4.4 Japón: El maestro en el hogar ......................... 44

Recuadro 4.5 Nueva Zelanda: Trabajando con la familia extendida de los Māori ....... 45

Recuadro 4.6 Corea: El apoyo escolar a la participación de los padres............. 46

Recuadro 5.1 Estados Unidos: Cultura Asombrosa (Cool Culture) ................. 51

Recuadro 5.2 ¿Qué pueden hacer los negocios y los gobiernos?................ 53

\section{GRÁFICAS}

Gráfica 2.1 Niños y niñas a quienes se les leyó desde muy pequeños, son mejores

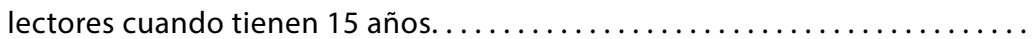

Gráfica 2.2 Las jóvenes y los jóvenes de 15 años a quienes sus padres y madres les contaron cuentos cuando eran pequeñas y pequños, son mejores lectores .

Gráfica 2.3 Lee a tu hija o hijo: no todas las madres y los padres lo hacen............

Gráfica 2.4 Algunas niñas y niños, especialmente en situaciones de desventaja, tienen poco o ningún acceso a un adulto que les lea $\ldots . \ldots \ldots \ldots \ldots . . . .$.

Gráfica 2.5 Leer a los niños no es una tarea exclusiva para papá o para mamá;

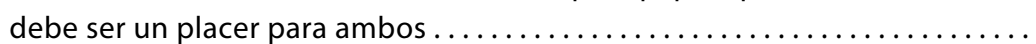

Gráfica 3.1 Los adolescentes que discuten con sus madres y padres sobre asuntos sociales y de política, son excelentes lectores $\ldots \ldots \ldots \ldots \ldots \ldots \ldots \ldots \ldots$

Gráfica 3.2 Habla de asuntos sociales y políticos con tu hijo adolescente .............

Gráfica 3.3 Mamás y papás: motiven a sus hijos compartir sus pensamientos sobre lo

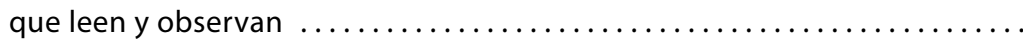

Gráfica 3.4 No tienes que ser experto en una materia para ayudar

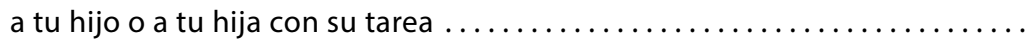


Gráfica 4.1 Discutir el progreso de tus hijos e hijas en la escuela, muestra que

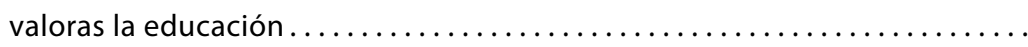

Gráfica 4.2 Participar en actividades extracurriculares en la escuela de tus hijos e hijas, solamente se asocia de manera débil con mejores resultados en el desempeño estudiantil

Gráfica 4.3 Los padres son una fuente importante de ayuda para estudiantes que tienen problemas

Gráfica 4.4 No esperen a tener problemas académicos o de conducta, para conocer al maestro de sus hijos e hijas

Gráfica 4.5 Haz un esfuerzo e involúcrate: sé voluntaria o voluntario

Gráfica 5.1 Muestra un buen ejemplo a tus hijos: lee tú mismo

Gráfica 5.2 Los estudiantes en situaciones de desventaja, frecuentemente carecen

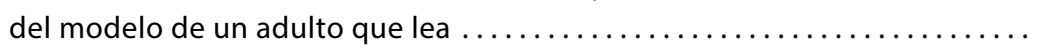

\section{CUADROS}

Cuadro A2.1 Leer libros a niñas y niños pequeños, y la relación con su

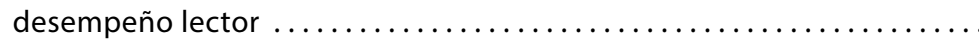

Cuadro A2.2 Contar cuentos a niñas y niños pequeños, y la relación con su

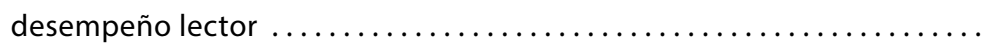

Cuadro A2.3 Leer libros a niñas y niños pequeños: la relación con el gozo de la lectura, y con la conciencia de estrategias efectivas de resumen ........

Cuadro A2.4 Contar cuentos a niñas y niños pequeños: la relación con el gozo de la lectura, y con la conciencia de estrategias efectivas de resumen...

Cuadro A3.1 Discutir sobre temas políticos o sociales con adolescentes de 15 años, y la relación con su desempeño lector .................

Cuadro A3.2 Discutir sobre libros, películas o programas de televisión con adolescentes de 15 años, y la relación con su desempeño lector ........

Cuadro A3.3 Ayudar a adolescentes de 15 años con sus tareas, y la relación

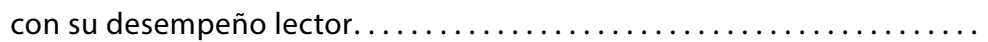

Cuadro A3.4 Discutir sobre asuntos sociales o políticos con adolescentes de 15 años, la relación con el gusto de leer, y con la conciencia de estrategias

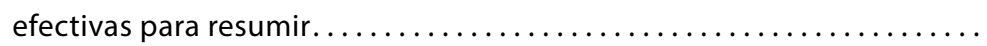

Cuadro A3.5 Discutir sobre libros, películas o programas de televisión con adolescentes de 15 años, la relación con el gusto de leer, y con la conciencia de estrategias efectivas para resumir .................

Cuadro A3.6 Ayudar a adolescentes de 15 años con sus tareas, la relación con el goce de la lectura, y con la conciencia de estrategias efectivas para resumir. . 
Cuadro A4.1 Discutir el progreso o la conducta de las niñas y los niños con los maestros, y su relación con su desempeño lector . .

Cuadro A4.2 Las mamás y los papás que trabajan como voluntarios en la escuela, y el desempeño lector de sus hijos.

Cuadro A4.3 Discutir el progreso o la conducta de las niñas y los niños con las maestras y los maestros, la relación con el goce de la lectura, y con la conciencia de estrategias efectivas para resumir .

Cuadro A4.4 Las mamás y los papás que participan como voluntarios en la escuela, la relación con el goce de la lectura, y con la conciencia de estrategias efectivas para resumir

Cuadro A5.1 Las mamás y los papás que leen por gusto, y la relación con el desempeño lector de sus hijos.

Cuadro A5.2 Las mamás y los papás que leen por gusto, la relación con el goce de la lectura, y con la conciencia de estrategias efectivas para resumir ....... 


\section{1}

\section{ilnvolúcrate!}

El Programa para la Evaluación Internacional de los Estudiantes (PISA, por sus siglas en inglés), tiene buenas noticias para padres y madres preocupados y estresados: no se requiere de un doctorado o de horas ilimitadas para que puedan contribuir eficientemente en la educación de sus hijas e hijos. Este capítulo explica cómo la participación parental beneficia a los estudiantes -y cómo algunas formas particulares de participación pueden ser de mayor beneficio que otras.

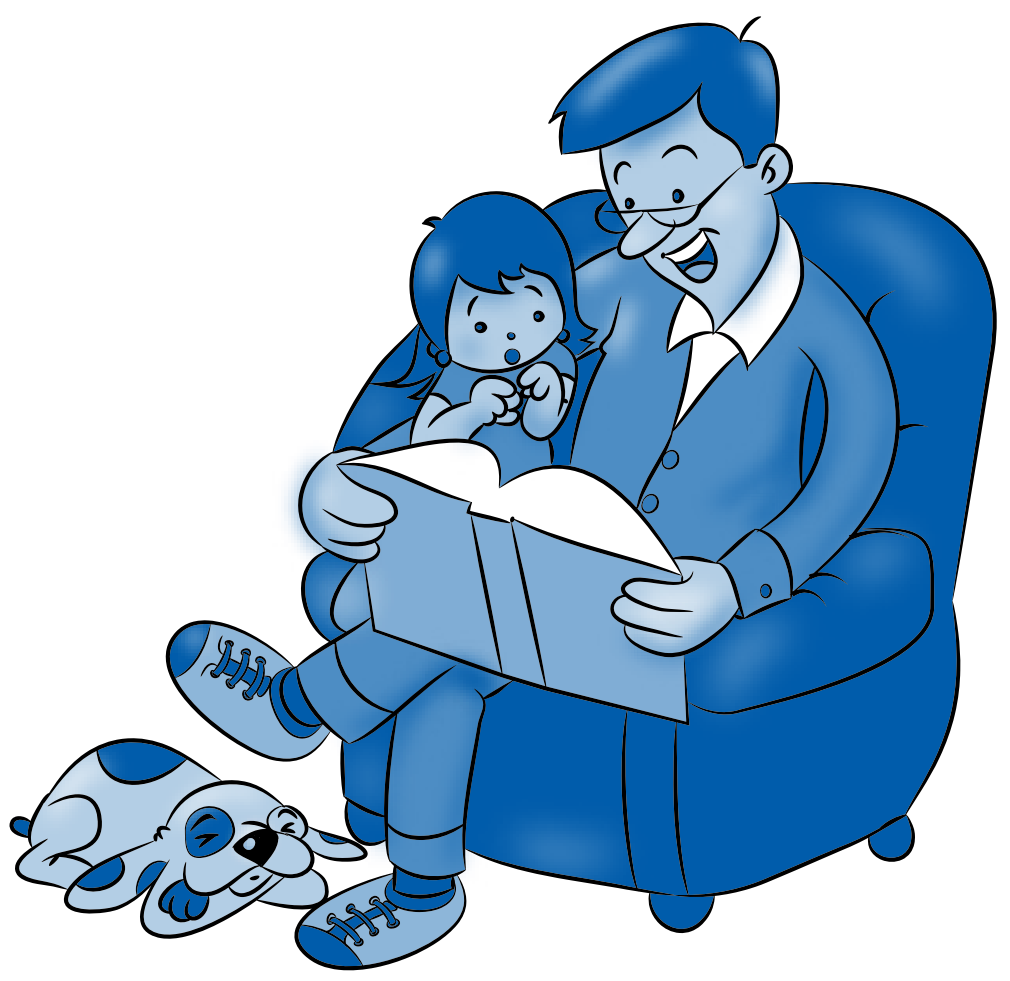


La mayoría de los padres y las madres saben instintivamente que si invierten más tiempo con sus hijas e hijos, y si se involucran en su educación, les pueden proporcionar una buena ventaja al inicio de su vida. Pero en vista de que la mayoría de los padres deben organizarse para cumplir con muchas y diversas responsabilidades, tanto en su trabajo como en su hogar, parecería que nunca tienen tiempo suficiente. También ocurre, algunas veces, que los padres evitan ofrecer ayuda a sus hijos porque se sienten mal preparados para hacerlo. Temen haber olvidado ya lo que aprendieron en la escuela en sus tiempos de estudio; o quizá jamás estudiaron los temas que sus hijos estudian actualmente, y piensan que no pueden ofrecerles una verdadera ayuda. Otras veces, los padres creen que la escuela es la única responsable de la educación de sus hijos.

El Programa para la Evaluación Internacional de los Estudiantes (PISA, por sus siglas en Inglés) de la $O C D E$, tiene buenas noticias para padres y madres preocupados y estresados: no se requiere contar con un doctorado o de horas ilimitadas para que puedan hacer una diferencia positiva en la educación de sus hijas e hijos. De hecho, muchas de las actividades entre padres e hijos, asociadas con un mejor desempeño lector entre los estudiantes, implican relativamente poco tiempo, y no requieren de un conocimiento especializado. Sin embargo, lo que estas actividades demandan es un genuino interés y un compromiso activo -bajo el entendido de que la educación es una responsabilidad compartida.

En el año 2009, los países que participaron en las evaluaciones de PISA recibieron un cuestionario dirigido a los padres y las madres de los estudiantes que realizaron el examen de PISA. El cuestionario buscó información sobre:

- Los antecedentes escolares de los padres y las madres; por ejemplo, su nivel educativo, ocupación y niveles de ingresos;

- El ambiente en el hogar, incluyendo el número de hermanas y hermanos que vivían con el estudiante que realizó el examen de PISA, así como la disponibilidad de fuentes de lectura, el gasto en servicios educativos, las percepciones de los padres sobre el desempeño de sus hijos en la escuela, las prioridades al escoger una escuela; $y$

- La participación de los padres y las madres en los hábitos de lectura, incluyendo si ellos (u otros miembros en el hogar) se habían involucrado activamente con sus hijos cuando éstos ingresaron a la escuela primaria, sus niveles actuales de participación (ya que sus hijos tenían 15 años cuando hicieron el examen PISA), y las propias actitudes de los padres frente a la lectura.

Catorce países y economías difundieron el cuestionario, aunque uno de ellos, Polonia, no realizó las preguntas relacionadas a la participación de los padres y las madres. El cuestionario se distribuyó en Dinamarca, Alemania, Hungría, Italia, Corea, Nueva Zelanda y Portugal (que son países miembros de la OCDE) y en Croacia, Hong Kong-China, Lituania, Macao-China, Panamá y Qatar (que no son miembros de la OCDE). ${ }^{1}$

Las respuestas de los padres y las madres a las encuestas fueron registradas y relacionadas con el desempeño de sus hijos en la evaluación de PISA. Con ello se pretendía determinar no sólo qué tipos de participación parental importan para el desarrollo de las habilidades cognitivas de los estudiantes -medidos en términos de qué tan bien leen los jóvenes de 15 años-; también se pretendía saber si los estudiantes cuyos padres están más involucrados en su educación, están mejor preparados para continuar aprendiendo a lo largo de sus vidas, en comparación con aquellos estudiantes cuyos padres no están tan involucrados.

La lectura es una habilidad que permite a la gente entender el mundo que le rodea. Los padres y las madres, naturalmente, se involucran en el proceso de adquirir esta habilidad, de la misma manera en que todos los nuevos padres son testigos del aparentemente milagroso desarrollo del lenguaje y del habla a lo largo de los primeros meses y años de vida de sus hijos, y estimulan este aprendizaje. PISA quería 
averiguar en qué medida la participación comprometida de los padres, a lo largo de la infancia, influye en qué tan bien leen los estudiantes, qué tan bien resuelven tareas académicas difíciles, y hasta qué punto pueden interesar a sus hijos en el hábito de la lectura.

A los padres y las madres se les preguntó si participaban en ciertas actividades dentro de la escuela de sus hijas e hijos, tales como discutir su progreso académico o su conducta con sus maestros, ya fuera por iniciativa propia, o impulsados por el propio docente; o bien, si participaban de manera voluntaria en la escuela en actividades extracurriculares, en la biblioteca o en el centro de medios. También se les preguntó si les habían contado cuentos a sus hijos cuando éstos ingresaron a la primaria, si les habían cantado canciones, o si habían jugado con ellos utilizando juguetes didácticos que contuvieran el alfabeto; si en el momento de tomar el examen de PISA -cuando sus hijos tenían 15 años- les ayudaban con la tarea, si compartían con ellos la comida principal alrededor de la mesa, o simplemente si hablaban con ellos. A los padres también se les hicieron preguntas acerca de sus propios hábitos de lectura, y de sus actitudes frente a los libros y la lectura.

Mediante la aplicación del cuestionario, PISA encontró que ciertas actividades, más que otras, estaban más fuertemente relacionadas con un mejor desempeño de los estudiantes. ¿Qué clase de actividades son las que benefician más a los estudiantes? El hecho de leerles libros a las niñas y los niños cuando éstos inician apenas su educación primaria, y de hablar con los hijos adolescentes sobre tópicos políticos o asuntos de justicia social, demostraron tener un impacto positivo en el aprendizaje de los hijos. El mero hecho de que se tenga la costumbre de leer en casa beneficia mucho a los infantes, porque les muestra que la lectura es algo que sus padres valoran.

A las niñas y los niños cuyos padres se involucraron de este modo en su educación, se les encontró más receptivos al lenguaje; también eran más hábiles para planear, para establecer metas, para iniciarlas y seguirlas a lo largo de sus estudios, y para realizar proyectos individuales. Por ello se puede afirmar que los infantes que han dominado estos tipos de habilidades han aprendido cómo aprender -y eso les ayudará no únicamente durante sus años escolares, sino a lo largo de toda su vida.

\section{Recuadro 1.1 ¿De qué manera beneficia a los estudiantes la participación de las madres y los padres?}

Así como el de PISA, muchos otros estudios muestran que los estudiantes manifiestan mejores habilidades para leer cuando sus padres y sus madres se involucran en su educación, y en especial cuando éstos valoran la lectura. En este sentido, el aprendizaje de los estudiantes es más efectivo cuando es el resultado de una asociación entre la escuela, los maestros, los padres y la comunidad.2 Expertos en estas áreas destacan el hecho de que los padres involucrados ayudan a sus hijas e hijos a desarrollar la recepción del lenguaje y la conciencia fonética, y les ayudan a adquirir las habilidades que necesitan para aprender, al enseñarles cómo planear, cómo monitorear, y cómo estar conscientes de su propio proceso de aprendizaje. Las maestras y los maestros suelen poner más atención a sus estudiantes cuando saben que los padres de éstos están más involucrados. En general, los niños de padres involucrados están más motivados a aprender por el mismo hecho de aprender, y tienen más control sobre su desempeño académico, porque adoptan una actitud positiva hacia la escuela, y por el aprendizaje que ven en sus propios padres. Saben también que pueden obtener orientación de sus padres sobre cómo conducirse en la escuela, y cómo sortear sus retos. Los niños de padres involucrados están más familiarizados con las tareas que les son requeridas en la escuela, porque sus padres comparten este tipo de información con ellos. ${ }^{3}$ Finalmente, los hijos de padres que leen y que disfrutan de la lectura adquieren el mismo interés que muestran éstos hacia la lectura, y sienten el mismo gusto que ellos cuando leen. 


\section{Recuadro 1.2 El Programa para la Evaluación Internacional de los Estudiantes (PISA)}

El Programa para la Evaluación Internacional de los Estudiantes (PISA), realizado por la Organización para la Cooperación y el Desarrollo Económicos (OCDE), examina hasta qué punto los estudiantes que se encuentran próximos a concluir su educación obligatoria, han adquirido los conocimientos y las habilidades necesarias para su participación plena en las sociedades modernas, y se enfoca en la comprensión de la lectura, las matemáticas y la ciencia. PISA no evalúa únicamente si los adolescentes de 15 años pueden reproducir conocimientos, sino si pueden utilizar lo que han aprendido, y si son capaces de aplicarlo en entornos poco familiares, tanto dentro como fuera de la escuela. Este estudio, que se realiza cada tres años, también recaba información contextual sobre los estudiantes, sus familias y sus escuelas, así como también información directa de los padres. En el 2009 participaron en el estudio de PISA, cuyo enfoque estuvo referido a la lectura, más de 400,000 estudiantes, en 65 países y economías. Las encuestas y evaluaciones de PISA, que son la medida internacional más comprensiva y rigurosa sobre las habilidades de los estudiantes en los tres temas centrales, están diseñados y probados específicamente para garantizar comparaciones justas entre los distintos países que forman parte de la muestra.

\section{Notas}

1. Se recomienda tener cuidado si se pretenden utilizar los resultados de este conjunto limitado de países y economías para tomar decisiones relacionadas con la participación de padres y madres en otros países y economías distintos, pues los resultados obtenidos en éstos aparecen en una muestra más amplia de las evaluaciones de PISA.

2. Epstein, J. (1995), "School Family Community Partnerships: Caring for the Children We Share", Phi Delta Kappan, Vol. 76(9), pp. 701-712.

3. Pomerantz, E.M., et al. (2007), "The How, Whom and Why of Parents' Involvement in Children's Academic Lives: More Is Not Always Better", Review of Educational Research, Vol. 77 (3), pp. 373-410 


\section{Lee a tus hijos un cuento}

La participación de los padres y las madres en la educación de sus hijas e hijos debe comenzar en el momento de su nacimiento -y no terminar nunca. Este capítulo, que muestra cómo contar cuentos y leer libros a los niños, cuando son muy pequeños, se correlaciona fuertemente con lo bien que éstos habrán de leer, y cuánto habrán de disfrutar de la lectura posteriormente.

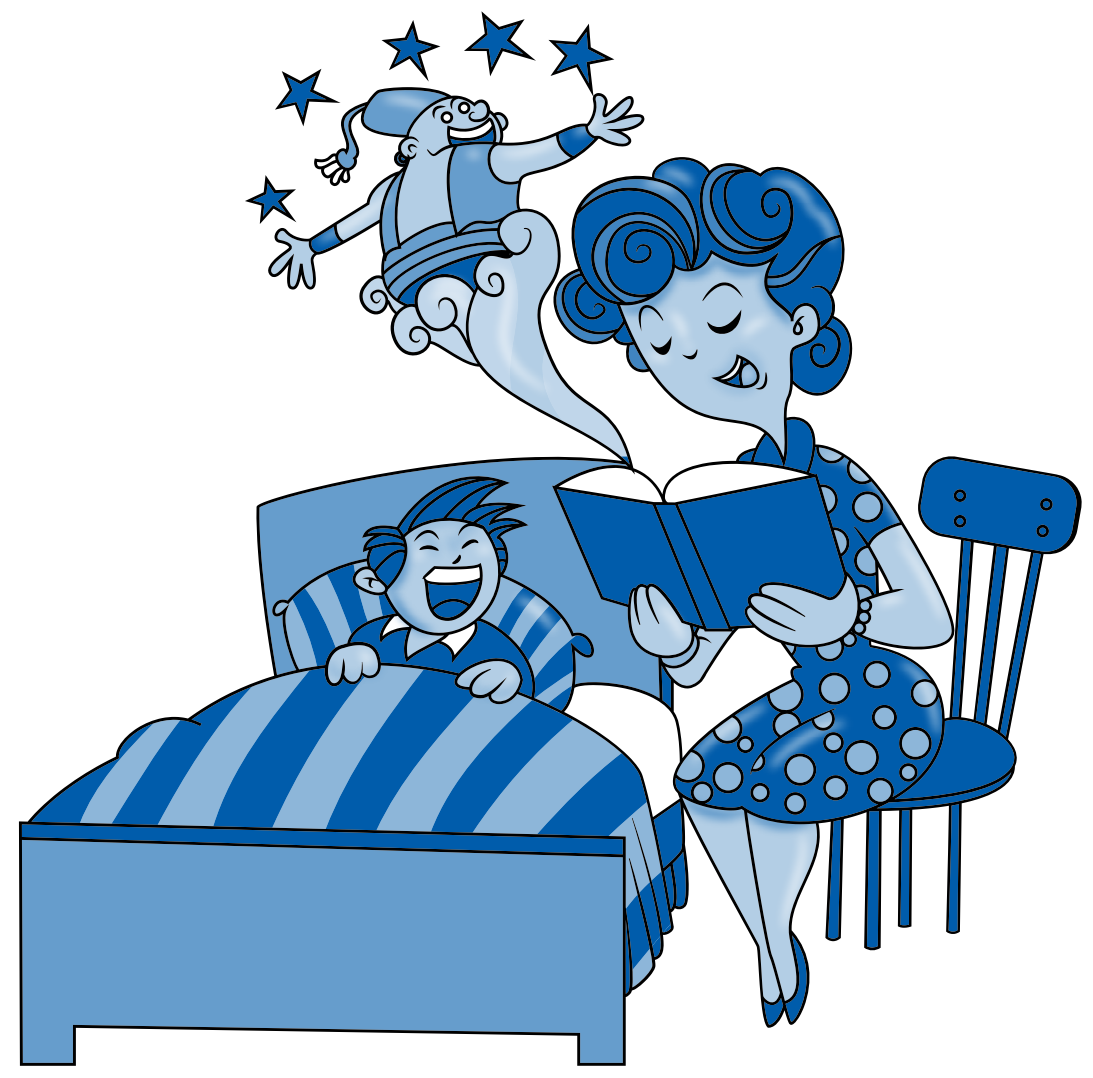


La participación de los padres en la educación de sus hijos comienza desde que éstos nacen. Al cantarles canciones de cuna, y al susurrarles palabras con dulzura, los padres presentan el universo del lenguaje a sus hijos desde su más tierna infancia. ${ }^{1} Y$ esto es -o debe ser- solamente el inicio.

PISA deseaba averiguar si los estudiantes de 15 años cuyos padres habían participado activamente en su educación desde el inicio de sus estudios de primaria, se desempeñaban mejor en la escuela que sus compañeros, cuyos padres no se habían involucrado tanto. PISA preguntó si los padres les habían leído libros a sus hijos a esa temprana edad, si les habían contado cuentos, si les habían cantado canciones, si habían jugado con ellos con juguetes didácticos de letras -alfabetos-, si les habían hecho comentarios sobre lo que habían leído, si habían hecho juegos de palabras con ellos, si les habían escrito letras o palabras, si les habían leído en voz alta señales y etiquetas, o bien si los padres hablaban frecuentemente con sus hijos sobre las actividades que realizaban en sus respectivos empleos.

Los resultados de PISA muestran que algunos tipos de participación parental, cuando los niños apenas comienzan la escuela primaria, se asocia fuertemente con su desempeño lector, pero más aún con el hecho de inculcarles el gusto por la lectura. Estos tipos de participación enfatizan el valor de leer y de usar palabras en su contexto -por ejemplo leer libros, o hablar sobre lo que padres y madres han hecho durante su jornada laboral-, en lugar de tratar a las palabras y a las letras como unidades independientes -como cuando se usan, por ejemplo, alfabetos de juguete.

Pese a que la mayoría de las actividades enlistadas se relacionan, en alguna medida, con el mejor desempeño lector de adolescentes de 15 años, la mayor correlación se presenta entre el hecho de leerle a un niño durante sus primeros años de vida, y el rendimiento lector cuando el chico ya ha alcanzado los 15 años. La correlación se muestra especialmente sólida en países como Nueva Zelanda y Alemania, donde los estudiantes a quienes sus padres les habían leído durante sus primeros años escolares, mostraron mayores calificaciones que los estudiantes a quienes sus padres no les habían leído -63 y 51 puntos, respectivamente- en la prueba de lectura de PISA. Para ponerlo en perspectiva, en la prueba PISA 39 puntos equivalen a un año de escuela. Esto significa que los adolescentes de 15 años, a quienes sus padres y madres les habían leído cuando estaban iniciando su vida escolar, leen al menos tan bien como sus compañeros de un grado inmediato superior.

Frecuentemente, la correlación que se encuentra en ciertas actividades desarrolladas entre padres e hijos, en relación con el desempeño de éstos como estudiantes, refleja simplemente los antecedentes socioeconómicos y los recursos a disposición de la familia. Pero los resultados de PISA muestran que incluso entre familias con antecedentes socioeconómicos similares, el hecho de leerles libros a niñas y niños pequeños está íntimamente relacionado con su mejor desempeño escolar cuando éstos llegan a la edad de 15 años. Esta asociación se acentúa especialmente en Nueva Zelanda, donde hubo una diferencia de 44 puntos entre las calificaciones de lectura de aquellos a quienes sus padres les habían leído cuando eran pequeños, y aquellos a quienes no les habían leído; en Alemania, donde la diferencia fue de 29 puntos; y en Qatar, con una diferencia de 27 puntos.

Ahora bien, PISA encontró también que son mejores las actividades que implican poner palabras dentro de contextos más amplios, tales como contar cuentos o cantar canciones, en comparación con ciertas actividades que aíslan letras o palabras, como por ejemplo jugar con alfabetos de juguete. Esto se debe a que son las primeras actividades las que ayudan a inculcar el gusto por la lectura en las niñas y los niños. En los trece países y economías en donde se administró el cuestionario parental, sin ninguna excepción, los estudiantes de 15 años a quienes sus padres les habían leído libros y les habían cantado canciones en sus primeros años de educación primaria, reportaron altos niveles de gusto por la lectura, 
significativamente mayores respecto a aquellos cuyos padres no se habían involucrado de esa misma manera con ellos. Esta correlación se acentúa especialmente en estudiantes de Dinamarca, Alemania, Hungría y Nueva Zelanda.

Independientemente del ingreso familiar, las niñas y los niños a quienes sus padres les leyeron cuando estaban comenzando su educación escolar, desarrollaron un mayor gusto por la lectura que aquellos a quienes no se les leyó, o a quienes no se les leyó tan frecuentemente. Esta relación se acentúa en especial en estudiantes de Alemania, Hungría, Corea y Portugal. Entre los países y economías examinados, el nivel de participación parental varía ampliamente, dependiendo de la forma específica de participación. Por ejemplo, en tanto un $75 \%$ de los padres, en promedio, reportan haberles leído libros a sus hijos, este porcentaje resulta particularmente alto en Nueva Zelanda y Dinamarca, en donde más del $90 \%$ de los padres reportan que leen a sus hijas e hijos, y relativamente bajo en Hong Kong-China y Macao-China, donde sólo $53 \%$ y $54 \%$ de los padres, respectivamente, reportaron lo mismo. Por otra parte, resulta patente que no se involucran de la misma manera ambos padres en el proceso lector: en la mayoría de los países y las economías, los padres son menos activos que las madres en su participación con hijas e hijos en edad de escolaridad primaria, en la mayoría de las actividades examinadas. Esto reafirma que, generalmente, los padres participan menos en las actividades del cuidado familiar cotidiano, y asumen menos responsabilidades en el hogar que las madres, como se ha mostrado en otros estudios ${ }^{2}$.

- Gráfica 2.1 . Niños y niñas a quienes se les leyó desde muy pequeños,
son mejores lectores cuando tienen 15 años

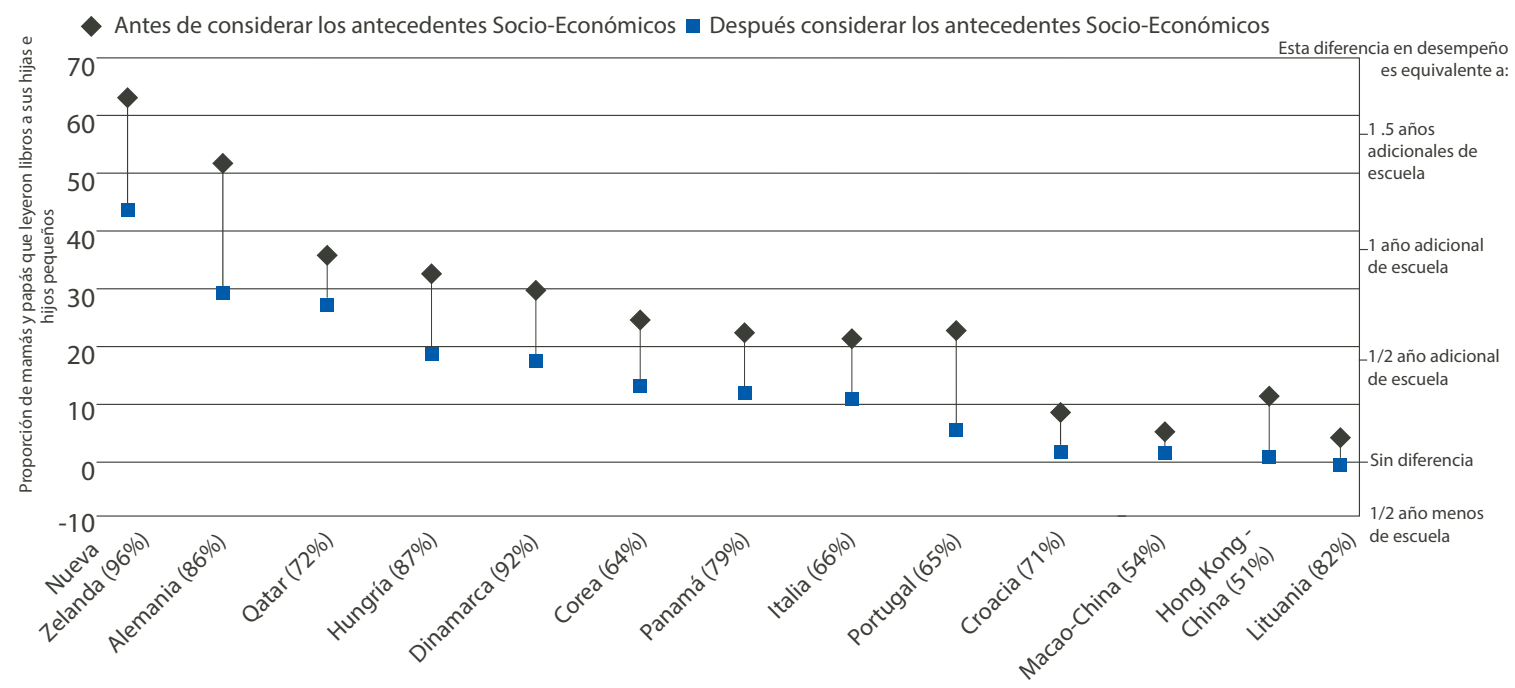

Nota: El porcentaje de padres y madres que manifestó haberles leído a sus hijos en casa durante su primer año de escuela primaria, se reporta entre paréntesis después del nombre del país. Los países están clasificados en orden descendente respecto a su diferencia en el desempeño lector, después de considerar los antecedentes socio-económicos. 
PISA encontró también que existía una mayor probabilidad de que los padres que habían tenido mayores ventajas socioeconómicas, les hubieran leído a sus hijas e hijos regularmente, les hubieran cantado canciones, hubieran hablado con ellos sobre lo que hicieron durante el día, y les hubieran leído letreros y anuncios en voz alta, respecto a los padres que habían tenido menos ventajas socioeconómicas. Esta diferencia fue encontrada de manera consistente en los países y las economías que fueron examinadas. En promedio, los padres con ventajas socioeconómicas presentan 14 puntos porcentuales más de probabilidades de haber participado en los tipos de actividades que están asociadas claramente con resultados positivos de sus hijas e hijos, tales como leerles libros cuando eran muy pequeños. Un análisis de los resultados de PISA sugiere que esta manera de involucrarse puede ser una de las razones por las que los estudiantes pertenecientes a estas familias tienden a tener, posteriormente, un mejor desempeño escolar que el de sus compañeros en desventaja.

\section{Las jóvenes y los jóvenes de 15 años a quienes sus padres y madres les contaron cuentos cuando eran pequeñas y pequeños, son mejores lectores}

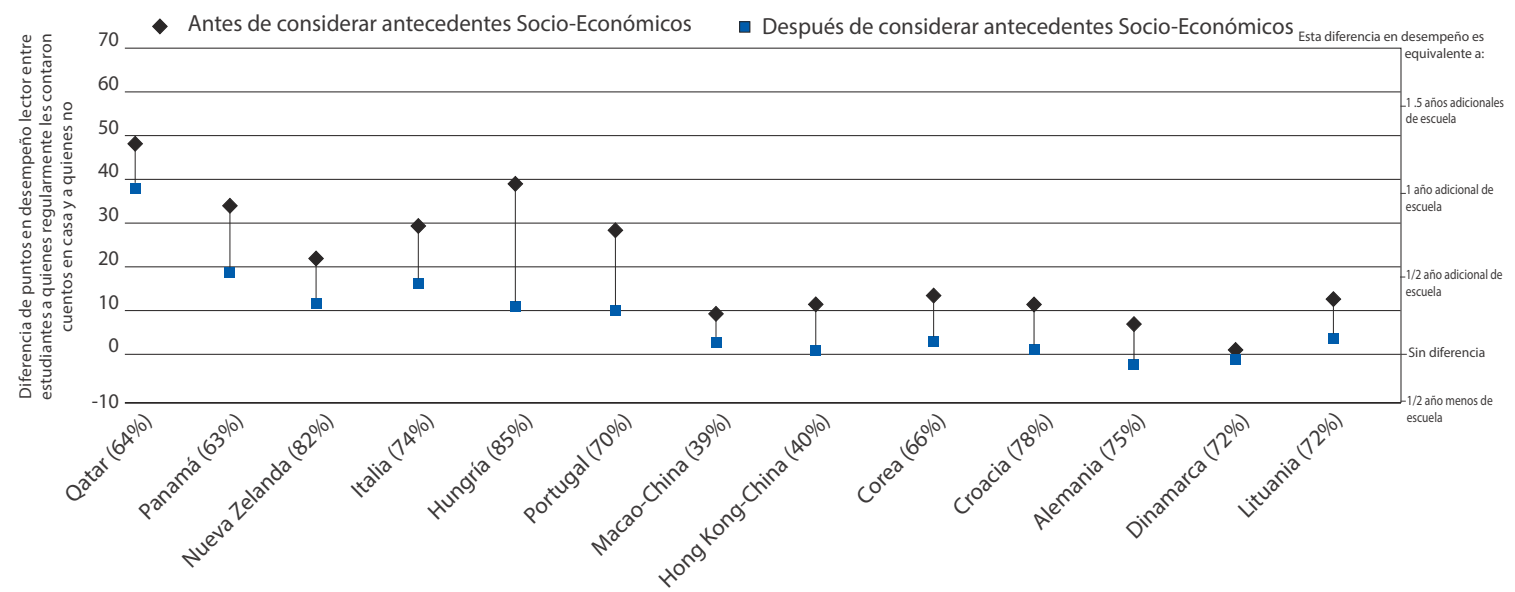

Nota: El porcentaje de papás/mamás que reportaron que contaban cuentos a sus hijos (hijas) en casa durante su primer año de escuela primaria se muestra entre paréntesis después del nombre del país.

Los países están ordenados en orden descendente, respecto a su diferencia en el desempeño lector, después de contar la diferencia por antecedentes socioeconómicos.

Fuente: Cuadro 2.2 


\section{Recuadro 2.1 Polonia: Toda Polonia Lee a los Niños}

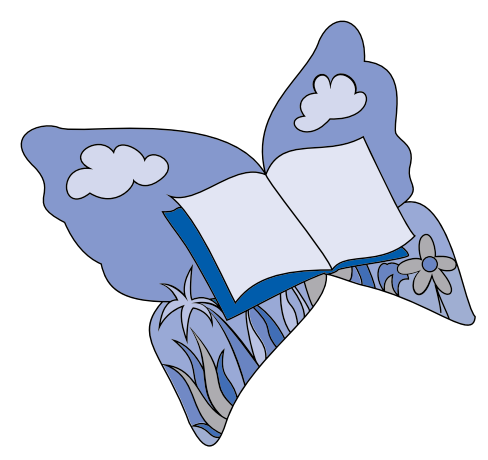

El objetivo general de la Fundación Toda Polonia Lee a los Niños es crear una cultura que valore la lectura, particularmente la lectura de las niñas y los niños pequeños. En el 2002, más de 150 villas, pueblos y ciudades participaron en la primera Semana Nacional de la Lectura a los Niños organizada por la Fundación; para el 2010, 2500 municipalidades participaron en el evento, durante el cual algunas figuras muy conocidas de las artes y la política visitaron jardines de niños, escuelas y bibliotecas a lo largo del país para leer a los niños. Para alcanzar un público más amplio aún, la Fundación produjo videos musicales, comerciales de televisión, películas cortas y telenovelas. Como una medida de su éxito, el programa ha sido replicado en la República Checa ("Cada Checo Lee a los Niños"), y ha sido adaptado en el programa "Toda Europa Lee a los Niños".

La fundación también apoya a las bibliotecas, y a través de su trabajo de gestión pública ha ayudado a obtener fondos públicos a nivel nacional para estos establecimientos. Asimismo, ha instituido un concurso dirigido a los escritores, que tiene por objetivo estimular a los autores a producir libros de alta calidad para niños y niñas, y ha lanzado programas de lectura en jardines de niños y escuelas, con el fin de generar en los padres las habilidades necesarias para crear ambientes propicios para la lectura. Adicionalmente a las conferencias y talleres para padres, maestros y público en general, la Fundación y la Academia para la Psicología Social en Varsovia lanzaron un curso de posgrado para los docentes acerca de "La lectura como Método de Desarrollo en Educación". La fundación también lleva a cabo programas enfocados en grupos específicos o regiones. Uno de ellos se lleva a cabo en una prisión que alberga a mujeres con hijos pequeños; otro provee materiales gratuitos de lectura a las escuelas, bibliotecas y a diversas instituciones culturales en áreas rurales con desventajas; y otro más reúne, a través de la lectura, a niños de orfanatos con estudiantes universitarios avanzados, que cursan su tercer año de estudios profesionales.

www.allofpolandreadstokids.org/

\section{Recuadro 2.2 Reino Unido: Inicio en los libros (Bookstart)}

"Inicio en los libros" (Bookstart) es un programa nacional que motiva a los padres y a las madres, así como a personas responsables del cuidado de las niñas y los niños, a disfrutar de los libros con éstos a la edad más temprana que sea posible. Provee material gratuito de lectura a las familias, invitándolas a que disfruten los libros juntos. La bolsa para los bebés Bookstart, que contiene dos libros, se entrega a los bebés de entre 8 y 12 meses cuando éstos son llevados a los servicios de salud. El "Baúl del Tesoro de Inicio en los Libros" se distribuye gratuitamente a infantes de tres años de edad a través de centros para niños, guarderías, preescolares, y otros lugares para niños pequeños. Cada año, alrededor de 3.3 millones de niños -alrededor del 95\% de todos los niños de Inglaterra, Gales e Irlanda del Norte- reciben los paquetes. Para ser lo más inclusivo posible, el programa "Inicio en los libros" provee de libros bilingües, y también materiales guía bilingües para los padres (hay libros y materiales en 27 idiomas). También hay paquetes para niños sordos (Libro Brillante), y para niños invidentes o con problemas visuales (Libro Palpable). El "Baúl del Tesoro de Inicio en los Libros" contiene también un cupón, de una libra esterlina, que es aceptado en la mayoría de las librerías en el Reino Unido. (continúa...) 


\section{Recuadro 2.2 Reino Unido: Inicio en los libros (continuación)}

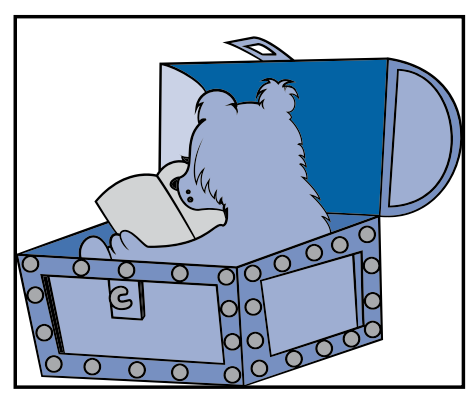

Los paquetes de "Inicio en los Libros" contienen guías para padres que explican cómo se benefician los niños al leer, que recomiendan cuándo leerles -en diferentes etapas de su vida-, y que explican cómo se pueden escoger libros apropiados para cada edad. Los dos paquetes de "Inicio en los Libros" contienen invitaciones para afiliarse a las bibliotecas públicas locales, muchas de las cuales ofrecen programas relacionados con el inicio en la lectura, lo cual permite que los padres se encuentren entre sí, y que puedan compartir sus experiencias. De hecho, aunque el programa "Inicio en los libros" motiva a los padres a leer con sus hijos, también busca crear una comunidad de lectores que abarque muchas generaciones.

El programa "Inicio en los Libros", que fue financiado en un principio, en 1999, por la compañía privada Sainsbury's, ahora es financiado por la Fundación Libro (Booktrust), una organización de beneficencia independiente. Alrededor del $25 \%$ de todo el financiamiento proviene de transferencias de Gales, del Departamento de Educación del Norte de Irlanda, y del Departamento de Educación de Inglaterra. Un grupo de publicistas de libros infantiles y de librerías también apoya al programa, y en su calidad de empresa de beneficencia, la Fundación Libro acepta donaciones del público en general. También se obtiene apoyo indirecto a través de quienes distribuyen los paquetes, es decir las bibliotecas, los profesionales de los servicios de salud, y los profesionales que se dedican al cuidado de los infantes.

\section{Recuadro 2.3 Suecia: Las For Mej Pappa ${ }^{3}$}

Las For Mej, Pappa ("Leeme, papá") es un proyecto de Suecia basado en la alfabetización, cuyo objetivo son los padres trabajadores, la mayoría inmigrantes, que forman parte de los sindicatos locales de comercio. El proyecto refleja la creencia, que prevalece en Suecia, de que la alfabetización es responsabilidad de cada uno, y no únicamente del sistema educativo. Comenzó por los sindicatos nacionales, en 1999, y surgió como una respuesta al problema de que los trabajadores agremiados en los sindicatos locales no leían lo suficiente y que, por tanto, no ayudaban a sus hijas e hijos a leer. Los sindicatos percibieron entonces a la falta de lectura incluso como una amenaza para la democracia.

Desde entonces, los sindicatos locales son responsables de diseminar la información sobre el programa entre sus miembros, y de almacenar libros de interés para ellos y para sus hijos. Cada sindicato local organiza "días de papás" (donde se incluye, por supuesto, a las mamás), en los que se reúnen un autor -también trabajador, que presenta su libro-, y un experto en desarrollo infantil, quien habla sobre la importancia que tiene leer y escribir, y asimismo explica cómo los trabajadores pueden mejorar los hábitos de lectura de sus hijos.

Actualmente todos los sindicatos locales en Suecia están desarrollando el programa. Hacia junio de 2008, alrededor de 1,500 padres ya habían participado en él.

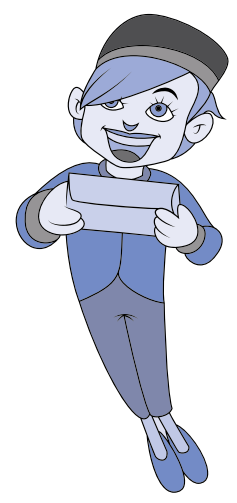




\section{Lee a tu hija o hijo; no todas las madres o los padres lo hacen}

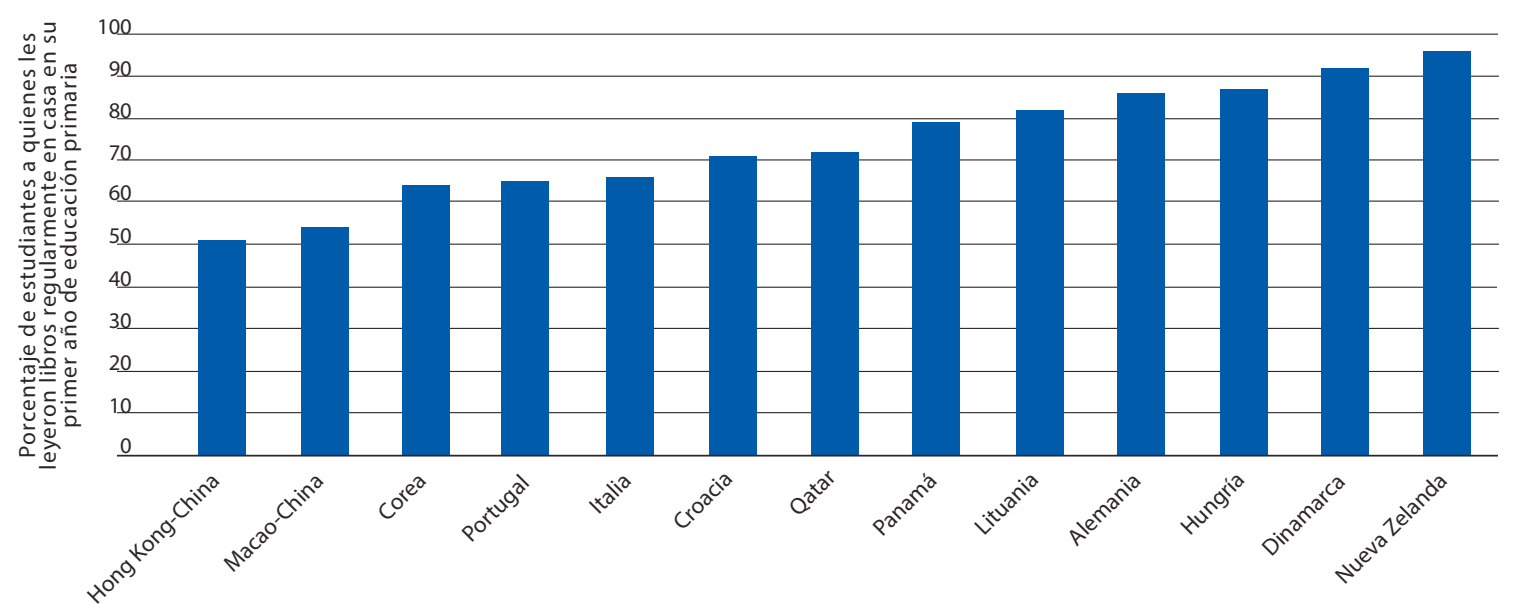

Lee a tus hijos no todas las mamás/los papás lo hacen

Porcentaje de estudiantes a quienes se les leyó con regularidad en su primer año de educación primaria.

Los Países/Economías están ordenadas de manera ascendente, y muestran el porcentaje de padres que reportaron haber leído a su hija o hijo regularmente en casa durante su primer año de educación primaria.

http://dx.doi.org/10.1787/888932606416

PISA también revela que las diferencias socioeconómicas en el desempeño lector pueden relacionarse con la participación parental, pero no sólo porque los padres en ventaja socioeconómica tiendan a involucrarse más, sino porque además los infantes en estos tipos de familias suelen beneficiarse más de la igualdad en las formas de participación, debido a la igualdad que existe entre los períodos de participación de cada uno de los padres.

\section{¿QUÉ PUEDEN HACER LAS MAMÁS Y LOS PAPÁS?}

Como papá o mamá, probablemente te encontrabas tan emocionado como tu hija o hijo cuando éste tuvo su primer día de clases. Quizá pasaste semanas enteras pensando qué mochila comprar, qué tipos de plumas y lápices adquirir, y cómo irías a proteger cada libro del inevitable desgaste normal, e incluso del jugo derramado. Pero, de acuerdo con los resultados de PISA, la mayoría de los papás y las mamás no dedican suficiente tiempo a reflexionar sobre un accesorio escolar más valioso que todos los demás: el desarrollo del hábito de la lectura. Durante el primer año escolar, cerca de una cuarta parte de las niñas y los niños, en promedio, no tienen a nadie en casa que les lea con regularidad; $y$ en tanto ellos luchan al recorrer su propio camino para leer sus primeras palabras y oraciones, solamente el $40 \%$ de los niños pequeños levantarán la vista del libro que leen para observar cómo sus papás y sus mamás disfrutan al leer 
su propio libro. En tanto los padres y las madres representan el modelo más importante para sus hijos, es crucial que muestren a éstos el valor de leer, mediante el hábito de leer con ellos cuando son pequeños, dándoles ejemplo así de una actitud positiva hacia la lectura.

Muchos papás y mamás se lamentan, porque consideran que es demasiado caro formar o incrementar regularmente una colección de libros que les permita proveer a sus hijos e hijas de materiales de lectura nuevos y atractivos. En realidad, leer con regularidad no tiene por qué ser costoso: los padres pueden llevar a las bibliotecas públicas a sus hijos, e incluso pueden hacer de la visita a la biblioteca, durante el fin de semana, un evento especial para toda la familia. Muchas bibliotecas organizan eventos especiales para los niños pequeños y sus familias. Y cuando sea posible, los padres también pueden apoyar a las bibliotecas locales, y a las bibliotecas escolares, donándoles libros.

Los resultados de PISA sugieren que las niñas y los niños que tienen conversaciones francas con sus padres desde una edad temprana, conversaciones que les exigen reflexionar sobre sus propias experiencias, aprenden mejor a procesar y a comunicar información cuando llegan a la edad de 15 años. No es difícil, ni tampoco requiere de mucho tiempo ayudar a los niños a desarrollar estas habilidades cognoscitivas a una edad temprana: todo lo que se requiere es que los padres les platiquen a sus hijos las cosas que hicieron durante el día, y que a su vez les pregunten qué hicieron ellos.

- Gráfica 2.4

\section{Algunas niñas y niños, especialmente en situaciones de desventaja, tienen poco o ningún acceso a un adulto que les lea}

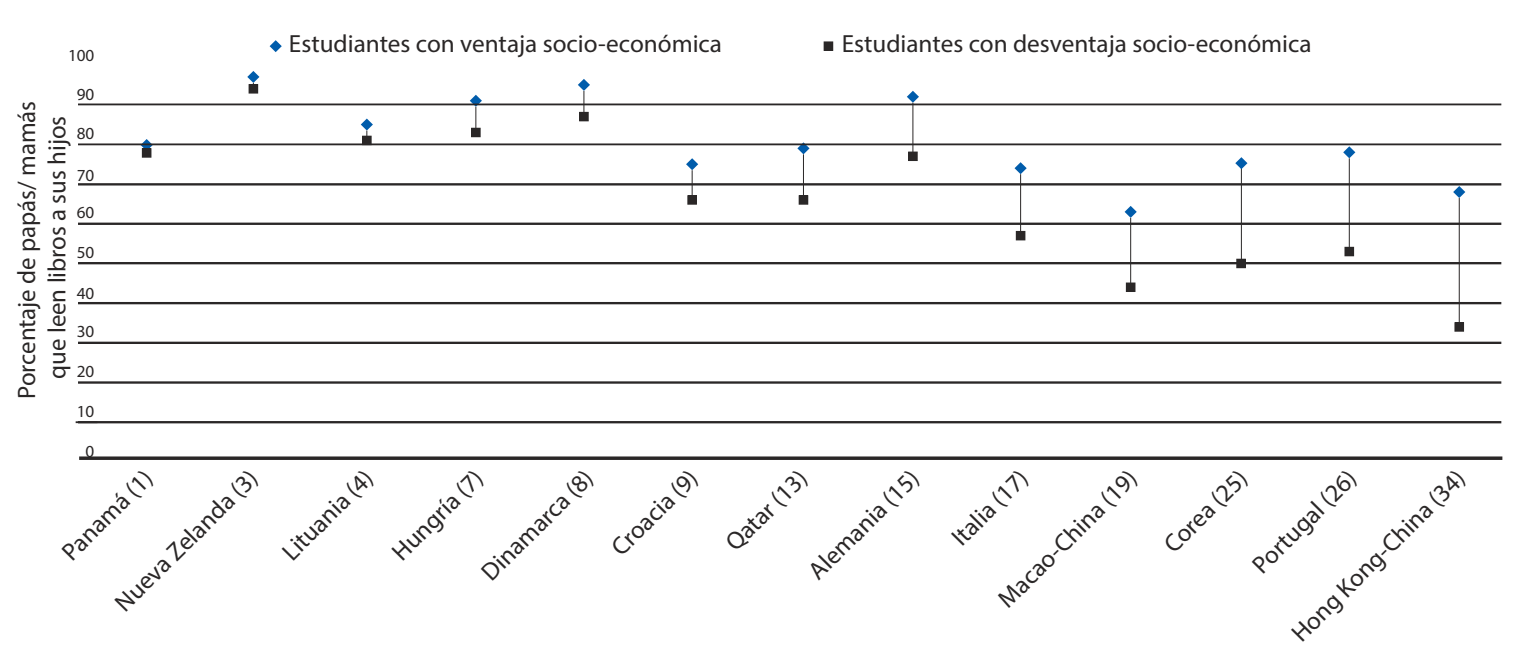

Nota: La diferencia entre el prcentaje de padres en ventaja socieconómica que reportaron haber leído a sus hijos en casa durante su primer año de educación primaria, y el porcentaje de aquellos en desventaja socioeconómica que no lo hicieron, aparece entre paréntesis después del nombre del país o la economía respectiva.

Países/Economías están presentadas en orden ascendente de acuerdo a la diferencia entre el porcentaje de padres en ventaja socioeconómica que reportaron haber leido a sus hijos en casa durante su primer año de educación primaria, y el porcentaje de mamás/papás en desventaja que lo hicieron.

Fuente: Cuadro A2.1

http://dx.doi.org/10.1787/888932606435 
Mantener las conversaciones abiertas motiva a las niñas y a los niños a reflexionar sobre lo que quieren decir, a poner sus pensamientos en un orden lógico, y a encontrar las palabras adecuadas para comunicar sus pensamientos. Un lugar en donde este tipo de motivación puede ocurrir de manera sencilla y natural es la mesa, a la hora de la comida diaria. Muy pronto este tipo de conversaciones se convertirán en un hábito, algo capaz de impulsar a cada miembro de la familia, sin importar cuál sea su edad, a la expectativa de que suceda. La hora de la comida se convertirá así en una oportunidad que es bienvenida, incluso necesaria, para que cada quien se exprese, para conectarse profundamente con otros miembros de la familia, y para que cada quien pueda sentirse cercano, cuidado y respetado.

\section{Leer a los niños no es una tarea exclusiva para papá o para mamá; debe ser un placer para ambos}

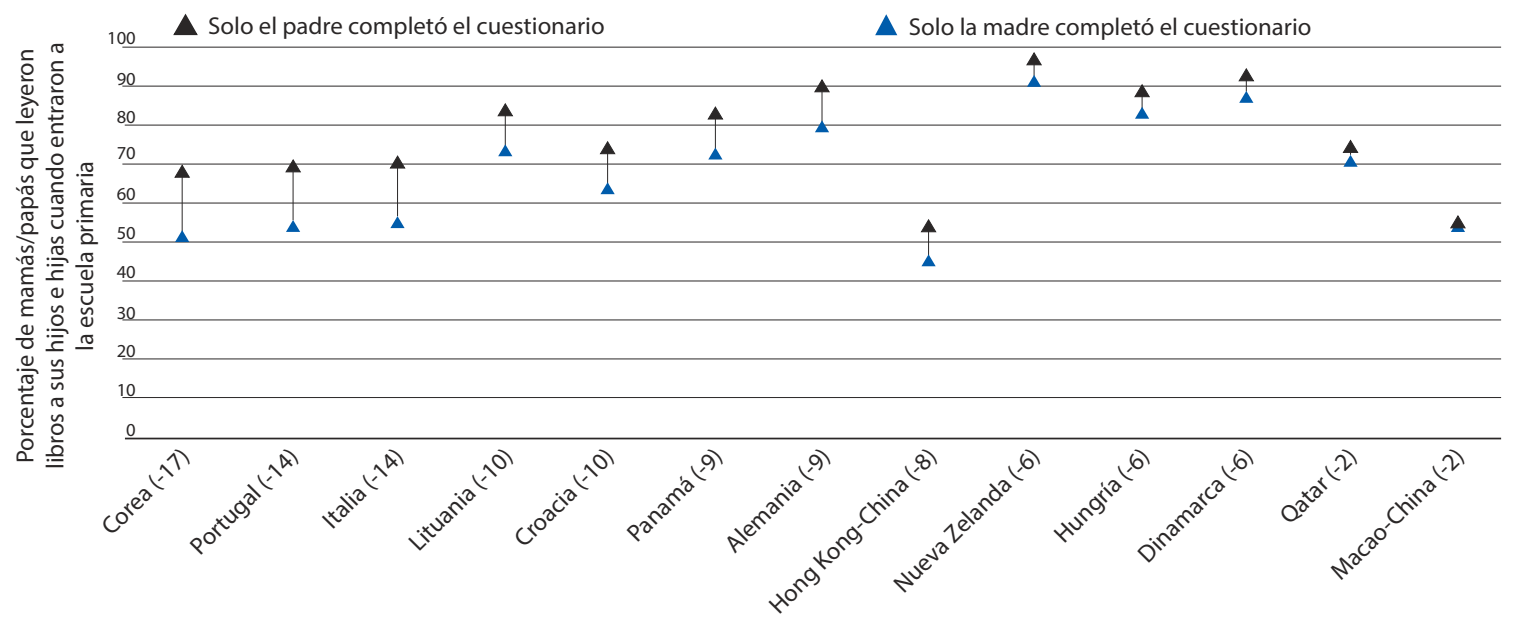

Nota: La diferencia entre el porcentaje de papás que reportaron haberle leído a su hijo o hija en casa en su primer año de educación primaria, y el porcentaje de mamás que lo hicieron, se presenta entre paréntesis después del nombre del país/economía.

Países/economías están presentados en orden descendente por la diferencia entre el porcentaje de padres que reportaron haberles leído a su hijo o hija en casa durante su primer año de educación primaria, y el porcentaje de madres que lo hicieron.

Fuente: Cuadro A2.1.

http://dx.doi.org/10.1787/8889326064542 


\section{¿QUÉ PUEDEN HACER LAS MAESTRAS Y LOS MAESTROS?}

Los maestros y las maestras pueden motivar a los papás y a las mamás a tomar un papel más activo en la educación de sus hijos, si les explican que las escuelas son sólo un lugar, de entre los muchos lugares en los cuales sus hijos pueden aprender. Asimismo, pueden difundir resultados de investigaciones, proponer mejores prácticas, y dar a conocer aquellas formas de participación de los padres que resultan particularmente benéficas para los hijos. Para ello, los docentes necesitan formar estrechas relaciones de confianza con todos los padres de familia, especialmente con aquellos que se muestren menos dispuestos a asociarse con las escuelas en su tarea formativa.

Debido a los múltiples compromisos y restricciones que enfrentan, algunos padres pueden considerar imposible el hecho de proveer de un apoyo activo y continuo a sus hijos. Por ejemplo, en muchos hogares ambos padres deben trabajar muchas horas $y$, de modo creciente, en horarios irregulares, para lograr sostener económicamente a sus familias. PISA muestra que el nivel socioeconómico está muy relacionado con el desempeño de los estudiantes. Así, muchos papás y mamás sienten que deben escoger entre proveer de seguridad económica a sus hijas e hijos, o bien pasar más tiempo con ellos. Los resultados de PISA muestran, sin embargo, que el tiempo que los padres dedican a leer o a hablar con sus hijos es menos importante que el simple hecho de comprometerse en esas actividades tanto como sea posible. Asimismo, los maestros pueden ayudar a las familias a asegurarse de que todos los niños tengan un tipo de atención personalizada, que puede provenir directamente de la escuela, o de la asociación con algunos grupos locales y organizaciones sin fines de lucro. Por ejemplo, los edificios y las instalaciones escolares pueden abrirse a las comunidades locales y, bajo la supervisión de maestros y directivos, los voluntarios pueden enlistarse para trabajar con los niños de manera individual. O bien, los maestros y los directivos escolares pueden proveer información de programas existentes en su comunidad, y trabajar con grupos locales para asegurarse de que estos programas estén disponibles después de las horas de la escuela y durante las vacaciones, y que de esta manera puedan complementar los materiales que son proporcionados por la escuela.

\section{Recuadro 2.4 Rumania: Programa Nacional Parental en Educación de la Niñez Temprana}

El Programa Nacional Parental en Educación de la Niñez Temprana fue iniciado en el 2001 por una asociación compuesta por la UNICEF, el Ministerio de Educación e Investigación de Rumania, y MATRA, un programa financiado por el Ministerio de Asuntos Exteriores de Holanda, en respuesta a una investigación que demostró que muchos padres y madres en Rumania no estaban bien preparados para apoyar la educación de sus hijas e hijos. Inicialmente, el programa proveyó de capacitación en educación parental a especialistas en el país; después se expandió para incluir la capacitación de los maestros. Para el 2005, el programa fue incorporado a la Estrategia Nacional de Rumania en Educación Temprana.

El programa, aún apoyado por la UNICEF, entrena en las 41 municipalidades de Rumania a capacitadores que a su vez adiestran a maestros y maestras de preescolar y primaria; y éstos, a su vez, entrenan a papás y mamás. Los docentes son provistos con manuales, videos y materiales adicionales para su trabajo con los padres. Las lecciones se enfocan en la comprensión de la niñez, en saber cómo valorar y apoyar a los niños, y en cómo evitar el uso de castigos físicos. Generalmente, dos instructores enseñan a 10 padres en un lapso de cinco semanas, con lecciones de dos horas semanales. Dichos padres son evaluados al final del curso, y se les ofrece una sesión de seguimiento seis meses después. En el 2011, más de 90,000 papás y mamás fueron entrenados en unos 5,000 jardines de niños, y en más de 600 primarias.

www.unicef.org/romania/education_11760.html 


\section{Recuadro 2.5 Estados Unidos: Valencia 826}

Valencia 826 es una organización sin fines de lucro que opera en San Francisco, Estados Unidos. Fundada en el 2002 por Ninive Calegari -educador- y Dave Eggers -escritor-, la organización tiene como objetivo ayudar a los estudiantes de entre 6 y 18 años a desarrollar sus habilidades de escritura, y ayudar a los maestros y las maestras a inspirar a sus estudiantes a escribir. Valencia 826 se apoya en tutores voluntarios capacitados -alrededor de 1,700 en el 2011-, y sirve a más de 6,000 estudiantes por año. El éxito del proyecto llevó a la apertura de siete organizaciones más, a lo largo de los Estados Unidos, basadas en los mismos principios.

Valencia 826 ofrece una amplia gama de programas, todos gratuitos, para estudiantes y escuelas. Los proyectos incluyen tutoría individualizada después de los horarios escolares, proyectos al interior de la escuela que apoyan a los maestros durante su tiempo regular de clases, talleres especiales, y organización de paseos escolares al "laboratorio de escritura" de la organización.

http://826valencia.org/

Los maestros y las maestras pueden desarrollar programas para alentar el deseo de leer. Programas como "Deja todo y lee", muestran a las niñas y a los niños que leer, especialmente leer por placer, resulta una actividad valiosa. Los maestros pueden motivar tanto a los estudiantes como a sus padres a utilizar las bibliotecas, a formar clubes de libros entre los infantes y sus padres, a vincularse entre sí de vez en cuando, y a dedicarle a la lectura determinados momentos durante el lapso escolar. El objetivo final es que los padres y las madres comiencen a considerar que el hecho de leerles a sus hijas e hijos es algo tan esencial como alimentarlos y vestirlos. Del mismo modo, se pretende que las niñas y los niños crezcan con la profunda convicción de que la lectura es una actividad valiosa, y al mismo tiempo placentera.

\section{Notas}

1. Hart and Risley (1995) encontraron diferencias importantes en el desarrollo cognitivo de los estudiantes a quienes los padres les hablaban frecuentemente, y aquellos a quienes les hablaban con menos frecuencia. Ver: Hart, Betty and Todd R. Risley (1995), Meaningful Differences in the Everyday Experience of Young American Children, P.H. Brookes, Baltimore.

2. Para mayor información sobre el nivel de compromiso de los papás y las mamás en las responsabilidades del hogar, ver el indicador LMF2.5 en la base de datos sobre la familia de la OCDE en www.oecd.org/ dataoecd/1/50/43199641.pdf. OECD (2011), Doing Better for Families, OECD Publishing.

3. Wright, A., M. Bouchart, K. Bosdotter and R. Granberg (2010), "Las for Mej Pappa: A Swedish model for addressing family literacy", Childhood Education, pp. 399-403.

4 OECD (2010), PISA 2009 Results: Overcoming Social Background (Volume II), PISA, OECD Publishing.

5. Ejemplos de Iniciativas para "Dejar todo y leer" pueden ser encontradas en los siguientes links: http://dropeverythingandread.com www.readwritethink.org/classroom-resources/lesson-plans/daily-dear-program-drop-55.html 



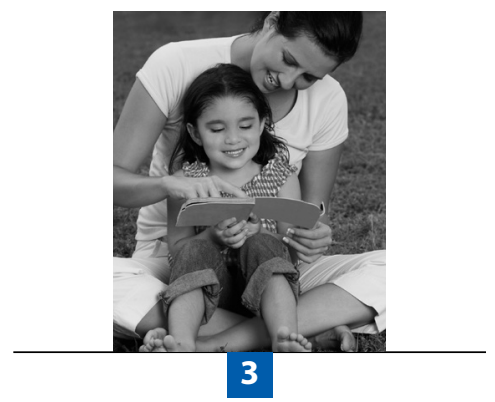

\section{Habla con tus hijos sobre el mundo que les rodea}

Las niñas y los niños mayores también se benefician con la participación de sus padres y sus madres. Este capítulo expone cómo hablar sobre temas sociales y políticos, o sobre libros, películas y programas de televisión con los hijos adolescentes, y cómo se relaciona esto con su mejor desempeño lector en la escuela.

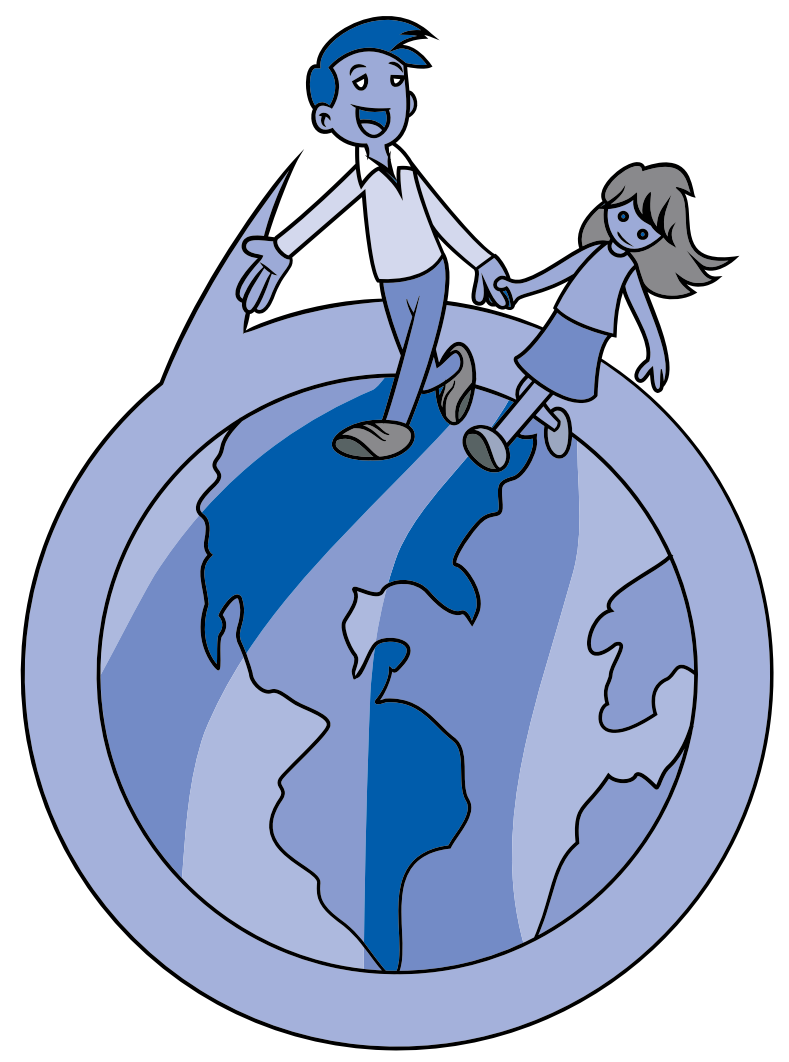


Algunos padres y madres creen que una vez que su hija o hijo comienza la escuela formal, únicamente los maestros son los responsables de educarlos. Pero la educación es una responsabilidad compartida; y los resultados de PISA muestran que incluso los estudiantes de grados superiores se benefician cuando sus padres están involucrados activamente en su educación. Y, como se ha observado en este estudio, esa participación no requiere estar relacionada directamente con el trabajo escolar.

Con el fin de saber qué tipos de participación parental resultan benéficos para los estudiantes mayores, PISA preguntó a los padres con cuánta frecuencia discutían sobre asuntos políticos o sociales, o si tenían discusiones acerca de libros, películas o programas de televisión con sus hijos de 15 años. También se les preguntó a los padres y a las madres si compartían la comida principal con sus hijos, alrededor de la mesa; si iban con sus hijos a las librerías o bibliotecas; si platicaban sobre lo que ellos estaban leyendo por su gusto, independientemente; y si pasaban tiempo tan sólo hablando con sus hijos.

En general, los jóvenes de 15 años cuyos papás y mamás muestran un interés activo en sus vidas y pensamientos, son más competentes en la lectura. Como ocurre con las actividades desarrolladas por los padres y las madres cuando sus hijos son muy pequeños, algunos tipos del compromiso parental que establecen con sus hijas e hijos mayores están asociados más estrechamente con mejores competencias lectoras que otros. Por ejemplo, conversar con jóvenes de 15 años es más benéfico que ir a la biblioteca o a la librería con ellos. Los estudiantes parecen beneficiarse más de las discusiones con sus papás y sus mamás, en particular acerca de asuntos políticos o sociales. En todos los países y las economías, los estudiantes que solían discutir estos asuntos tuvieron mejor desempeño lector que aquellos cuyos papás y mamás no lo hacían. Esta relación resulta muy significativa en algunos países. En el caso de Italia, por ejemplo, la diferencia en los resultados de PISA entre los estudiantes cuyos padres discuten este tipo de asuntos con ellos, y aquellos otros estudiantes cuyos padres no lo hacen, es de 42 puntos. En Panamá es

\section{Recuadro 3.1 Alrededor del Mundo: El enfoque Reggio Emilia}

El enfoque Reggio Emilia es una filosofía educativa que privilegia el desarrollo natural de las niñas y los niños en su relación con el ambiente exterior. Esta filosofía se basa en la participación de los padres, las madres y las comunidades.

El enfoque nació en la ciudad Reggio Emilia en Italia, tras las secuelas de la Segunda Guerra Mundial. Al mismo tiempo que los papás, las mamás y la comunidad trabajaban juntos en la reconstrucción de los edificios escolares para sus hijas e hijos pequeños, desarrollaban un programa preescolar y básico, que ha sido adoptado en muchas instituciones alrededor del mundo.

De acuerdo con la filosofía Reggio Emilia, los papás y las mamás son considerados como "Ios primeros maestros". Los "segundos maestros" son los maestros del salón de clases; el "tercer maestro" es el ambiente. Consecuentemente, papás y mamás se involucran en cada aspecto de la vida escolar: son invitados a participar en los procesos de toma de decisiones de las escuelas; participan en las discusiones sobre las políticas, el currículo y las evaluaciones; son informados regularmente del progreso de sus hijas e hijos en la escuela y, en cambio, se les solicita que reporten las experiencias de aprendizaje de sus hijos en casa; asimismo se encuentran involucrados, frecuentemente, en las actividades y proyectos estudiantiles. Padres y madres participan con frecuencia en actividades en el salón de clases, y son motivados a aplicar los principios Reggio Emilia en el hogar. Las reuniones se realizan, normalmente, después de las horas de trabajo, para que más papás y mamás puedan asistir.

http://zerosei.comune.re.it/inter/index.htm 
de 38 puntos y en Portugal de 37, mientras que en Nueva Zelanda y Qatar es de 32. Dado que una puntuación de 39 puntos en PISA es el equivalente de un año de educación formal, este resultado confirma que padres y madres no tienen que dedicar largas horas a la atención de sus hijos, o tener un conocimiento especializado para influir sustancialmente en el buen desempeño lector de éstos. Todo lo que se requiere es el interés genuino de un padre o una madre por su hija o hijo, y la interrelación que éstos logran gracias a eso con el mundo que les rodea.

En todos los países y economías, excepto en Hungría y Lituania, los estudiantes que discuten sobre libros, películas y programas de televisión con sus padres, también muestran mejor desempeño lector. Esta relación se acentúa en particular en Italia, Nueva Zelanda, Portugal y Qatar, países en los cuales los estudiantes que discuten sobre estos asuntos con sus padres y madres alcanzan puntuaciones 25 puntos por arriba, en promedio, respecto a los estudiantes que no lo hacen.

- Gráfica 3.1 -

\section{Los adolescentes que discuten con sus madres y padres sobre asuntos sociales y de política, son excelentes lectores}

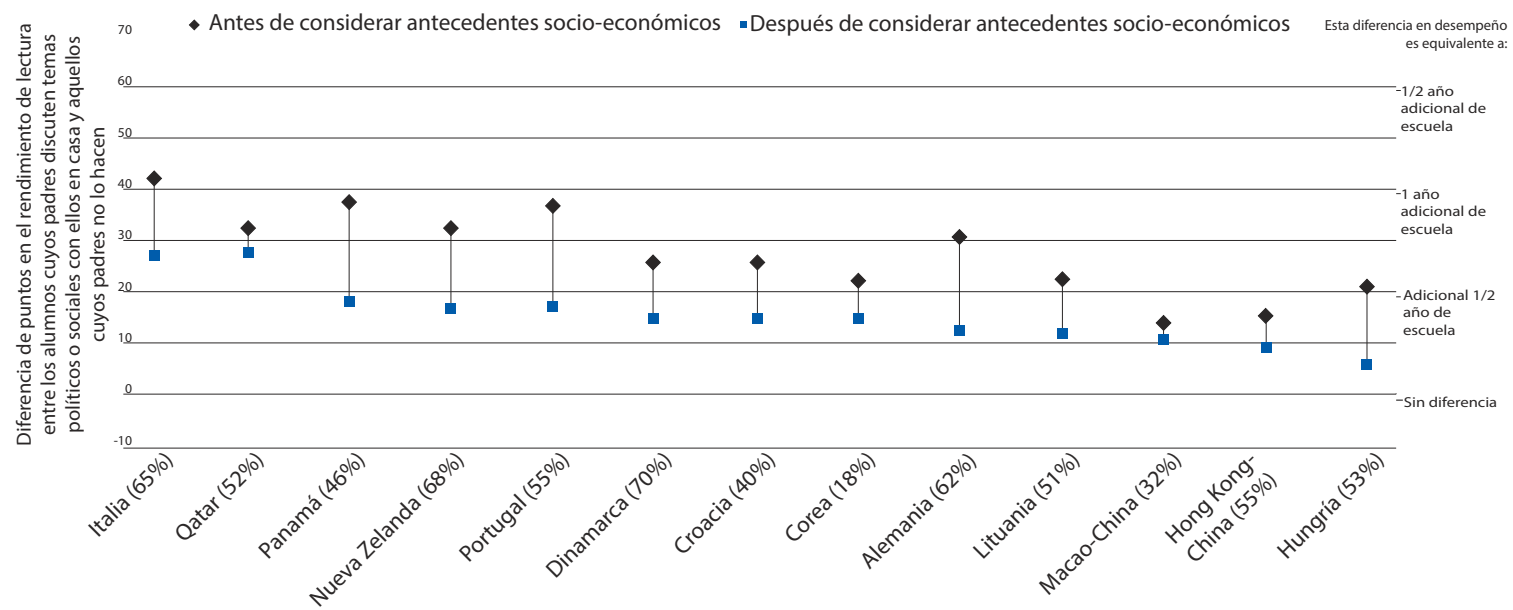

Nota: El porcentaje de papás y mamás que discuten asuntos políticos o sociales con sus hijos/hijas se muestra entre paréntesis después de cada país/economía. Países/economías se muestran en orden descendente de acuerdo a la diferencia en desempeño lector después de considerar los antecedentes socio-económicos.

Fuente: Cuadro A3.1. 
Aunque estas relaciones resultan evidentes, no son tan decisivas, aún después de dar cuenta de las diferencias en los antecedentes socioeconómicos de los estudiantes. Esto podría ser porque los estudiantes más avanzados cuentan generalmente con una participación mayor de los padres o las madres, o bien se debe a que la participación parental es un atributo asociado con la ventaja socioeconómica y, por ello, es una de las maneras en que las diferencias socioeconómicas influyen en el desempeño lector. Aún así, en todos los países y las economías, los estudiantes procedentes de antecedentes socioeconómicos similares, que discuten sobre asuntos políticos o sociales con sus padres, alcanzan mejores resultados en lectura que aquellos estudiantes que no discuten de estos asuntos con sus mentores. En Nueva Zelanda, Panamá, Portugal y Qatar, esta diferencia en el desempeño es mayor a 15 puntos en las calificaciones.

PISA encuentra también que los estudiantes que discuten sobre asuntos políticos y económicos con sus padres, disfrutan más de la lectura que aquellos que no lo hacen. Esto puede ser porque los estudiantes que disfrutan intrínsecamente de la lectura tienden a tener este tipo de conversaciones con su padre o madre. Cualquiera que sea la razón, la fuerza de esta asociación trasciende los antecedentes

\section{Recuadro 3.2 Israel: La familia como Educador ${ }^{1}$}

Siguiendo un proyecto de investigación realizado en la década de 1990, algunas escuelas en Israel adoptaron el uso de "pruebas" para motivar a los padres y las madres a participar en la educación. Las "pruebas" consistían en preguntas de entrevista sobre un tópico específico, utilizadas para comenzar una discusión. Por ejemplo, las preguntas relacionadas con los tópicos "historias de familia" o "comidas familiares", incluían discusiones sobre diferentes maneras de celebrar, y sobre diferentes estilos, basados en los orígenes étnicos de las familias. Cada día festivo es celebrado con su propia comida típica; y cada grupo étnico de judíos inmigrantes usa diferentes tipos de comidas en ese mismo día festivo. Esto da pauta para la discusión entre padres, madres y estudiantes.

Estas pruebas fueron usadas como una base para unidades curriculares, tales como el Álbum Familiar, o el Currículo de la Biblia Familiar. El Álbum Familiar comienza en el primer grado, y se desarrolla a lo largo de los seis años de educación primaria. Se basa en las "fotografías familiares" y en "nombrar" pruebas. Para este programa se solicita a las familias coleccionar fotografías y escribir historias que les acompañen en un álbum especial. El currículo de la Biblia Familiar, aún usado en alrededor de 20 escuelas, combina diferentes pruebas, tales como las "historias familiares", los "rituales familiares", las "comidas familiares", el "hogar familiar" y el cuarto del niño o la niña, para motivar discusiones en el hogar sobre temas que surgen de la Biblia. Esto hace a la Biblia más accesible y relevante para los estudiantes, pues se muestran similitudes entre las historias bíblicas familiares, y las historias de la propia vida del niño o la niña.

El proyecto de investigación inicial, y el desarrollo de los programas subsecuentes y del currículo, fueron financiados por la escuela donde se realizó el trabajo experimental, y por diferentes fundaciones: la Agencia Judía por Israel, la Fundación Judía Metro-Oeste, la organización Hdassah y la Fundación Nacional Judía en Israel. Se obtienen fondos adicionales mediante la venta de unidades curriculares a varias agencias y escuelas.

Una evaluación conducida al final del proyecto de investigación mostró que con esta estrategia aumenta la conciencia de los papás y las mamás sobre su papel como educadores. El clima escolar también mejoró, con relaciones más positivas entre las escuelas, los estudiantes, y sus padres y madres; además, los logros académicos de los estudiantes que participaron en el programa fueron mayores que los de aquellos niños que no participaron. 
socioeconómicos. En todos los países y todas las economías, disfrutan más de la lectura los estudiantes con antecedentes similares, cuyos padres y madres suelen discutir con ellos sobre asuntos políticos o sociales. Esta correlación se acentúa particularmente en los estudiantes de Alemania, Italia, Corea, Lituania y Nueva Zelanda.

El hecho de que los padres hablen con sus hijos -cuando éstos son estudiantes de mayor edad- sobre asuntos complejos, tales como temas políticos o sociales, también parece estar asociado con una mayor conciencia adquirida por los propios estudiantes sobre determinadas estrategias efectivas de aprendizaje, pues así aprenden éstos la manera en que se debe resumir la información obtenida mediante la lectura. En todos los países y las economías participantes en PISA, los estudiantes cuyos padres y madres discuten sobre temas políticos o sociales con ellos, tienen más conciencia de estos tipos de estrategias. Esta relación es particularmente significativa en Dinamarca, Italia, Corea, Panamá y Portugal.

Lo anterior podría significar simplemente que es probable que los estudiantes que tienen una mejor ventaja socioeconómica -y quienes podrían establecer con mayor frecuencia este tipo de discusiones con su padres- tienen una mayor conciencia sobre las estrategias más efectivas para resumir información, respecto a aquellos de sus compañeros que no se envuelven en este tipo de discusiones con sus padres.

- Gráfica 3.2 ш

\section{Habla de asuntos sociales y políticos con tu hijo adolescente}

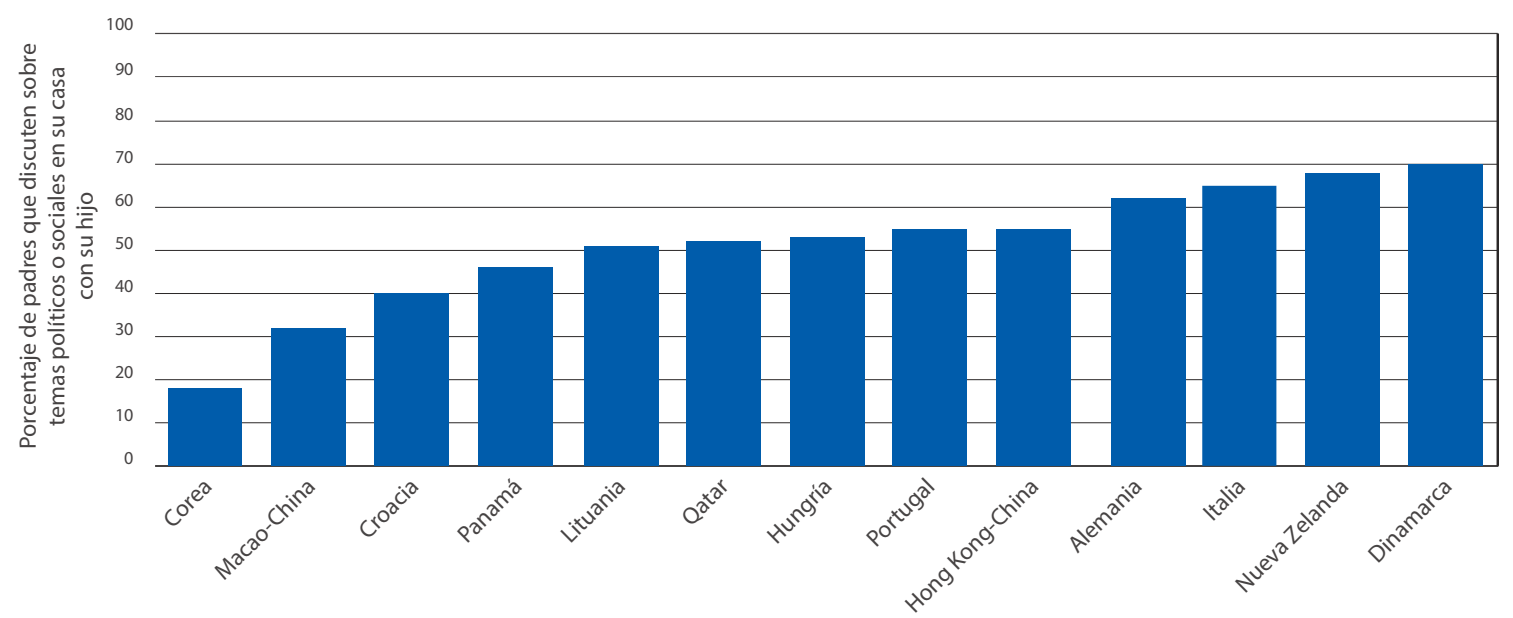

Países/Economías están ordenados de manera ascendente, de acuerdo al porcentaje de papás y mamás que discuten asuntos políticos y sociales con sus hijos e hijas.

Fuente: Cuadro A3.1.

http://dx.doi.org/10.1787/888932606492 
En promedio, en el conjunto de los países y las economías examinados en este reporte, cerca de la mitad de los padres y las madres reportaron que discutían sobre asuntos políticos y sociales con sus hijas e hijos. Alrededor de dos terceras partes de los padres en Dinamarca, Italia y Nueva Zelanda discuten esos tópicos con sus hijos de 15 años de edad, pero solamente una tercera parte de los padres en Corea y Macao-China lo hacen. En promedio, los padres con mejores ventajas socioeconómicas tienen 20 puntos porcentuales más de probabilidad que los padres en condiciones de desventaja, de discutir sobre temas políticos o sociales con sus hijos. Esta diferencia se acentúa particularmente en Alemania, Italia y Portugal. Las familias en ventaja socioeconómica tienen también, en promedio, mayores probabilidades de discutir sobre libros, películas o programas de televisión con sus hijos de 15 años, en comparación con otras familias.

- Gráfica 3.3 .

Mamás y papás: motiven a sus hijos a compartir sus pensamientos, sobre lo que leen y observan

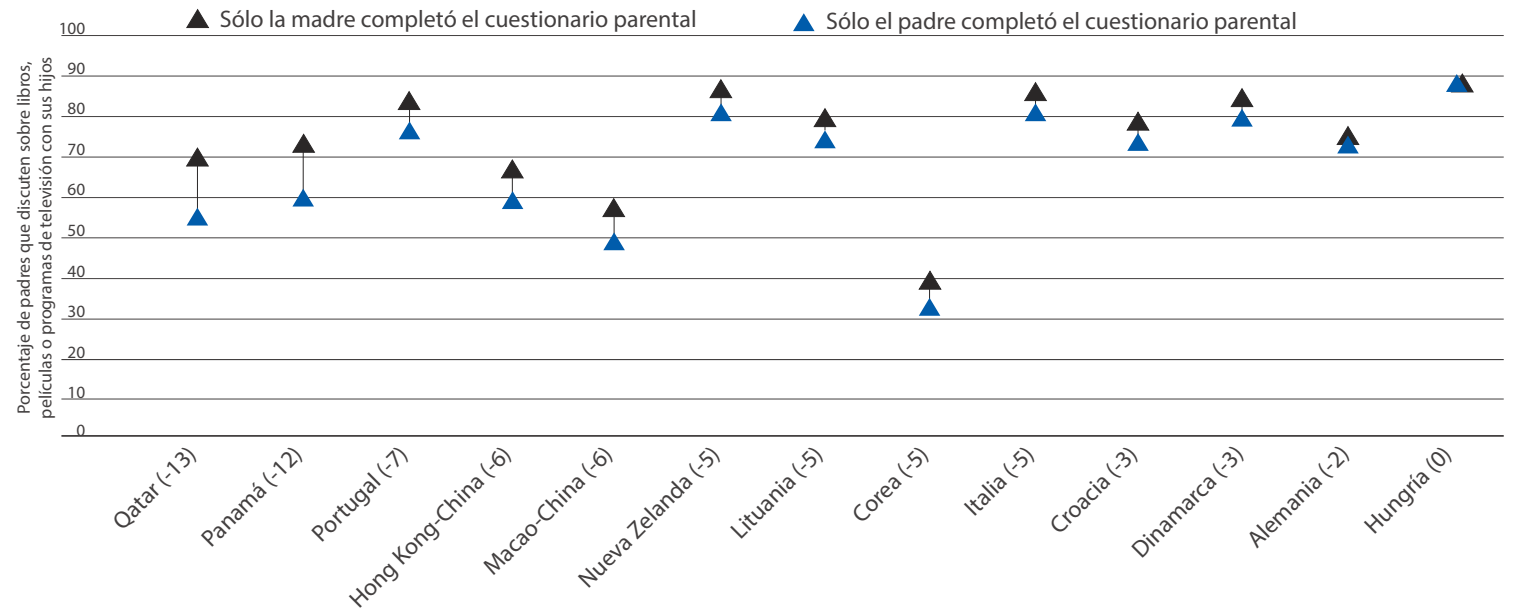

Nota: La diferencia entre el porcentaje de padres que completaron el cuestionario parental y discuten sobre libros, películas o programas de television con sus hijos/hijas, y el porcentaje de madres que contestaron el cuestionario y también lo hacen, se muestra entre paréntesis después de cada país/economía.

Países/economías están ordenadas de manera descendente de acuerdo con la diferencia de papás que completaron el cuestionario y discuten sobre libros, películas o programas de televisión con sus hijos/hijas y el porcentaje de madres que lo hace.

Fuente: Cuadro A3.2.

http://dx.doi.org/10.1787/888932606511 
Las escuelas también parecen marcar una diferencia entre aquellos padres que participan en la educación de sus hijas o hijos, y aquellos que no lo hacen. Por ejemplo, los padres de los estudiantes de 15 años que ingresaron a mejores escuelas tienen más probabilidad de discutir sobre asuntos políticos o sociales con sus hijos, que los padres de similar situación socioeconómica, cuyos hijos asistieron a escuelas con mayores desventajas para el conjunto de los estudiantes. Esto se debe quizá a que en las mejores escuelas, que cuentan con un conjunto de estudiantes avanzados, los padres están más motivados -o presionados- a involucrarse en la educación de sus hijos, probablemente por los otros padres, y asimismo por los maestros. $\mathrm{O}$ tal vez sucede que este tipo de escuelas atrae precisamente a papás y mamás que están más dispuestos a involucrarse en la educación de sus hijos.

Las mamás muestran un poco más de disposición que los papás -y además, de manera consistentepara discutir sobre libros, películas o programas de televisión con sus hijas e hijos, para indagar sobre el desempeño que éstos tienen en la escuela, o tan sólo para dedicar cierto tiempo a hablar con ellos. Sin embargo, en ocho de los países y las economías consideradas en este reportaje, son los papás quienes tienen mayores probabilidades de ayudar a sus hijos con sus tareas - una actividad que, en la mayoría de las familias, significa ayudar a los estudiantes que están en problemas. Esto sugiere que muchos papás son capaces y están dispuestos a involucrarse en la educación de sus hijos, a pesar de que aún prevalezca la noción de que corresponde a la mamá estar más involucrada en la educación de éstos. En todo caso, los papás parecen involucrarse por lo general sólo de manera reactiva, es decir cuando sus hijos se muestran vacilantes en su desempeño escolar. Como muestra este reporte, la participación temprana -conjunta de los papás y las mamás- puede prevenir malos resultados en el desempeño escolar y, sobre todo, promover el bienestar de los estudiantes.

- Gráfica 3.4 .

\section{No tienes que ser experto en una materia para ayudar a tu hijo o a tu hija con su tarea}

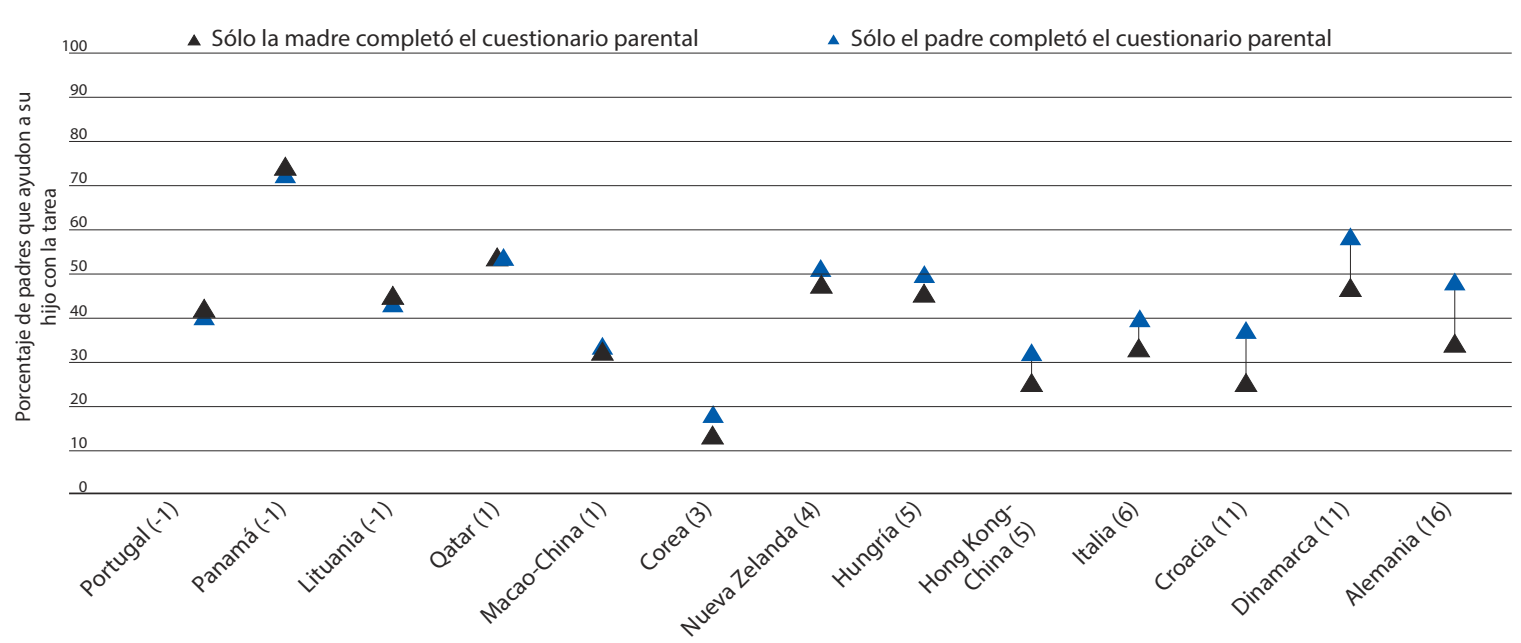

Nota: La diferencia entre el porcentaje de padres que completaron el cuestionario parental y ayudaron a su hijo con sus tareas, y el porcentaje de madres que lo hicieron, aparece entre paréntesis después del nombre de cada país/ economía. Países/economías están ordenados de modo ascendente, de acuerdo con la diferencia del porcentaje de padres que contestaron el cuestionario y ayudaron a sus hijos con las tareas, y el porcentaje de madres que lo hicieron. Fuente: Cuadro A3.3. 


\section{¿QUÉ PUEDEN HACER LAS MAMÁS Y LOS PAPÁS?}

Cuando los padres tienen discusiones abiertas con los adolescentes sobre asuntos políticos y sociales, o acerca de libros, películas, música y otras expresiones y eventos culturales, los hijos e hijas desarrollan opiniones informadas, y esto les ayuda a mejorar su pensamiento crítico. Los niños y los adolescentes encuentran un mayor placer en la lectura cuando tienen mamás o papás que quieren escuchar sus opiniones sobre lo que apenas acaban de leer. Este tipo de participación parental puede tener lugar durante las comidas familiares, por ejemplo, y requiere tan sólo del tiempo que dedican los padres a entablar pláticas con sus hijos.

\section{¿QUÉ PUEDEN HACER LAS MAESTRAS Y LOS MAESTROS?}

Las maestras y los maestros pueden promover la participación de los papás y las mamás en el hogar, aún cuando esta forma de participación no esté directamente relacionada con lo que pasa en la escuela; las asociaciones entre los padres y los maestros no necesitan restringirse a actividades basadas en el programa escolar. Cuando los maestros establecen relaciones de confianza con los padres, pueden compartir mejor con sus estudiantes el conocimiento que tienen, y compartir también sus aspiraciones, sus necesidades y sus preferencias. Al hacerlo, los maestros ayudan a los estudiantes y a sus padres a desarrollar un terreno común sobre el que es posible construir una relación franca y abierta. Los maestros también pueden apoyar e informar a los padres sobre cómo vincularse mejor con sus hijos en casa, y cómo desarrollar conversaciones interesantes con ellos. Finalmente, los docentes tienen la capacidad para entablar discusiones directamente con sus estudiantes, cuando los padres enfrenten algunas restricciones que les dificulten conversar regularmente con sus propios hijos.

\section{Nota}

1. Serok, E. (2004), The Family as Educator - Using the Cultures, Traditions and Heritages of Families as Enrichment Resources for an Israeli School: An Educational Chronicle, Proquest Information and Learning Company, Ann Arbor, Michigan. 


\section{Involúcrate en la escuela} porque quieres,

no porque debes hacerlo

Cuando los padres y las madres se toman un tiempo para tener reuniones con los maestros de sus hijas e hijos; o cuando participan como voluntarios en actividades escolares, están mostrando a sus hijos que ellos mismos valoran la educación. Este capítulo examina algunas de las formas en que los padres ocupados se pueden involucrar en actividades escolares, y enfatiza que los padres y los maestros deben reunirse cuanto antes entre sí.

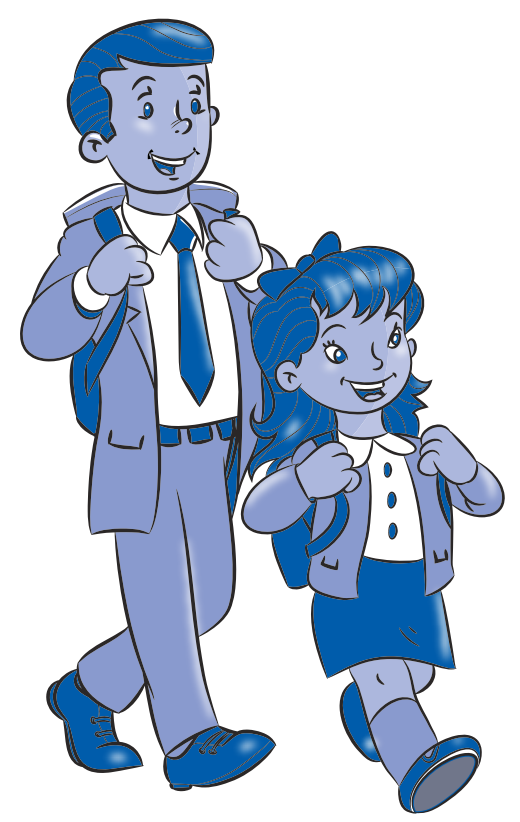


Las madres y los padres pueden involucrarse en la educación de sus hijas e hijos al participar en las actividades de la escuela, tales como las juntas con los maestros o las autoridades; o al participar como voluntarios en la escuela. Las investigaciones han mostrado que este tipo de participación parental se asocia con un mayor compromiso de los estudiantes en la escuela. Esto se debe a que ese tipo de actividades muestra a los estudiantes que sus padres valoran el aprendizaje y la educación; y al mismo tiempo, manifiesta a las escuelas que los padres están realmente interesados en la educación de sus hijos -lo cual puede motivar a los maestros a dedicar una mayor atención a éstos.

El cuestionario de PISA preguntó a los padres si durante el año escolar previo habían conversado sobre la conducta de sus hijos con un maestro, ya fuera por su propia iniciativa, o por la de los propios docentes; si el padre o la madre se habían ofrecido para participar como voluntarios en actividades extracurriculares o en la biblioteca; si habían ayudado a un maestro en la escuela; o si habían participado, como oradores invitados, en los actos públicos de las escuelas.

Los resultados de PISA muestran que los estudiantes cuyos padres o madres se involucran en las actividades de la escuela, tienden a no tener tan buen desempeño lector, respecto a aquellos estudiantes cuyos padres están menos involucrados activamente en las actividades escolares. En 11 países y economías analizados, los niños cuyos padres discuten sobre su comportamiento o su progreso con los maestros, ya sea por iniciativa propia o por iniciativa del maestro, no tienen tan buen desempeño lector como los niños cuyos padres no tienen ese tipo de discusiones. Esto significa, probablemente, que las escuelas esperan que los estudiantes tengan problemas, para entonces buscar la presencia de papá y mamá; y que también éstos esperan que sus hijos tengan dificultades con sus tareas, para asumir entonces un papel activo en la escuela.

\section{Recuadro 4.1 El reconocimiento oficial de las madres y los padres como socios en Irlanda}

La Ley de Educación de 1998 enfatiza que la educación en Irlanda es entendida como una sociedad compuesta por muchos implicados que tienen un interés activo, incluyendo a los padres y a las madres. La Ley especifica que los padres tienen el derecho de ser consultados e informados en todos los aspectos de la educación de sus hijos, y por ello se requiere que las escuelas involucren a los padres en los planes de la escuela. También se solicita a las escuelas considerar a los padres como miembros de la junta directiva del Consejo de Administración. La Ley especifica que, entre otras responsabilidades, los padres deben: "nutrir un ambiente de aprendizaje, cooperar con la escuela y darle apoyo, así como a otros socios individuales, y cumplir con su papel especial en el desarrollo de las niñas y los niños".

Sin embargo, la legislación irlandesa ya reconocía y promovía el papel de los padres en el sistema de educación desde antes de la Ley de 1998. La Constitución de Irlanda de 1937 reconoce a padres y madres como los primeros educadores de los niños. El cambio de la estructura administrativa de las escuelas nacionales, que tuvo lugar en 1975, incluía la indicación de que al menos dos padres de los niños inscritos en una escuela primaria debían servir en la junta directiva del Consejo de Administración; y la circular de 1991, que hace referencia a los padres como socios en la educación, requiere que todas las escuelas, después de la primaria, se aseguren de que la asociación de padres se forme en la escuela, y asimismo se motiva a cada asociación para que se una a la red nacional.

Casi cada primaria y escuela post-primaria en Irlanda tiene ahora a padres representantes dentro del consejo directivo de administración. 
De modo similar, en siete países y economías, los niños y niñas cuyos padres se ofrecieron voluntariamente para hacer trabajos extracurriculares, tienen más probabilidades de tener bajas calificaciones que aquellos estudiantes cuyos padres no participaron como voluntarios.

Aún cuando se infiere de estos resultados una relación negativa entre la participación de los padres y el desempeño de los estudiantes, resulta muy probable que los resultados de estos mismos estudiantes hubieran sido aún menores en sus puntuaciones de lectura, si sus padres no se hubieran involucrado en las actividades escolares.

Las formas de participación ya mencionadas tienden a ser reactivas: los padres y las madres se involucran únicamente hasta que han decidido que es necesario hacerlo, posiblemente por haber sido alertados por la escuela. Por esto, los padres de los estudiantes con dificultades tienen más probabilidades de asistir a las reuniones con los maestros, de participar como voluntarios en actividades extracurriculares, y de ayudar a sus hijas e hijos con sus tareas. Como resultado, en muchos países y economías, los padres en desventaja socioeconómica, en particular con hijos varones, tienen más probabilidades de involucrarse en estas actividades, dado que el bajo nivel de desempeño tiende a asociarse precisamente con un estatus socioeconómico inferior, y con niños varones. Estas actividades son benéficas para todos los chicos con estas características -a menos que los estudiantes con problemas sean estigmatizados por la participación de sus padres en la escuela-, pero la participación de los padres resulta más benéfica cuando comienza mucho antes de ser considerada necesaria, o incluso cuando ya es impostergable.

- Gráfica 4.1

\section{Discutir el progreso de tus hijos e hijas en la escuela, muestra que valoras la educación}

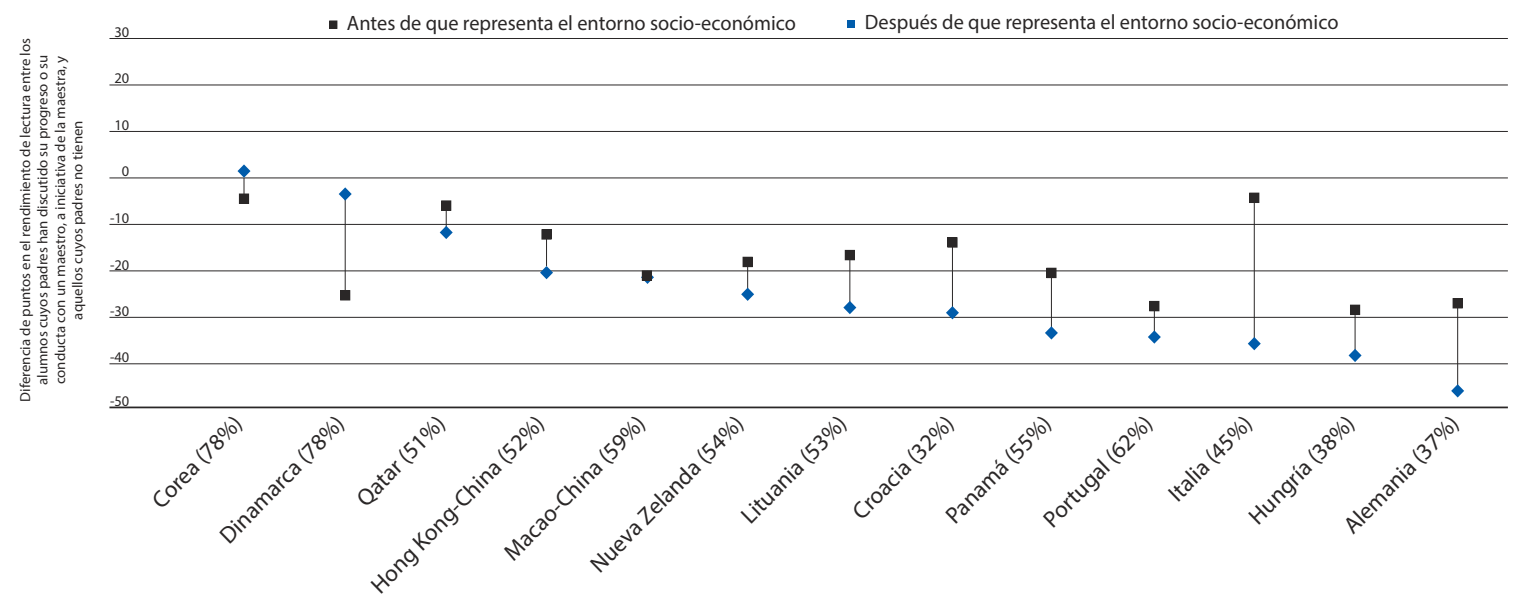

Nota: Cuando los padres o las madres han discutido el comportamiento o el progreso de su hijo o hija con su maestro, por iniciativa de éste, su porcentaje se muestra entre paréntesis, después del nombre de los países / economías. Los países o economías se ordenan de modo descendente de acuerdo con la diferencia en desempeño lector, después de considerar los antecedentes socioeconómicos.

Fuente: Cuadro A4.1.

http://dx.doi.org/10.1787/888932606549 
El hecho más sorprendente de la participación de los padres y las madres en las actividades escolares es su relativa ausencia, así como el hecho de que ocurre, principalmente, sólo cuando resulta absolutamente necesaria: por ejemplo, cuando los estudiantes tienen problemas. Los resultados de PISA ponen de relieve cómo generalmente, en la mayoría de las escuelas, los padres y los maestros se reúnen sólo cuando los estudiantes están en dificultades. Pocos padres y madres se comprometen en actividades en la escuela que no estén directamente relacionadas con ayudar a sus hijos, actividades tales como presentarse como orador invitado, como voluntario para actividades deportivas, asistiendo a los maestros, o bien participando en labores que tienen lugar fuera de la escuela.

\title{
¿QUÉ PUEDEN HACER LAS MAMÁS Y LOS PAPÁS?
}

La participación de los padres y las madres en la escuela depende de las propias actitudes e iniciativas de la escuela para invitarlos a colaborar en sus actividades (ver, más adelante, qué pueden hacer las escuelas). Pero asumiendo que las escuelas dan la bienvenida a la participación, los padres pueden hacer mucho más que tan sólo discutir el progreso académico de sus hijos con los maestros. Pueden, por ejemplo, acordar con la escuela visitar una clase o varias para entender mejor cómo es un día de labores de sus hijas e hijos en la escuela; pueden ofrecer su ayuda voluntaria para ser entrenadores de deportes, ayudando en la realización de actividades extra curriculares o clubs, o trabajando en la biblioteca del colegio; o pueden ofrecer su tiempo como voluntarios para ser oradores invitados en la escuela, para compartir con los estudiantes algún tema que les interese en especial, para comunicarles un logro, para darles una perspectiva de una profesión desde el interior de ésta, o bien para realizar un trabajo específico.

\author{
- Gráfica 4.2 .
}

\section{Participar en actividades extracurriculares en la escuela de tus hijos e hijas solamente se asocia de manera débil con mejores resultados en el desempeño estudiantil}

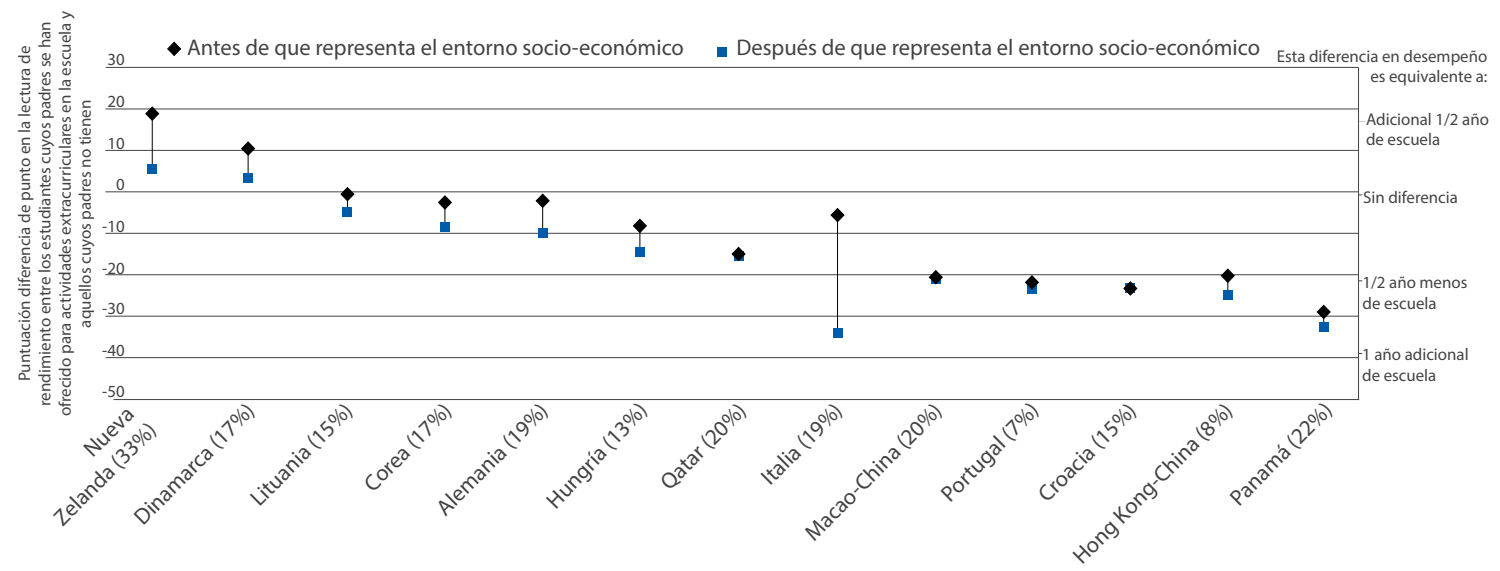

Nota: El porcentaje de padres/madres quienes han participado como voluntarios en actividades extracurriculares en la escuela se muestra entre paréntesis después del nombre del país/economía.

Países/Economías están ordenadas de manera descendente de acuerdo a su desempeño lector después de considerar los antecedentes socioeconómicos.

Fuente: Cuadro A4.2.

http://dx.doi.org/10.1787/888932606568 


\section{Recuadro 4.2 Estados Unidos: La zona infantil de Harlem}

La Zona de Niños de Harlem (HCZ, por sus siglas en inglés) es una organización sin fines de lucro que fundamenta su trabajo en la idea de rediseñar las escuelas como centros comunitarios. El programa comenzó a inicios de la década de 1990, como un intento de canalizar los muchos problemas que enfrentaban las familias en condiciones marginales dentro de una sola manzana en Harlem, en la Ciudad de Nueva York. Ofrece escuela, programas para realizar después de la escuela, servicios de salud y sociales, y programas para el desarrollo de la comunidad. También lleva a cabo una serie de programas dirigidos a padres e hijos, desde el nacimiento de éstos hasta su temprana edad adulta. El Colegio de Bebés, por ejemplo, provee de capacitación a padres y madres que están en la espera de un hijo, y si tienen ya hijos pequeños, hasta que éstos cumplan tres años. Enfatiza la importancia de leerles a los niños, y de utilizar la disciplina verbal en vez del castigo corporal. El programa, de tres años de duración, ayuda a los padres a construir el lenguaje y las habilidades parentales necesarias para apoyar el desarrollo de sus hijos. La Administración del Caso Académico emplea un enfoque para el desarrollo de la juventud utilizado por la escuela secundaria, la preparatoria, y por los estudiantes en edad de ingresar a la universidad, que motiva la colaboración entre las mamás, los papás y el personal de la escuela, con el fin de apoyar el desempeño de los estudiantes.

El programa, que se ofrece de manera gratuita, es financiado mediante donaciones y gracias a un subsidio gubernamental. Ha sido replicado en otras veinte ciudades de Estados Unidos, y atendió en el 2009 a más de 10,000 niñas y niños, y a 10,000 adultos únicamente en Harlem.

www.hcz.org

\section{Recuadro 4.3 Estados Unidos: La Red Nacional de Escuelas Asociadas}

La Red Nacional de Escuelas Asociadas (The National Network of Partnership Schools -NNPS), establecida en 1996 en la Universidad John Hopkins, pretende apoyar tanto a familias como a comunidades en los Estados Unidos para que se involucren en la educación de sus hijas e hijos. La NNPS ha desarrollado varias herramientas con este propósito, incluyendo un "proceso de asociación" Ilamado "Los Maestros Involucran a los Papás en el Trabajo Escolar con Tareas Interactivas" (Teachers Involve Parents in Schoolwork Interactive Homework -TIPS-). A través de TIPS se les asigna una tarea a los estudiantes, basada en un tópico discutido en clase, que requiere que éstos interactúen con alguien en casa. De este modo, tanto maestras y maestros, como papás y mamás, están involucrados en el trabajo de los estudiantes.

La NNPS, que inicialmente fue financiada con subsidios del Instituto Nacional de Salud Infantil y el Departamento de Desarrollo del Departamento de Educación de los Estados Unidos, motiva a las escuelas que son miembros de la red a buscar financiamiento independiente para el programa. Para convertirse en un miembro, cada escuela debe dedicar un equipo a la iniciativa, definir metas y asignar un presupuesto. Las escuelas pagan una cuota de registro y una cuota anual para renovarlo, y se les pide que completen anualmente una encuesta que permite a la NNPS evaluar su trabajo. Ahora hay más de 1,000 escuelas en veintidós estados de los Estados Unidos. Cada miembro recibe el anuario Prácticas Prometedoras de los Socios, un compendio de alrededor de 100 actividades en asociación que fueron implementadas por miembros de la NNPS durante el ciclo escolar anterior. Las actividades son organizadas e indexadas de acuerdo con los resultados de los estudiantes, con su nivel escolar, y con el tipo de involucramiento realizado.

www.partnershipschools.org 


\section{¿QUÉ PUEDEN HACER LAS ESCUELAS?}

Los maestros y las maestras pueden desarrollar relaciones de confianza con las mamás y los papás para motivarlos a involucrarse más en la educación de sus hijos adolescentes. Muy frecuentemente, las interacciones entre los maestros y los padres ocurren solamente cuando los estudiantes presentan problemas académicos o de conducta. Adicionalmente, cuando los estudiantes se hacen mayores, generalmente tienen más de un maestro, lo cual dificulta la conformación de relaciones sólidas entre los docentes y los padres. Algunas escuelas secundarias promueven la existencia de maestros-tutores, quienes coordinan el intercambio de información entre todos los maestros con los que trabajan los estudiantes, y los padres de éstos. Otras escuelas asignan un número pequeño de estudiantes a cada maestro quien, adicionalmente a su carga normal de trabajo académico, funge también como tutor de esos estudiantes.

- Gráfica 4.3

\section{Los padres son una fuente importante de ayuda para estudiantes que tienen problemas}

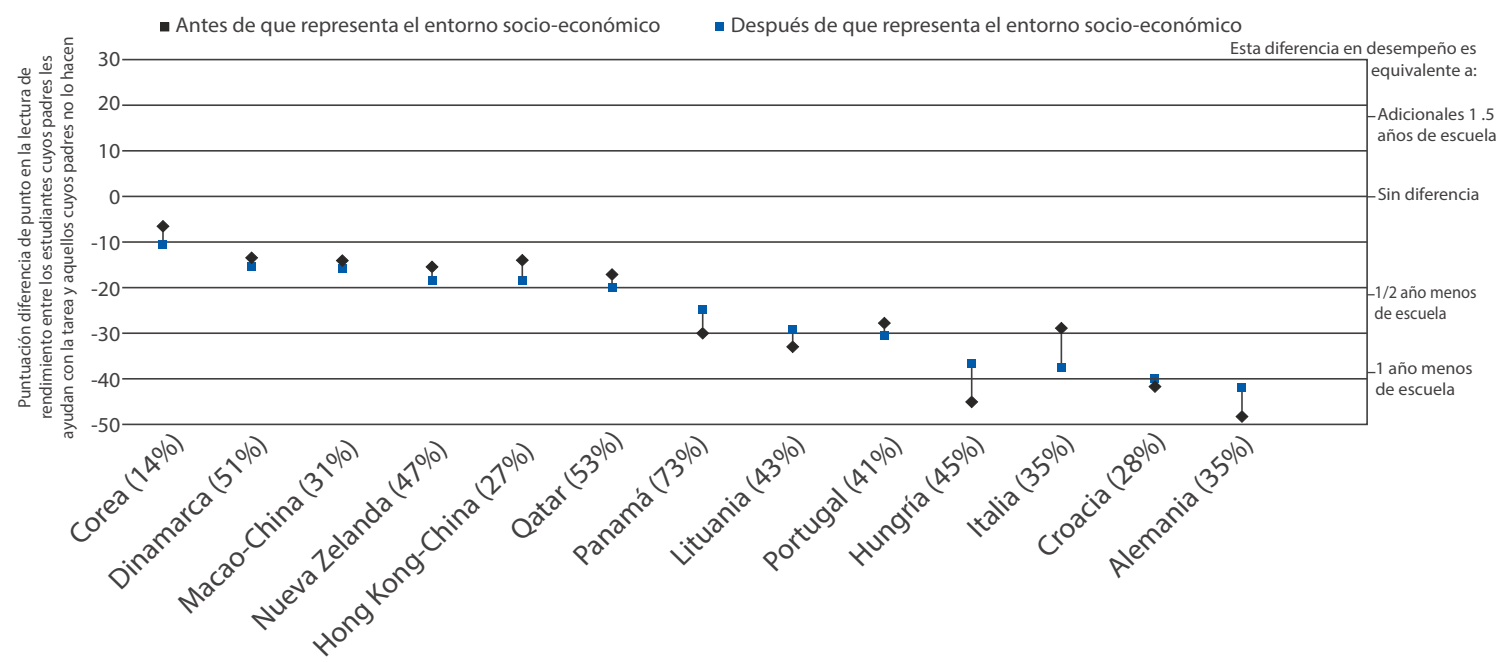

Nota: El porcentaje de papás/mamás que ayudan a sus hijas/hijos con sus tareas se muestra en paréntesis después del nombre del país/economía. Los países/economías están ordenados de manera descendente de acuerdo a la diferencia en desempeño lector después de considerar los antecedentes socioeconómicos.

Fuente: Cuadro A4.1.

http://dx.doi.org/10.1787/888932606587 
- Gráfica 4.4 -

\section{No esperen a tener problemas académicos o de conducta para conocer al maestro de sus hijos e hijas}

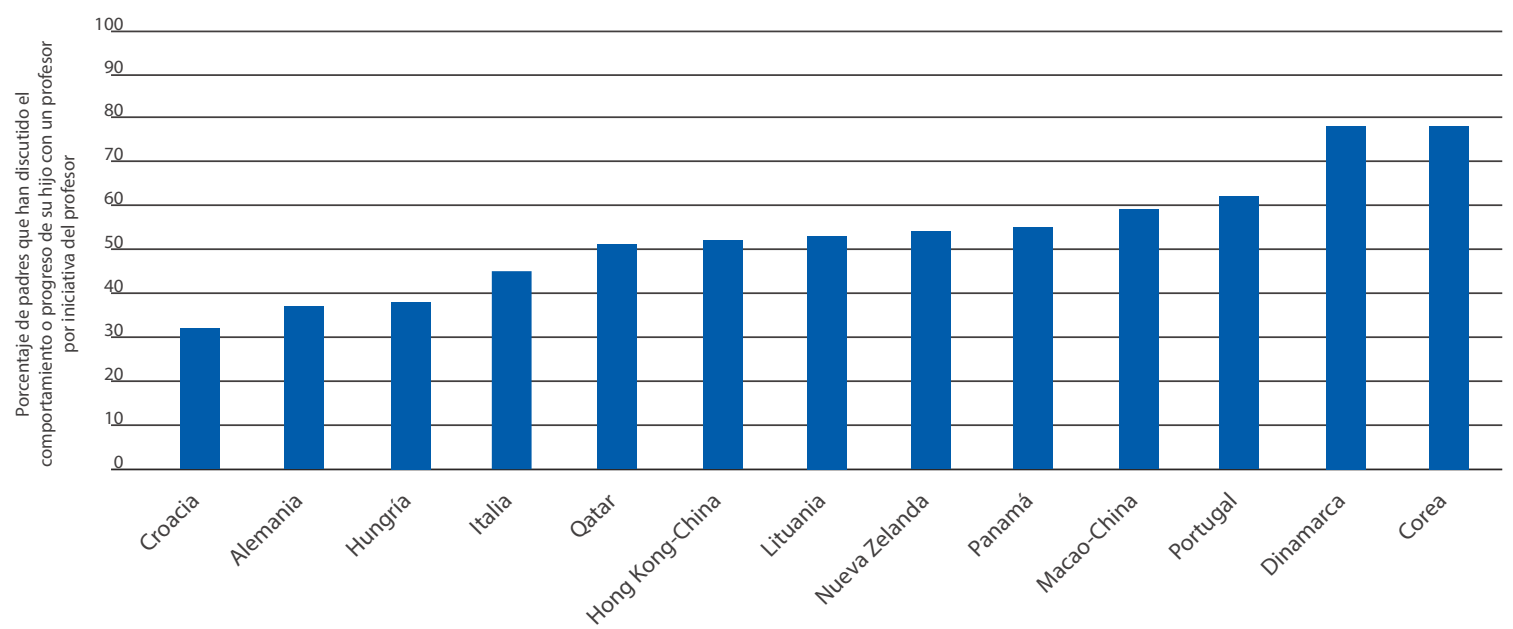

Países/Economías están ordenados de manera ascendente de acuerdo al porcentaje de papas/mamás que discuten con sus hijos/hijas su progreso o conducta con los maestros a partir de la iniciativa de estos últimos. Fuente: Cuadro A4.1.

http://dx.doi.org/10.1787/888932606606

- Gráfica 4.5 .

Haz un esfuerzo e involúcrate: sé un voluntaria o voluntario

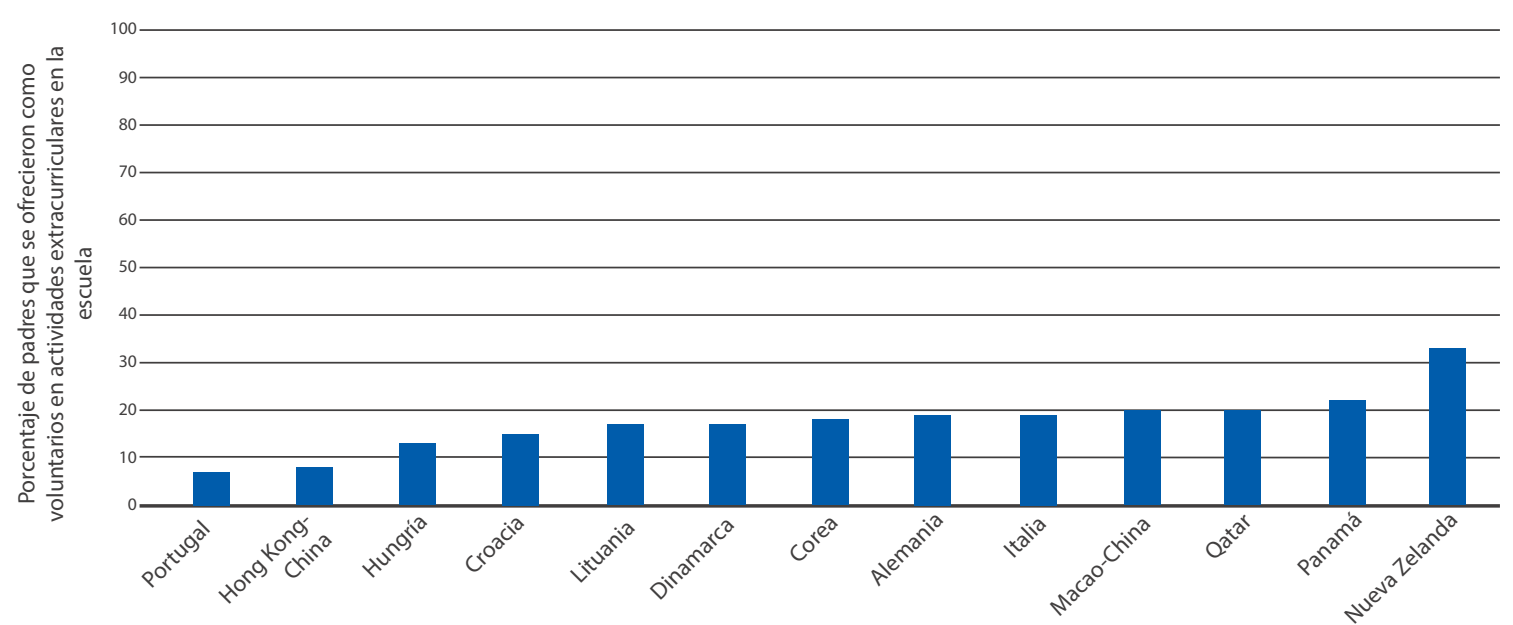

Países/Economías están ordenados en orden ascendente de acuerdo al porcentaje de padres/madres que participan como voluntarios en actividades extracurriculares

Fuente: Cuadro A4.2.

http://dx.doi.org/10.1787/888932606625 
En algunas otras escuelas se suelen designar tutores cuyo papel no consiste en enseñar, sino en coordinar las relaciones entre los maestros -y en general la escuela- y los padres. Los maestros pueden involucrar a las familias de muchas maneras. Por ejemplo, presentamos aquí una secuencia de esfuerzos que tienen el objetivo de involucrar a las familias en un orden creciente de complejidad -y efectividad:

- Fase 1, Los maestros y las maestras hacen poco o ningún esfuerzo para conocer a las familias y comunicarse con ellas a lo largo del año. Cuando se comunican con las familias, es porque éstas tienen un problema o alguna preocupación sobre la conducta de sus hijas e hijos. Las familias no saben cómo ponerse en contacto con los maestros.

- Fase 2, Los maestros y las maestras hacen algún esfuerzo para conocer a las familias a lo largo del año. Para ello comparten su información con las familias, así como información sobre las reglas del salón de clases, y sus propias expectativas. Contactan a la familia a lo largo del año escolar cuando surgen problemas, o para invitarlos a los eventos escolares y a las juntas.

- Fase 3, Los maestros y las maestras se ponen en contacto con las familias al inicio del año escolar para compartir información, y para obtener datos mínimos sobre la familia, incluyendo la información necesaria para que puedan ser contactados, y las expectativas que tienen los padres sobre sus hijas e hijos. Contactan a las familias a lo largo del año para avisarles cuando surge algún problema, y también para comunicarles noticias positivas.

- Fase 4, Los maestros y las maestras están en contacto con las familias a lo largo del año para compartir información, incluyendo lo que ocurre en el salón de clase, así como para conocer las esperanzas y los sueños que las propias familias tienen sobre sus hijas e hijos, y sus preferencias para mantenerse en comunicación. Las familias y los maestros están en contacto en forma regular, no sólo cuando los problemas surgen, sino también para compartir noticias positivas.

Los maestros y las maestras también pueden organizar sesiones de "tan sólo llegar"; establecer una política de salones de clase con las puertas abiertas; hacer una página web de sus salones, con un espacio dedicado a preguntas y respuestas para los padres; y organizar visitas a los hogares. Pueden invertir más tiempo en forjar relaciones con aquellas familias que presentan mayor resistencia para hacerlo, en lugar de dedicarlo a las familias que ya están dispuestas y comprometidas con las escuelas y con los propios maestros. Los programas para alcanzar a las familias deben ser universales, de manera que no se señale

\section{Recuadro 4.4 Japón: El maestro en el hogar}

Los maestros y las maestras son un factor crucial en el éxito del sistema educativo japonés. Cuando comenzó la Restauración Meiji, y el Estado modernizó su sistema educativo, la mayoría de los maestros pertenecían a las clases altas; algunos eran incluso Samurai. En la tradición de Confucio, el hecho de ser maestro confería a la persona un alto honor. Los maestros en Japón están, por ley, entre los mejor pagados de los servidores públicos; sin embargo, trabajan muchas horas, debido a que, adicionalmente al tiempo que dedican a preparar clases y enseñar, deben visitar las casas de sus estudiantes regularmente, y establecer un contacto permanente con las familias de sus estudiantes.

En el sistema educativo japonés, los "maestros del hogar" siguen el progreso de sus estudiantes a lo largo de los diferentes grados, y se involucran en la vida de éstos incluso afuera de la escuela. Los docentes en Japón son responsables, de la misma manera que un papá o una mamá, en una forma única: por ejemplo, si un estudiante viola la ley, las autoridades que mantienen el orden llaman al "maestro del hogar" del estudiante, y todos los miembros de la comunidad académica se disculpan por la conducta de éste. 
el mal desempeño de los estudiantes o el mal ambiente familiar, que, a su vez, pueden estigmatizar tanto a estudiantes como a familias. Aquellas familias que requieran una ayuda adicional, guía o consejo en determinados temas, pueden ser atendidas con actividades personalizadas de seguimiento.

Una vez que las maestras y los maestros han desarrollado una relación con las familias de sus estudiantes, pueden pensar en proyectos y actividades que requieran de la participación directa de los padres. Al hacerlo así, estarán ayudando no sólo a sus estudiantes directamente, sino también, indirectamente, a las mamás o a los papás de sus estudiantes.

Muchos padres tienen realmente muy poco conocimiento directo de lo que ocurre en la escuela cada día. En la mayoría de los países, los papás y las mamás raramente entran al edificio escolar a observar la rutina normal de la escuela -si es que alguna vez lo hacen. Pero las escuelas pueden cambiar eso: pueden organizar, por ejemplo, visitas de grupos pequeños, para no interrumpir las clases. Cabe señalar que en pocos países se abren de manera regular los salones de clase a los padres.

Así como los papás y las mamás saben muy poco acerca de las actividades diarias de sus hijas e hijos en la escuela, los adolescentes suelen saber muy poco acerca de lo que sus propios padres hacen cada día. Las escuelas pueden ayudar en esto también, al abrir sus puertas para invitar a los padres a que acudan a compartir relatos sobre sus vidas y sus experiencias de trabajo, así como para introducir a los estudiantes al ambiente de ciertas profesiones, oficios y trabajos, mediante la reflexión sobre sus mayores problemas, y también sobre las principales recompensas o satisfacciones que han obtenido en sus labores. Este tipo de pláticas son una oportunidad de aprendizaje muy valiosa para los estudiantes mayores, quienes pronto deberán tomar decisiones sobre su próximo desarrollo profesional para ingresar al mercado laboral, y sobre el campo productivo en el que desean insertarse. En una misma región, varias escuelas con estudiantes de diversos antecedentes socioeconómicos podrían conformar un grupo más amplio de padres para dar estas pláticas, con el fin de reunir la mayor cantidad posible de profesiones y ocupaciones que habrán de ser presentadas.

\section{Recuadro 4.5 Nueva Zelanda: Trabajando con la familia extendida de los Māori}

En el sistema educativo de Nueva Zelanda, aproximadamente uno de cada cinco estudiantes es identificado como Mãori, la población indígena del país. Los padres, las familias y Whānau ("la familia extendida" en Māori) se establecieron como equipo: "PFW", para trabajar con whānau, lo cual incluye a papás, mamás, tías y tíos, abuelas y abuelos, en comunidades seleccionadas para ayudarles a comprometerse con la educación de sus hijas e hijos. Al trabajar con otras organizaciones gubernamentales y no-gubernamentales, el equipo PFW provee de información a los whānau sobre: los beneficios de la educación en la niñez temprana; los papeles y las responsabilidades de whānau y los maestros con respecto a los Estándares Nacionales (los resultados esperados en lectura, escritura y matemáticas después de ocho años de educación obligatoria); cómo apoyar en casa el desarrollo de las capacidades lectoras y de razonamiento matemático; lo que se requiere para obtener el Certificado Nacional de Logro Académico -la principal acreditación de la escuela secundaria-; y las oportunidades disponibles a través de Promesa Joven, una iniciativa para incrementar el logro académico de jóvenes de 16 y 17 años, que busca hacer que el sistema educativo responda mejor a las necesidades de éstos.

El Ministerio de Educación también promueve el programa Leyendo Juntos entre los whānau. A través de este programa, los whānau aprenden estrategias de lectura que los maestros utilizan para enseñar a las niñas y a los niños a leer, y se les presentan los recursos de alfabetización disponibles en su comunidad. Así, cuando las familias extendidas mejoran su comprensión sobre cómo aprenden a leer los infantes, obtienen mejores condiciones para trabajar en los procesos de aprendizaje, ya que se convierten en socios tanto de sus hijos e hijas, como de los maestros y las escuelas. 
Las escuelas también pueden abrirse a compañías locales, para que los estudiantes puedan unirse a sus propios padres en iniciativas tales como "Lleva a tu hijo al trabajo". ${ }^{2}$ Estas iniciativas han sido desarrolladas en muchos países, pero las escuelas rara vez se involucran en ellas. Si bien el hecho de realizar estas actividades en estrecha coordinación entre las escuelas y las compañías locales volvería más compleja dicha iniciativa, este tipo de vinculaciones ofrece a los estudiantes una gran oportunidad para conocer los ambientes de las compañías locales, para desarrollar expectativas y aspiraciones bien informadas para su futuro, y para aprender más acerca de sus padres y sus madres -además, hablar acerca del trabajo de sus padres fomenta que conversen con ellos sobre diversos asuntos, relacionados o no con el trabajo. Este tipo de programas puede integrarse a algunos esquemas de equilibrio en los negocios, capaces de establecer un balance entre vida y trabajo; al mismo tiempo, proporcionan a los líderes de la industria o el comercio la oportunidad de conocer nuevos trabajadores potenciales.

\section{¿QUÉ PUEDEN HACER LOS SISTEMAS EDUCATIVOS?}

En la mayoría de los casos, las iniciativas para motivar a la familia a participar en la escuela dependen de la buena voluntad de algunos profesores, o del liderazgo y la visión de los directores escolares. ${ }^{3}$ Trabajar directamente con los padres y las madres como socios no es una propuesta que se emprenda normalmente en la capacitación profesional, o en el desarrollo de los maestros y las maestras. Como consecuencia de ello, la mayoría de los docentes no sienten que parte de su labor consista en propiciar la participación familiar, o bien consideran que tienen un entrenamiento insuficiente para hacerlo. ${ }^{4}$

\section{Recuadro 4.6 Corea: Apoyo Escolar para la Participación Parental}

Corea ha implementado un sistema comprensivo que incluye la educación parental, así como la de los niños y las niñas. Los padres y madres son invitados a visitar las escuelas, para que vean cómo se concretan las políticas educativas, y para que emitan comentarios sobre su implementación. En el 2011 el Ministerio de Educación, Ciencia y Tecnología (MEST, por sus siglas en inglés) seleccionó a 500 monitores presenciales y 3,200 monitores en línea -alrededor de 30 personas por cada una de las 16 oficinas de educación provinciales y municipales-, a través de un proceso público de reclutamiento. El papel de éstos consiste en monitorear la implementación de las políticas educativas gubernamentales, y reportar sus resultados al MEST. Asimismo, los monitores notifican en caso de que el MEST proponga alguna acción de seguimiento, como resultado de sus reportes. Las oficinas provinciales y municipales de educación, así como las escuelas, llevan a cabo programas para padres sobre políticas educativas. El Ministro y el Viceministro del MEST participan en estas "Presentaciones de políticas educativas para padres", las cuales se han realizado en más de 20 localidades desde noviembre del 2011. Adicionalmente, los centros de apoyo parental y las instituciones educativas en cada región ofrecen varios programas de ayuda dirigidos a los padres, para que éstos mejoren sus habilidades parentales en áreas tales como la comunicación y la orientación vocacional.

El Centro Nacional para el Apoyo Parental (NPSC, por sus siglas en inglés), bajo el auspicio del Instituto Nacional de Educación durante Toda la Vida, fue establecido en Octubre del 2010 para proveer de información sobre educación, diseminar mejores prácticas de participación de los padres en las escuelas, establecer una red municipal y provincial de centros de apoyo parental, y ofrecer servicios de terapia psicológica de corto plazo para madres y padres.

www.parents.go.kr 
Los sistemas educativos pueden ayudar a los maestros y a otros profesionales de la educación a desarrollar programas que involucren a las familias, por medio de las siguientes acciones:

>Identificar las metas y los resultados esperados que los maestros, los administradores y otros profesionales educativos proyectan respecto a la participación y al compromiso de las familias;

> Proveer de una capacitación -tanto la inicial como la necesaria para impulsar el desarrolloque permita construir fuertes asociaciones con las familias;

>Evaluar los recursos que se necesitan para alcanzar los objetivos sobre la participación familiar, y destinar recursos adecuados para alcanzar dichos objetivos;

> Desarrollar asociaciones, o dar autonomía a las escuelas para que se asocien con organizaciones no gubernamentales, grupos de la sociedad civil y organizaciones sin fines de lucro, para incrementar la capacidad y diversidad del personal disponible; $y$

>Evaluar a los maestros y a las escuelas con base en sus habilidades, y en las competencias de su trabajo con las familias.

\section{Notas}

1. La fundación Flamboyan, en los Estados Unidos, desarrolló una rúbrica dirigida a los maestros y maestras. http://flamboyanfoundation.org/wp/wp-content/uploads/2011/06/Classroom-Family-EngagementRubric-7-29-2011.pdf.

2. Muchas compañías tienen la iniciativa de "Lleva a tu hijo al trabajo". La organización Familias Trabajando, en el Reino Unido, es una de muchas organizaciones sin fines de lucro que ha desarrollado un conjunto de consejos y guías para que los empleadores, los empleados y sus hijos puedan aprovechar al máximo iniciativas como esa. Disponible en www.workingfamilies.org.uk/articles/employers/national-work-lifeweek/take-your-child-to-work-day.

3. Graue, E. and C.P. Brown (2003), "Preservice teachers' notions of families and schooling", Teaching and Teacher Education, Vol. 19, pp. 719-735. Denessen, E., et al. (2009), "Teacher-parent partnerships: Preservice teacher competences and attitudes during teacher training in the Netherlands", International Journal about Parents in Education, Vol. 3(1), pp. 29-36.

4. De acuerdo al sondeo MetLife 2005 sobre los Docentes de Estados Unidos, los maestros consideran que el mayor reto que tienen es que las familias se comprometan en la educación de sus hijos. Markow, D. and S. Martin (2005), The MetLife Survey of the American Teacher, 2004-2005: Transitions and the Role of Supportive Relationships, MetLife, Inc., New York. Available at www.eric.ed.gov/PDFS/ED488 837.pdf. 



\section{Muestra a tus hijos \\ que tú también valoras la lectura}

Los niños -y aún los niños más grandes, aunque no quieran admitirlo- miran a sus padres como modelos a seguir. Este capítulo explora cómo los niños cuyos padres tienen actitudes más positivas hacia la lectura son, ellos mismos, mejores en lectura, y por qué disfrutan más de ésta.

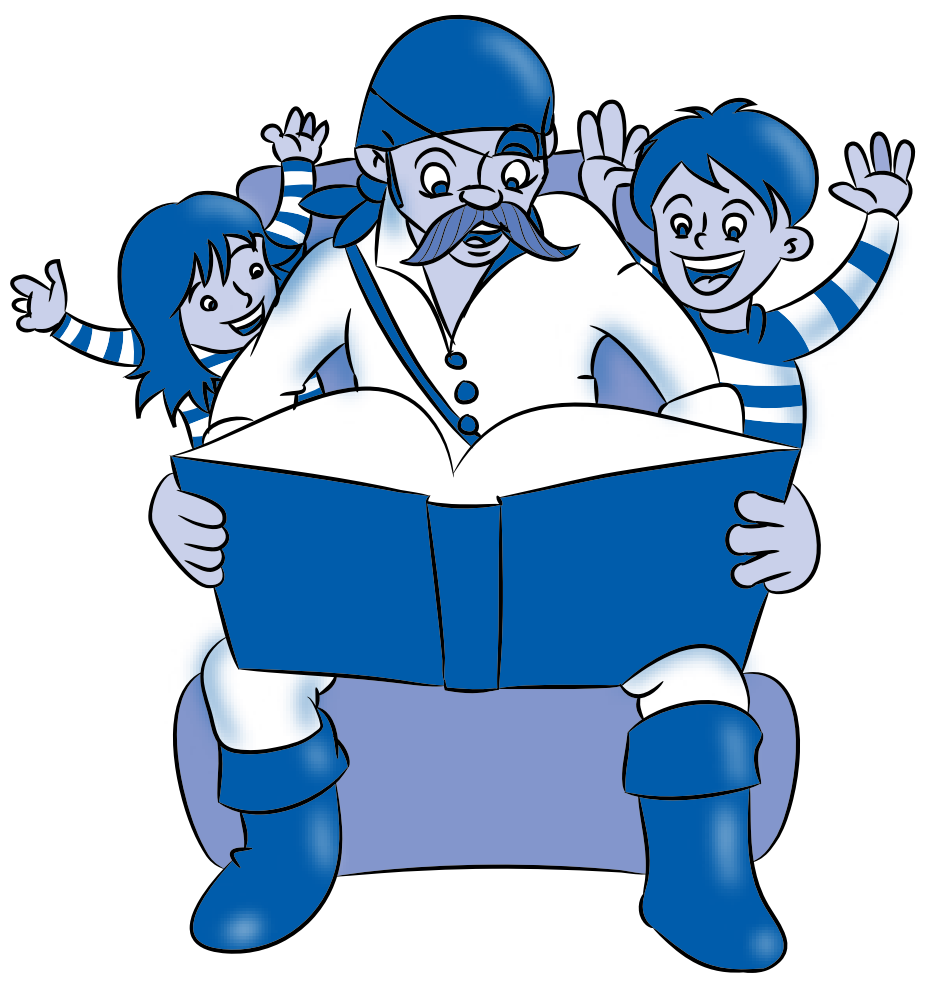


Cuando las hijas y los hijos crecen, la influencia de los padres y las madres disminuye, en tanto que aumenta la de sus compañeros, y la de otras personas fuera de la familia. Pero eso no significa que los adolescentes ya no necesiten -y en lugar de ello requieran, aún cuando lo nieguen- el interés genuino de sus padres en sus vidas. Aunque observen quizá, como adolescentes, a sus padres de modo más crítico que cuando eran más pequeños, aún asimilan sus actitudes y se dan cuenta de sus acciones. Por eso los padres, adicionalmente a su participación activa en la vida académica de sus hijos, también pueden involucrarse de manera implícita, al actuar como modelos a seguir, a partir de acciones tales como ayudarles a tomar decisiones sobre su educación, monitorear el progreso en su trabajo escolar, y comprometerse con su desarrollo intelectual.

La imitación no consiste sólo en una forma de adulación; es también una de las principales herramientas que las niñas y los niños usan para transitar en su camino hacia la vida adulta. Los hábitos y actitudes que muestran papá y mamá respecto a las actividades intelectualmente interesantes, respecto a los libros y a los logros académicos, moldean las actitudes de los hijos hacia la lectura, la escuela y el aprendizaje, y pueden relacionarse también, en última instancia, con su desempeño escolar.

\section{- Gráfica 5.1 .}

\section{Muestra un buen ejemplo a tus hijos, lee tú mismo}

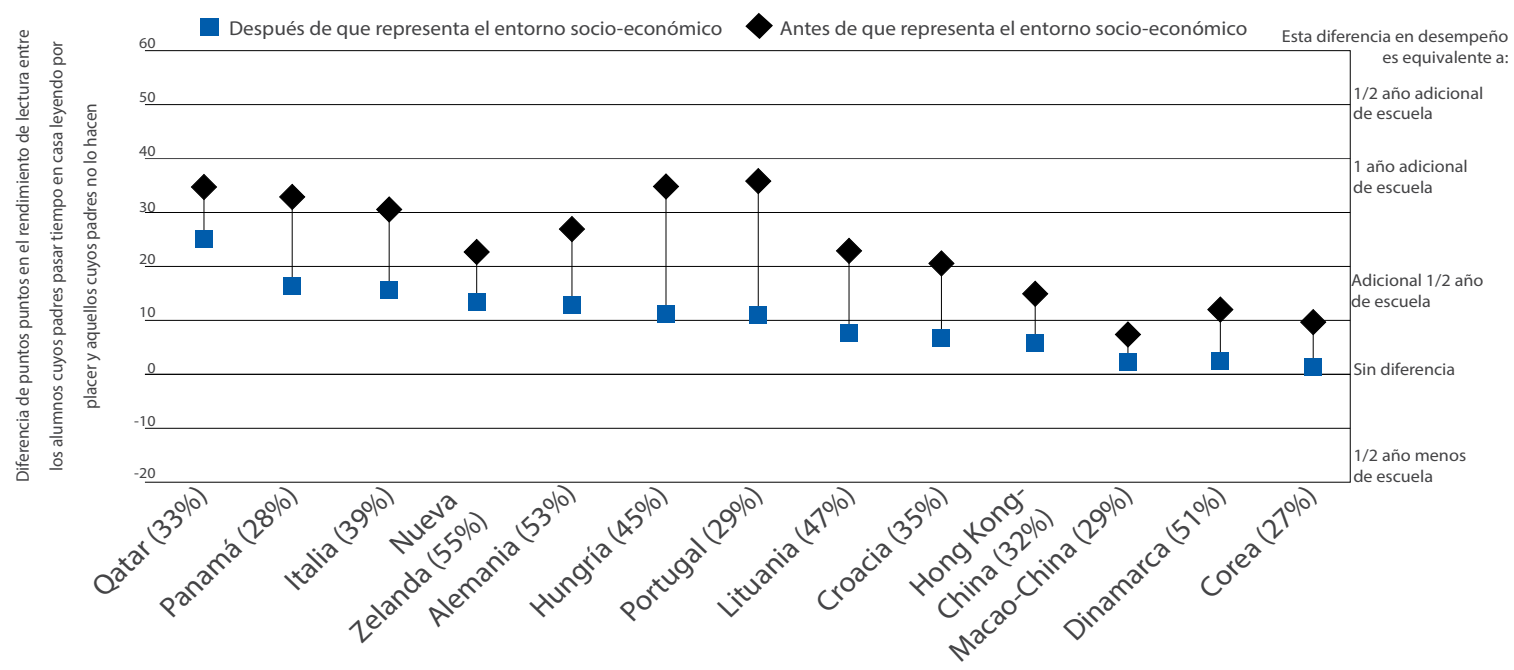

Nota: El porcentaje de padres o madres que pasan parte de su tiempo leyendo por placer se muestra entre paréntesis después del nombre del país/economía. Países/economías están ordenadas de manera descendente por la diferencia en desempeño lector, después de considerar los antecedentes socioeconómicos.

Fuente: Cuadro A5.1.

http://dx.doi.org/10.1787/8889326066445 
Para averiguar si existe alguna relación entre las actitudes de los padres hacia la lectura y el desempeño lector de sus hijos, PISA preguntó a papás y mamás si consideraban a la lectura como una afición, o como una pérdida de tiempo; si dedicaban tiempo a leer en casa por placer; $y$ si disfrutaban al visitar la biblioteca o la librería.

Las hijas e hijos de padres más proclives a leer, y que tienen actitudes positivas hacia la lectura, son mejores leyendo que las hijas e hijos de padres que no comparten estas mismas actitudes positivas. En todos los países y economías evaluados, los hijos cuyos padres piensan que leer no es una pérdida de tiempo, o que pasan más tiempo en sus casas leyendo por placer, tienen calificaciones más altas en lectura. Por ejemplo en Hungría, Italia, Nueva Zelanda, Panamá, Portugal y Qatar, los infantes cuyos padres piensan que leer es una pérdida de tiempo obtuvieron alrededor de 50 puntos -o sea, más de un año de escolaridad- menos en lectura, que aquellos niños cuyos padres piensan que leer no es una pérdida de tiempo. De manera similar, en estos países, los infantes cuyos padres invierten su tiempo leyendo por placer en casa, alcanzan un puntaje de más de 30 puntos -el equivalente de casi un año escolar-por arriba de los niños cuyos padres no leen en el hogar.

Se ha mostrado que los padres que tienen ventajas socioeconómicas presentan más probabilidades que otros padres de mantener este tipo de actitudes positivas hacia los libros y la lectura. Sin embargo, cuando se consideran familias con antecedentes socioeconómicos similares, se sigue encontrando la misma y decisiva correlación entre las actitudes y los hábitos lectores de papás y mamás, y el desempeño de los estudiantes. Esto significa que la relación entre los padres lectores y los hijos con un mejor desempeño escolar no depende de los antecedentes socioeconómicos de la familia.

\section{Recuadro 5.1 Estados Unidos: Cultura Asombrosa (Cool Culture)}

Cultura Asombrosa (en inglés Cool Culture) es una organización sin fines de lucro en Nueva York, que ofrece a las familias de escasos recursos acceso gratuito a instituciones culturales. La iniciativa, inaugurada en 1999, parte de la idea de que asistir a actividades culturales ayuda a desarrollar las capacidades lingüísticas de las niñas y los niños, debido a que éstos expresan sus observaciones y opiniones acerca de la experiencia adquirida en museos, jardines y zoológicos.

Las familias que cuentan con un hijo registrado como miembro en un programa de primera infancia, reciben de manera personalizada un "Pase Familiar de Cultura Asombrosa" que otorga el acceso gratuito, para hasta cinco miembros, a 91 instituciones culturales en la ciudad. Cultura Asombrosa también desarrolla "Cartas para la Cacería Cultural", disponibles en diferentes idiomas, que motivan a las familias a encontrar objetos, en particular en las instituciones culturales que ellos visitan -y a conversar sobre los objetos y sobre las instituciones, antes y después de las visitas.

Cultura Asombrosa está financiada, en dos terceras partes, por donaciones privadas, y en una tercera parte por instituciones públicas. Todos los centros que brindan atención a la primera infancia, que están financiados con fondos públicos en la Ciudad de Nueva York, y que sirven a familias de bajos recursos, están invitados a enlistarse en el programa. La organización trabaja ahora con más de 400 centros de iniciación infantil, guarderías, y programas de jardín de niños universales en la ciudad. En 2010 y 2011, unos 180,000 niños y adultos visitaron instituciones culturales usando el Pase Familiar de Cultura Asombrosa. 
No es de sorprender entonces que, en todos los países y economías analizados, los niños cuyos padres consideran que leer es un buen pasatiempo, que disfrutan al ir a la biblioteca y a la librería, y que dedican algunos minutos del día a leer por placer en su casa, tienen más probabilidades de disfrutar ellos mismos de la lectura. Esto resulta verdadero aún cuando se compara a las niñas y a los niños con antecedentes socioeconómicos similares, lo que indica que los chicos tienen más probabilidades de disfrutar de la lectura cuando en sus hogares encuentran un ambiente que les conduce precisamente a ella. Esta relación se acentuó en particular en Hungría, Italia, Lituania y Qatar.

PISA encontró también una estrecha relación entre las actitudes positivas de los papás y las mamás hacia la lectura, y la conciencia de sus hijas e hijos acerca de qué estrategias son las más efectivas para resumir la información de lo que han leído. En buena medida, esta relación se vincula con los antecedentes socioeconómicos de los estudiantes. Por ejemplo, en 11 países y economías, cuando fueron comparados estudiantes con antecedentes socioeconómicos diferentes, se encontró que los infantes cuyos padres leen en casa por diversión, tienen un mejor conocimiento de las estrategias más efectivas que existen para sintetizar información. Pero cuando se comparan estudiantes con antecedentes socioeconómicos similares, esta relación solamente se mantiene en Hungría, Italia, Panamá y Qatar. Esto indica que los hábitos lectores de los padres están relacionados con el estatus socioeconómico -las mamás y los papás que tienen ventajas socioeconómicas tienen más probabilidades de leer en casa por diversión. Asimismo, se observa que en la mayoría de los países y las economías, cualquier relación entre los hábitos lectores

\section{- Gráfica 5.2 .}

\section{Los estudiantes en situaciones de desventaja carecen frecuentemente del modelo de un adulto que lea}

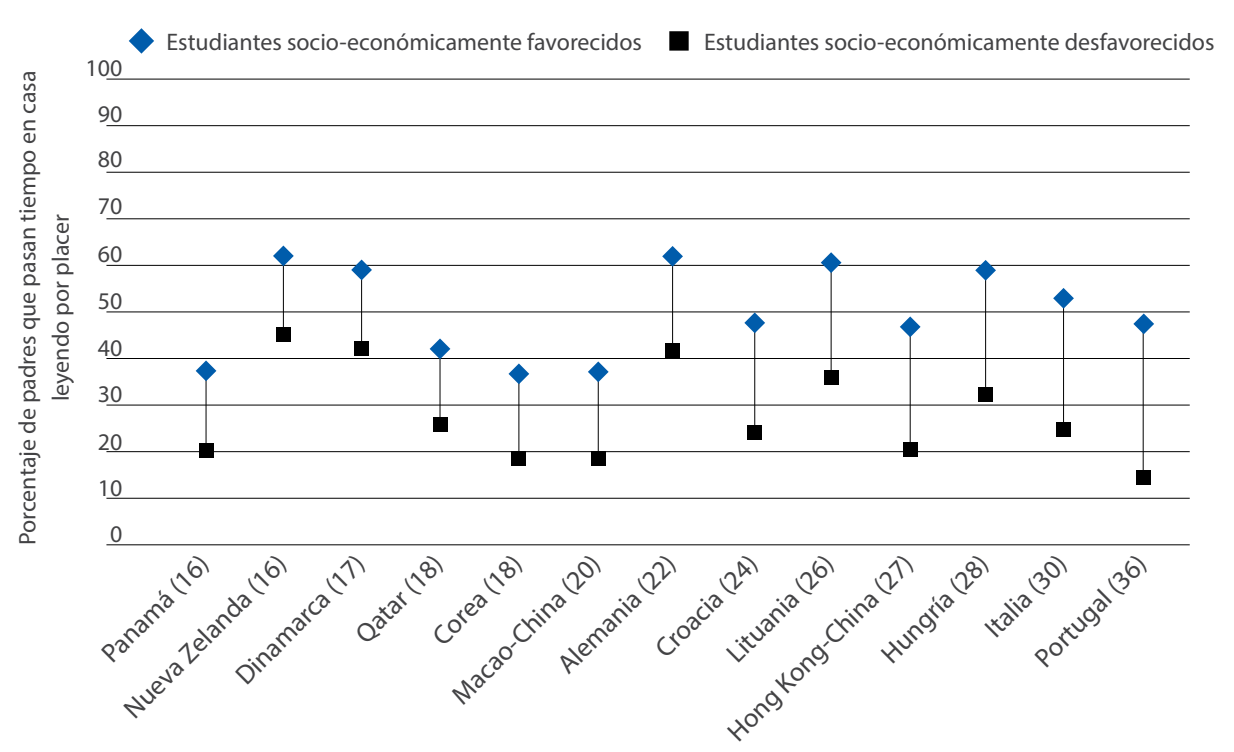

Nota: La diferencia entre el porcentaje de padres/madres que tienen ventaja socioeconómica y que dedican tiempo en su hogar para leer por placer, y el porcentaje de padres/madres que tienen desventaja socioeconómica, se muestra entre paréntesis después del nombre de cada país/economía.

Países/economías están ordenados de modo ascendente por la diferencia entre el porcentaje de padres/madres en ventaja socioeconómica que leen por placer en el hogar, y aquellos padres/madres en desventaja socioeconómica que lo hacen.

Fuente: Cuadro A5.1. http://dx.doi.org/10.1787/888932606663 
de los padres, y la conciencia de los estudiantes para utilizar estrategias efectivas de síntesis, reflejan, en buena medida, los antecedentes socioeconómicos familiares.

De los países y las economías en los cuales PISA midió la participación parental, únicamente en 4 de 10 se lee regularmente en casa, por placer. En todos los países y economías, los papás y mamás que leen en casa por placer tienen más probabilidades de tener ventajas socioeconómicas, y esto explica en parte las diferencias en el desempeño lector entre aquellos estudiantes que provienen de familias con ventajas socioeconómicas, y aquellos que provienen de familias con desventajas.

Las madres muestran, marginalmente, más probabilidades que los padres de tener actitudes positivas hacia la lectura. PISA encuentra que es más probable que las madres consideren a la lectura como su pasatiempo favorito, y que se sientan felices al recibir un libro como regalo, y también es más probable que manifiesten un gusto mayor por el hecho de ir a una biblioteca o a una librería. En algunos países y economías, estas diferencias se acentúan notablemente: en Alemania, alrededor de tres cuartas partes de las madres, y solamente la mitad de los padres, consideran a la lectura como su pasatiempo favorito, o disfrutan cuando acuden a una librería o a una biblioteca. Las diferencias son también muy grandes en Nueva Zelanda. Por otra parte, en la mayoría de los países y las economías, ni las madres ni los padres son ávidos lectores; solamente en Dinamarca, Alemania y Nueva Zelanda la mayoría de las madres leen por diversión, mientras que en la mayoría de los países, solamente la tercera parte de los papás y las mamás lo hacen.

\section{¿QUÉ PUEDEN HACER LAS MAMÁS Y LOS PAPÁS?}

Leer. Es así de sencillo. Si los padres -ambos: mamás y papás- no gustan de la lectura de novelas, por decir algo, sino que prefieren leer revistas y periódicos, está bien. Lo que importa es que muestren a sus hijas e hijos - de todas las edades- que leer es una actividad valiosa que puede disfrutarse cada día, y que el placer es aún mayor cuando la persona conversa con otros sobre lo que ha leído.

Aquellos padres y madres a quienes no les gusta leer, o bien que sienten que no tienen tiempo suficiente para leer por placer, pueden motivar de todos modos a sus hijos a la lectura. Por ejemplo, pueden ofrecerles libros como regalos, o bien, llevar a sus hijas e hijos pequeños a la biblioteca, o entablar conversaciones con ellos acerca de lo que están leyendo, ya sea por su propio gusto, o en la escuela.

\section{Recuadro 5.2 ¿Qué pueden hacer los negocios y los gobiernos?}

Motivar una mayor participación parental en la educación de las niñas y los niños será una acción más efectiva si la sociedad percibe que ese compromiso es una inversión valiosa, y si se flexibilizan algunas de las restricciones de tiempo que tienen los papás y las mamás. Los gobiernos pueden jugar un papel directo en esto, al diseñar e implementar políticas que ayuden a los padres a conciliar sus actividades laborales con sus responsabilidades como protectores de sus hijos e hijas. Las autoridades pueden jugar una función indirecta, al proveer de apoyo financiero, tanto por medio de becas o subsidios, como a través de incentivos en los impuestos, a organizaciones no gubernamentales o negocios locales, en las comunidades que promueven la participación parental. Los negocios también pueden ayudar a implementar estas políticas.

** Flexibilidad para ajustar las prácticas de trabajo, lo cual implica reducir las horas de trabajo (trabajo parcial); acuerdos de flexibilidad de tiempo (flexibilidad para definir el inicio y el final de las horas de trabajo, y "contabilidad de ahorro de tiempo" (en el que la duración del día de trabajo o de la semana pueden ser ajustados); y teletrabajo, o trabajo desde casa. ${ }^{2}$ 


\section{Recuadro 5.2 ¿Qué pueden hacer los negocios y los gobiernos? (Continúa...)}

** Permisos para ausentarse del lugar de trabajo, incluyendo vacaciones, licencias para madres y padres, y derecho a faltar por causas de salud, para que éstos puedan hacer frente a emergencias familiares imprevisibles.

* Apoyo para niños, y servicios de guardería fuera de las horas de escuela. De manera creciente, los países de la OCDE proveen de servicios formales de atención infantil fuera del horario escolar (FHE), así como durante las vacaciones escolares. Estas actividades se desarrollan frecuentemente, pero no siempre, dentro de las instalaciones escolares o en centros juveniles, e implican actividades recreativas y/o ayuda con las tareas. Las actividades de cuidado FHE han recibido considerable atención porque, además de ofrecer una solución en el cuidado de los hijos para los padres y las madres que trabajan, han sido asociadas con un buen desempeño escolar, incluyendo la asistencia regular a la escuela, un logro académico mayor, y menores tasas de abandono escolar. En la mayoría de los países, los programas de tipo FHE se encuentran aún en sus primeras etapas de desarrollo, y su cobertura es limitada. En Alemania, Italia, Corea, Polonia y España, por ejemplo, menos del $10 \%$ de las niñas y los niños de primaria participan en ese tipo de programas. En cambio, en Australia, Dinamarca, Hungría y Suecia, más del 50\% de los niños pequeños participan en ellos. Los servicios de FHE son más importantes para las niñas y los niños de 6 a 9 años; las tasas de matriculación de los adolescentes se reducen notablemente, debido a que estos estudiantes se vuelven más independientes, y prefieren pasar más tiempo con sus compañeros, o en actividades organizadas. ${ }^{3}$

No todos los padres ni las madres trabajan en lugares que ofrezcan convenios de trabajo que sean amigables con la familia; e incluso si éstos existen, las madres, y particularmente los padres, no suelen usarlos, porque piensan que si los utilizan, sus carreras y su potencial de ingreso podrían peligrar. Este tipo de convenios, por tanto, deben ofrecerse como parte de una cultura general del lugar de trabajo, que apoye a los padres en su necesidad de balancear mejor sus responsabilidades familiares y sus responsabilidades de trabajo.

Muchos gobiernos de la OCDE han implementado políticas para motivar a los padres a tomar licencias de trabajo, con el fin de que asuman en la medida de lo posible el cuidado de sus hijos pequeños. Muchos de esos programas incluyen una licencia con goce de sueldo que no es transferible, para el uso exclusivo de los padres. Hasta ahora, sin embargo, la aceptación ha sido baja. Aún así, los hombres que hacen uso de su derecho a gozar de una licencia de padres suelen tener más probabilidades de compartir el cuidado de los hijos y las responsabilidades del trabajo en casa con sus parejas, y es más probable que se comprometan más en otros tipos de actividades ya descritas en este reporte. ${ }^{4}$ 


\section{Notas}

1. OECD (2011), Doing Better for Families, OECD Publishing.

2. Un tipo de medida flexible que puede ser particularmente útil para los padres y las madres que trabajan es el teletrabajo, es decir el trabajo que puede ser realizado fuera y desde lejos del lugar de trabajo usual. Su uso, sin embargo, es limitado. Información disponible sobre el teletrabajo sugiere que un máximo de 15\% de personas empleadas en países de la OCDE utilizan esta forma flexible de trabajo de manera regular. (OECD Family Database - Indicator LMF2.4) www.oecd.org/social/family/database.

3. OECD (2011), Doing Better for Families, OECD Publishing.

4. Nepomnyaschy y Waldfogel (2007) muestran que en los Estados Unidos, los padres que se toman dos o más semanas fuera del trabajo después del nacimiento de un hijo o hija tienen muchas más probabilidades de participar en las actividades del cuidado infantil nueve meses después. Adicionalmente, Haas y Hwang (2008), muestran que la cantidad de licencias parentales tomada por los padres en Suecia se asocia de manera positiva con muchos aspectos del cuidado infantil. Más aún, mientras más licencias toman los padres, más satisfacción reportan en su relación padre-hijo. Los hombres tienen más probabilidades de establecer fuertes vínculos con sus hijos si dedican el debido tiempo para su cuidado desde una edad temprana.

(Nepomnyaschy, L. y J. Waldfogel [2007], "Paternity Leave and Fathers' Involvement with their Young Children", Community, Work and Family, Vol. 10, No. 4, pp. 427-453; Haas, L. y P.C. Hwang [2008], "The impact of taking parental leave on fathers' participation in childcare and relationships with children: Lessons from Sweden", Community, Work and Family, No. 11, pp. 85-104). 



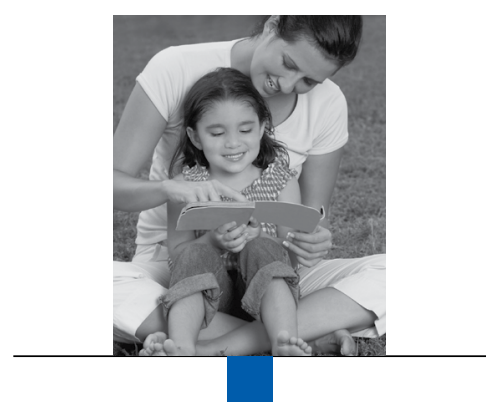

\section{Listas de control}

Estas Listas de Control recomiendan maneras específicas en que los padres y las madres pueden involucrarse más en la educación de sus hijas e hijos, y también acciones para que los maestros, los líderes educativos y los encargados de las políticas públicas puedan promover una mayor participación parental. 


\section{Madres y padres}

Para ambos, hombres y mujeres al cuidado de los niños:

$\square \quad$ Habla y lee a tu hijo desde una edad temprana

$\square$ Desarrolla canales de comunicación con los chicos para que se motiven a tomar una postura y a defenderla (por ejemplo, discute con ellos sobre asuntos políticos o sociales, o bien acerca de libros, películas y programas de televisión. También pueden tomar la cena juntos, para platicar)

Muestra interés en lo que sucede en la escuela, aún cuando tu hijo esté teniendo buenos resultados; participa en actividades escolares, y mantén una comunicación fluida con los maestros de tu hijo

Pregunta a los maestros qué puedes hacer para ayudar a tu hijo a aprender

Pon el ejemplo: lee en casa, muestra interés en actividades intelectualmente estimulantes 


\section{Escuelas y maestros}

$\square$ Desarrollen el hábito de la lectura en las niñas y los niño desde pequeños

Sondeen las diversas maneras en que los padres y las madres puedan y deseen involucrarse en la educación de sus hijos, y motívenlos a realizarlas

Inicien un diálogo frecuente y constante con todos los padres y las madres, para forjar un trabajo conjunto, y abran varios canales de comunicación; no esperen hasta que los chicos tengan problemas para llamar a sus papás

Diversifiquen las formas de participación, para ofrecer a los papás y a las mamás tiempo e interés

Provean a los maestros y a las maestras de la oportunidad de dedicarse a programas de desarrollo profesional, orientados específicamente a promover la participación de los padres y las madres

Organicen al personal de la escuela para que una persona sea el punto de contacto para cada papá o mamá a lo largo de la trayectoria escolar de su hijo o hija, para evitar tener que recrear nuevamente las relaciones cada año

Provean de apoyo personalizado a aquellos niños cuya mamá o papá se encuentren limitados en sus posibilidades reales de participación 


\section{Sistemas educativos}

Incluir la comunicación parental y la participación en los programas de capacitación para el desarrollo docente

Considerar el compromiso y el apoyo familiar como parte del proceso formal de evaluación

Permitir cierta flexibilidad en las agendas de los maestros y los directivos escolares, con el fin de que tengan el tiempo necesario para dialogar con los papás y las mamás

Apoyar a los papás y a las mamás que no puedan participar tanto como quisieran, ofreciéndoles servicios de guardería, horarios flexibles y transporte para asistir a las juntas o para participar en otras actividades en la escuela

Permitir a los papás y a las mamás participar en la dirección de la escuela

Garantizar que todos los niños y las niñas -especialmente aquellos que muestran desventajas- tengan acceso a libros que puedan leer y compartir con sus padres

Organizar eventos de lectura en espacios públicos, tales como bibliotecas, en los cuales puedan participar tanto los niños como sus padres

Desarrollar alianzas con diversas organizaciones, más allá de la escuela, para promover la lectura y la participación parental 


\section{Información en cuadros \\ sobre la participación de las mamás y los papás en la lectura}

Cuadro A2.1 Leer libros a niñas y a niños pequeños, y la relación con su desempeño lector

Cuadro A2.2 Contar cuentos a niñas y a niños pequeños, y su relación con su desempeño lector

Cuadro A2.3 Leer libros a niñas y a niños pequeños, la relación con el gozo de la lectura, y con la conciencia de estrategias efectivas de resumen

Cuadro A2.4 Contar cuentos a niñas y a niños pequeños, la relación con el gozo de la lectura, y con la conciencia de estrategias efectivas de resumen

Cuadro A3.1 Discutir sobre temas políticos o sociales con adolescentes de 15 años, y la relación con su desempeño lector

Cuadro A3.2 Discutir sobre libros, películas o programas de televisión con adolescentes de 15 años, y la relación con su desempeño lector

Cuadro A3.3 Ayudar a adolescentes de 15 años con sus tareas, y la relación con el desempeño lector

Cuadro A3.4 Discutir sobre asuntos sociales o políticos con adolescentes de 15 años, la relación con el gusto de leer, y con la conciencia de estrategias efectivas para resumir

Cuadro A3.5 Discutir sobre libros, películas o programas de televisión con adolescentes de 15 años, la relación con el gusto de leer, y con la conciencia de estrategias efectivas para resumir

Cuadro A3.6 Ayudar a adolescentes de 15 años con sus tareas, la relación con el goce de la lectura, y con la conciencia de estrategias efectivas para resumir

Cuadro A4.1 Discutir el progreso o la conducta de los niños con los maestros, y la relación con el desempeño lector

Cuadro A4.2 Las mamás y los papás que trabajan como voluntarias en la escuela y el desempeño lector de sus hijos

Cuadro A4.3 Discutir el progreso o la conducta de los niños con los maestros, la relación con el goce de la lectura, y con la conciencia de estrategias efectivas para resumir

Cuadro A4.4 Las mamás y los papás que participan como voluntarios en la escuela, la relación con el goce de la lectura, y con la conciencia de estrategias efectivas para resumir

Cuadro A5.1 Las mamás y los papás que leen por gusto, y la relación con el desempeño lector de sus hijos e hijas

Cuadro A5.2 Las mamás y los papás que leen por gusto, la relación con el goce de la lectura, y con la conciencia de estrategias efectivas para resumir 


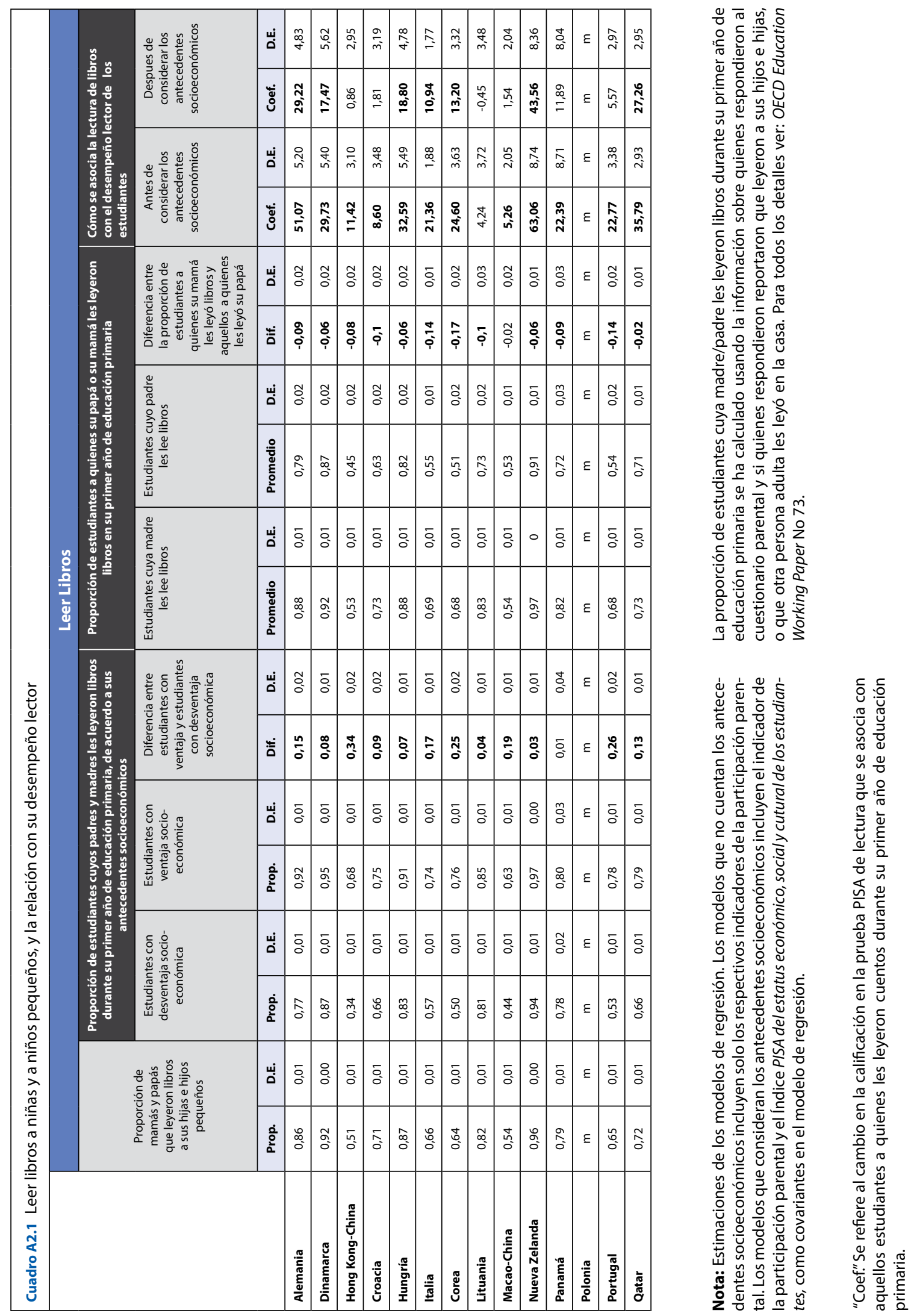




\begin{tabular}{|c|c|c|c|c|c|c|c|c|c|c|c|c|c|c|c|c|c|}
\hline & $\bar{\Phi}$ & 응 은 & щ山் & $\stackrel{\infty}{m}$ & 寜 & $\hat{i}$ & i & $\underset{\substack{\infty \\
\infty \\
m}}{m}$ & ă & $\bar{\rho}_{\dot{m}}$ & $\begin{array}{l}q \\
m \\
m\end{array}$ & $\mid \begin{array}{l}n \\
\substack{n \\
2}\end{array}$ & 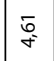 & $\cong$ & $\varepsilon$ & ${ }_{\substack{n \\
m}}^{n}$ & $\stackrel{\infty}{\sim}$ \\
\hline & 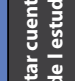 & 今. & sّ̊ & 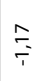 & $\frac{1}{ \pm}$ & $\begin{array}{l}n \\
\stackrel{n}{m} \\
\dot{m}\end{array}$ & $\stackrel{m}{i}$ & $\begin{array}{l}7 \\
0 \\
0\end{array}$ & $\begin{array}{l}\text { th } \\
\stackrel{0}{6}\end{array}$ & $\underset{\substack{\infty \\
m \\
m}}{m}$ & $\frac{O}{i}$ & 号 & $\stackrel{M}{=}$ & 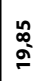 & $\varepsilon$ & $\bar{m}$ & $\stackrel{\infty}{\frac{\infty}{\pi}}$ \\
\hline & 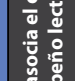 & 离 & щ山் & $\bar{\varnothing}$ & $\stackrel{\circ}{\circ}$ & \begin{tabular}{|l}
$\underset{m}{N}$ \\
$\stackrel{n}{*}$
\end{tabular} & $\underset{m}{\tilde{m}}$ & $\begin{array}{l}\infty \\
0 \\
i n\end{array}$ & $\stackrel{\circ}{i}$ & $\frac{\infty}{m}$ & $\underset{m}{\tilde{m}}$ & $\underset{\tilde{v}}{\tilde{v}}$ & $\stackrel{n}{\sim}$ & 总 & $\varepsilon$ & $\begin{array}{c}\hat{m} \\
m \\
m\end{array}$ & $\stackrel{\infty}{i}$ \\
\hline & 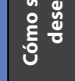 & 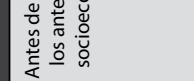 & $\dot{\Xi}$ & $\stackrel{\Re}{\sim}$ & $\stackrel{\Xi}{=}$ & 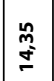 & $\stackrel{\underset{\infty}{\infty}}{=}$ & 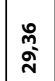 & సू. & $\stackrel{\infty}{\stackrel{\infty}{N}}$ & $\frac{0}{6}$ & $\bar{m}$ & $\stackrel{\text { กี }}{\tilde{n}}$ & 惫 & $\varepsilon$ & 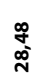 & 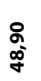 \\
\hline & $\underline{\underline{y}} \underline{0}$ & نَ & 㟧 & $:$ & $\begin{array}{l}\tilde{O} \\
0\end{array}$ & $\tilde{O}$ & $: 0$ & 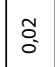 & : & $\tilde{o}_{0}$ & $\therefore$ & $\tilde{O}$ & 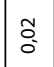 & 咅 & $\varepsilon$ & o. & Б。 \\
\hline & 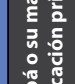 & 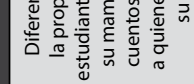 & :் & o̊ & 号 & ồ & $\hat{o}$ & $\begin{array}{l}0 \\
0 \\
i\end{array}$ & ồ & $\bar{i}$ & D. & : & $\mid \begin{array}{l}0 \\
0 \\
i\end{array}$ & $\bar{i}$ & $\varepsilon$ & $\bar{i}$ & : \\
\hline & 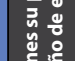 & & 쎰 & $\stackrel{0}{8}$ & $\begin{array}{l}0 \\
0 \\
0\end{array}$ & $\begin{array}{l}0 \\
0 \\
0\end{array}$ & O: & $\begin{array}{l}0 \\
0 \\
0\end{array}$ & $\bar{o}_{0}$ & : & 芯 & $\begin{array}{l}\overline{0} \\
0 \\
0\end{array}$ & : & 雚 & $\varepsilon$ & $\tilde{o}_{0}^{2}$ & $\bar{\delta}_{0}^{\circ}$ \\
\hline & 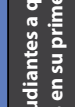 & 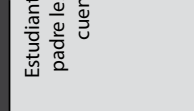 & 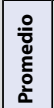 & $\stackrel{m}{o}$ & 苔 & 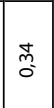 & E. & $\stackrel{\substack{\infty \\
\infty}}{\circ}$ & $\stackrel{\infty}{\circ}$ & $\begin{array}{l}\infty \\
h_{0}^{2}\end{array}$ & $\hat{o}$ & $\begin{array}{l}m \\
m \\
0 \\
0\end{array}$ & $\hat{O}$ & 号 & $\varepsilon$ & : & $\stackrel{\circ}{\circ}$ \\
\hline & 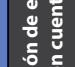 & & 㟧 & : & 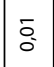 & $\bar{o}$ & io & $\bar{o}$ & $\circ$ & $\bar{\delta}_{0}$ & $\bar{o}$ & $\bar{\delta}$ & io & : & $\varepsilon$ & $\bar{o}_{0}$ & $\bar{\sigma}_{0}$ \\
\hline ᄒ & 을 & 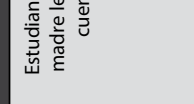 & 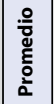 & $\stackrel{2}{\circ}$ & 合 & F & $\hat{a}$ & $\begin{array}{c}\infty \\
\substack{\infty \\
0}\end{array}$ & $\hat{n}$ & : & $\begin{array}{l}N \\
0 \\
0\end{array}$ & F́ & $\begin{array}{c}\substack{\infty \\
\vdots \\
0} \\
0\end{array}$ & $\ddot{O}_{0}^{\circ}$ & $\varepsilon$ & No & $\hat{o}$ \\
\hline 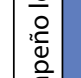 & ह & 苋 & щேํ & 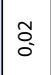 & : & $\therefore$ & $: 0$ & $\therefore$ & : & : & $: 0$ & s. & : & 莣 & $\varepsilon$ & $\delta_{0}^{2}$ & ¿. \\
\hline$\frac{\tilde{d}}{0}$ & 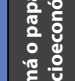 & 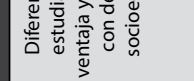 & $\ddot{\bar{\Delta}}$ & $\hat{0}$ & $\begin{array}{l}0 \\
0 \\
0\end{array}$ & $\begin{array}{l}\infty \\
\substack{0 \\
0}\end{array}$ & $\bar{E}$ & $\frac{N}{0}$ & $\frac{\pi}{0}$ & $\frac{\infty}{0}$ & $\frac{N}{0}$ & $\begin{array}{l}\hat{0} \\
0\end{array}$ & $\begin{array}{l}\infty \\
0 \\
0\end{array}$ & $\frac{m}{0}$ & $\varepsilon$ & : & $\stackrel{\text { Na }}{0}$ \\
\hline : & 䓀 & ฮ & щ̈ㅁ & $\bar{o}$ & $\overline{0}$ & O̊ & $\bar{o}_{0}^{\circ}$ & $\overline{0}$ & : & io & 立 & $\overline{0}$ & $\bar{o}_{0}$ & 囱 & $\varepsilon$ & $\bar{o}_{0}$ & $\bar{o}_{0}$ \\
\hline $\bar{n}$ & 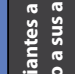 & 总 & $\frac{0}{2}$ & $\begin{array}{l}\infty \\
\stackrel{\infty}{0} \\
0\end{array}$ & $\mid \begin{array}{l}\text { 芯 } \\
0\end{array}$ & 畄 & $\underset{\substack{\infty \\
0 \\
0}}{0}$ & 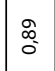 & $\underset{\infty}{\infty}$ & $\begin{array}{l}\text { I } \\
0\end{array}$ & \begin{tabular}{|l}
$\infty$ \\
0 \\
0
\end{tabular} & 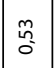 & 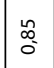 & $\begin{array}{l}0 \\
0 \\
0\end{array}$ & $\varepsilon$ & 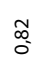 & $\stackrel{0}{\circ}$ \\
\hline$\frac{\sigma}{\sigma}$ & 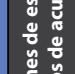 & 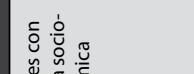 & 㟧 & : & 治 & io & $\bar{\delta}_{0}$ & $\overline{0}$ & so & $\delta_{0}$ & 立 & E. & : & : & $\varepsilon$ & $\delta_{0}^{\circ}$ & $\bar{o}_{0}$ \\
\hline : & 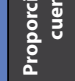 & 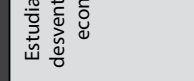 & $\stackrel{8}{\frac{\delta}{2}}$ & $\begin{array}{l}\overline{1} \\
\hat{0}\end{array}$ & 氐 & $\tilde{\Xi}$ & 令 & 令 & : & ho & : & $\begin{array}{l}\hat{N} \\
0\end{array}$ & $\begin{array}{l}\hat{0} \\
0\end{array}$ & ha & $\varepsilon$ & 崖 & nू. \\
\hline ") & & 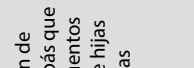 & 亗 & $\bar{o}_{0}$ & $\overline{0}$ & $\overline{0}$ & $\bar{o}_{0}$ & $\bar{\vdots}$ & $:$ & $\bar{\delta}_{0}$ & $\bar{o}$ & $\bar{\delta}$ & $\overline{0}$ & $\tilde{\sigma}_{0}$ & $\varepsilon$ & $\bar{o}_{0}$ & ס. \\
\hline 总 & & 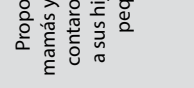 & $\frac{\dot{0}}{2}$ & 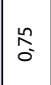 & 㣽 & 是 & $\begin{array}{c}\infty \\
0 \\
0 \\
0\end{array}$ & 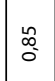 & $\stackrel{\Delta}{\Delta}$ & $\stackrel{\circ}{\circ}$ & $\begin{array}{l}\text { Na } \\
0\end{array}$ & 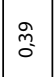 & 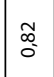 & $\ddot{0}_{0}^{0}$ & $\varepsilon$ & $\begin{array}{l}0 \\
0 \\
0\end{array}$ & 㕝 \\
\hline 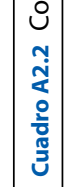 & & & & & 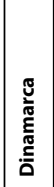 & 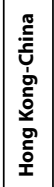 & \begin{tabular}{|l}
$\stackrel{0}{5}$ \\
g్ \\
$\stackrel{5}{5}$
\end{tabular} & 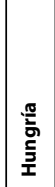 & 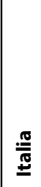 & 气ूँ & 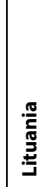 & 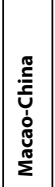 & 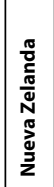 & 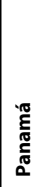 & 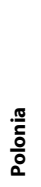 & 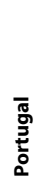 & 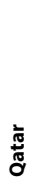 \\
\hline
\end{tabular}

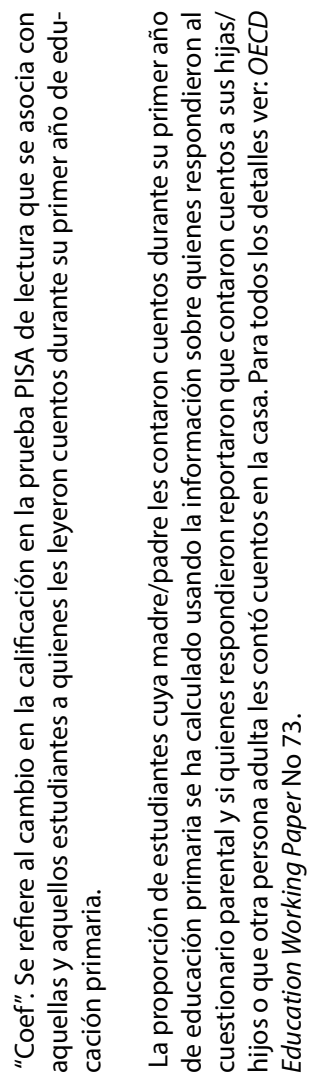

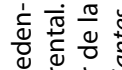

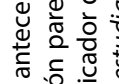

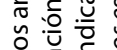

동

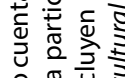

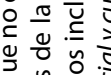

뭉. 원

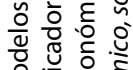

을

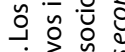

:웝

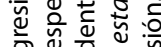

बie

응 응 뚱

는응 든 $\frac{2}{0}$

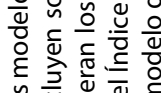

은 흔

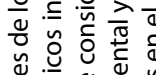

产.

ชั

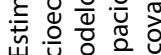

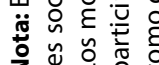




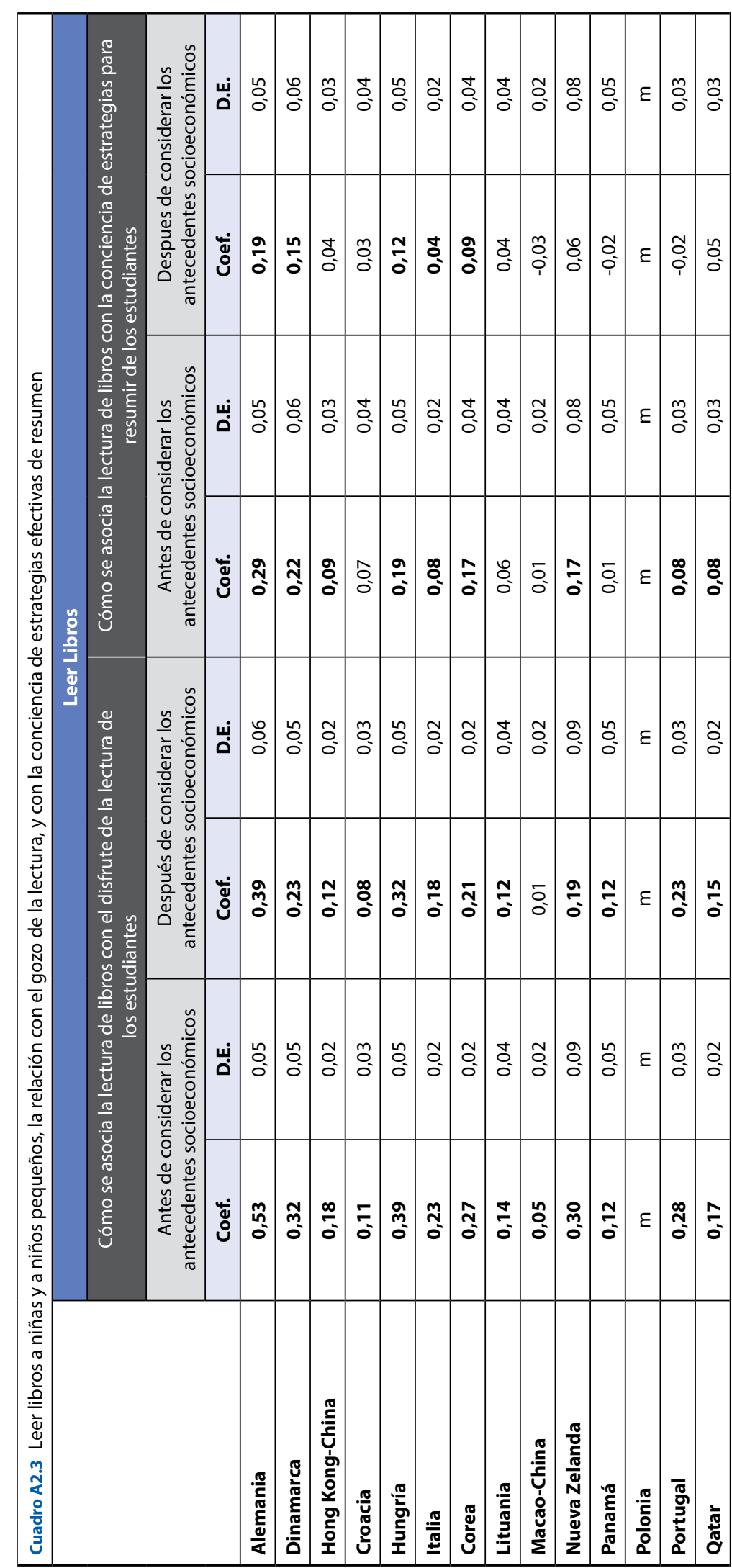

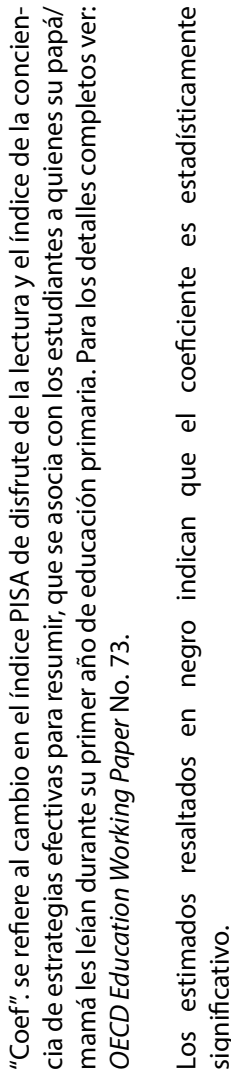

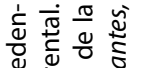

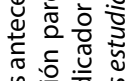

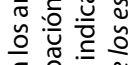

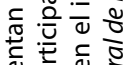

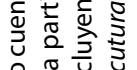

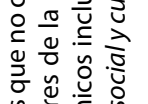

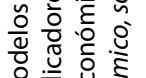

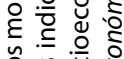

งิ

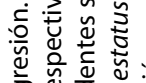

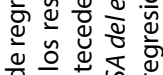

응 응 空

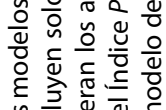

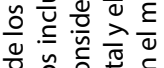

응

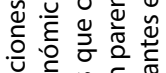

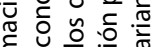

政

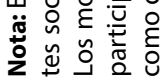




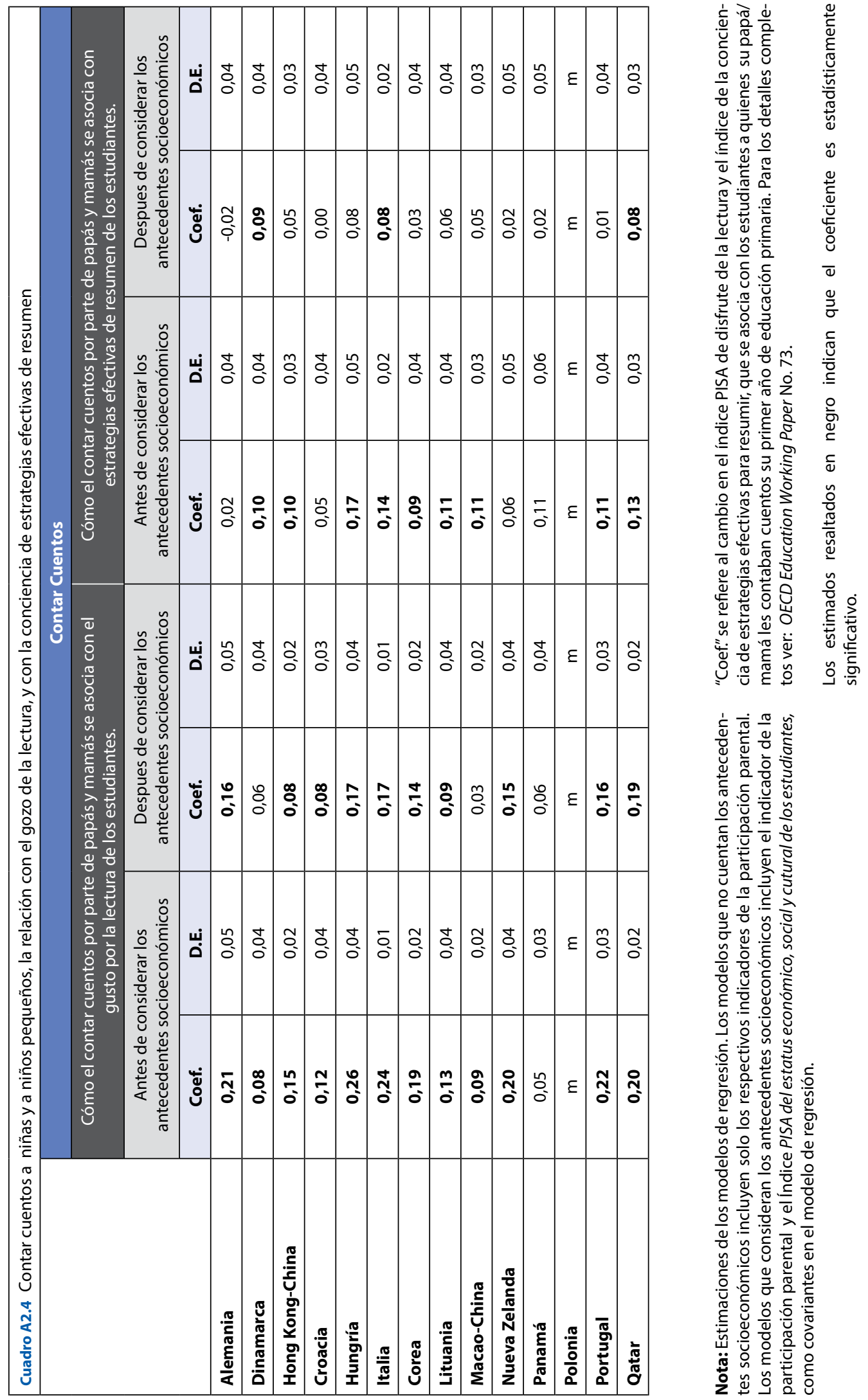




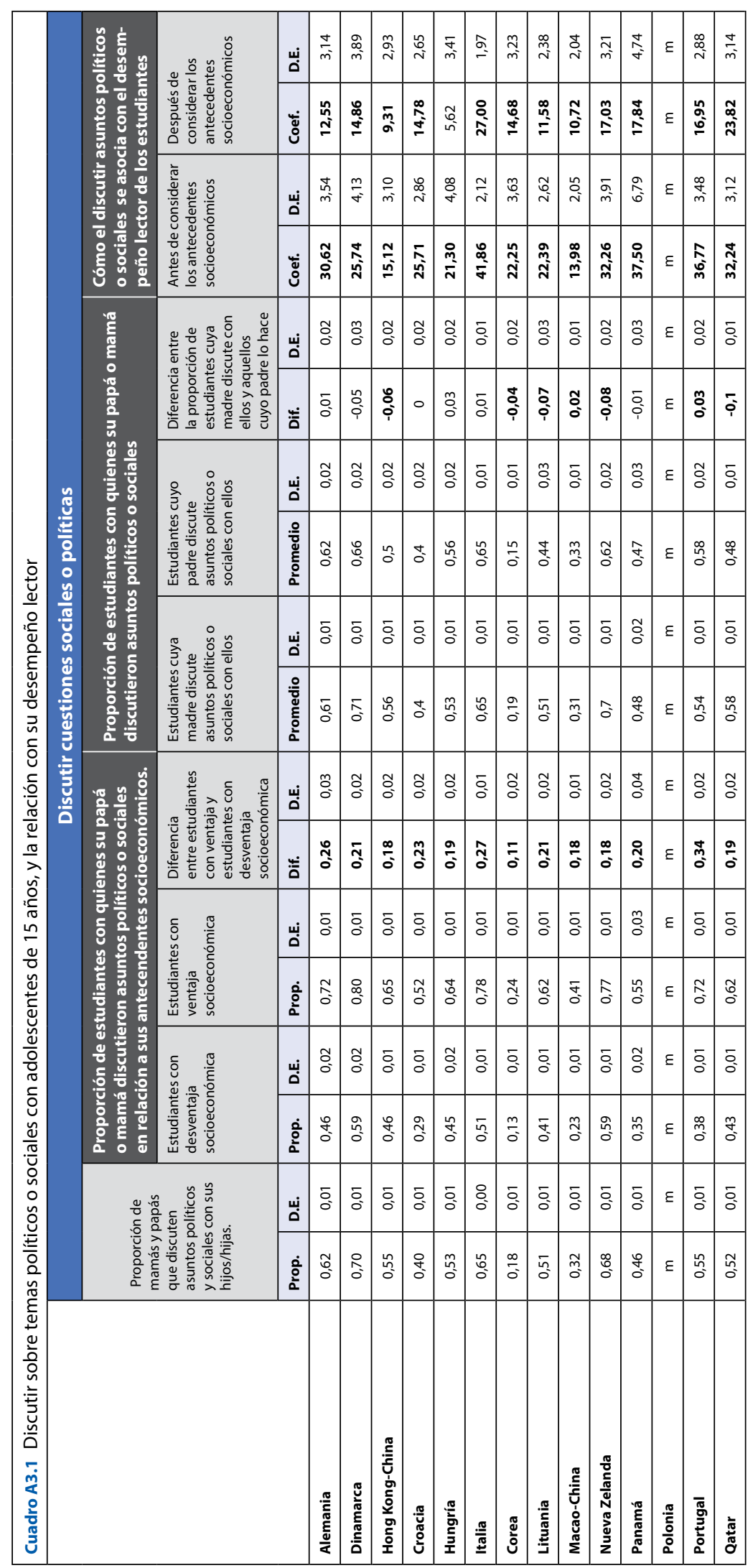

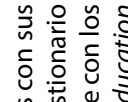

崶苛

은 능 냉

응 홍

家

은 은

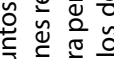

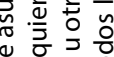

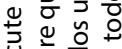

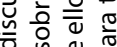

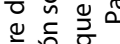

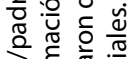

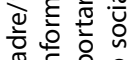

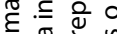

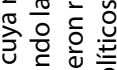

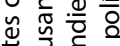

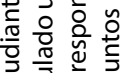

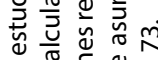

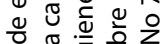

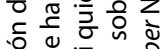

ㄴ.

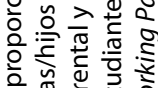

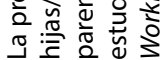

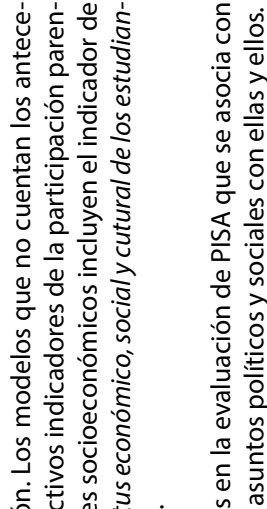

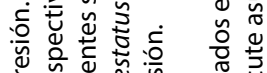

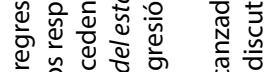

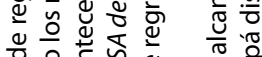

응응 능

은

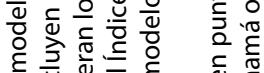

政

을

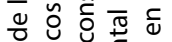

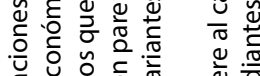

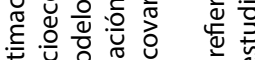

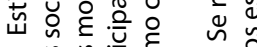

बึ

눈

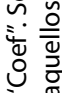




\begin{tabular}{|c|c|c|c|c|c|c|c|c|c|c|c|c|c|c|c|c|c|}
\hline \multirow{4}{*}{\multicolumn{2}{|c|}{ 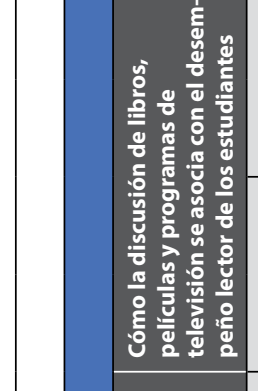 }} & \multirow{2}{*}{ 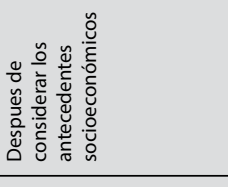 } & 迵 & $\underset{m}{F}$ & \begin{tabular}{c}
\multirow{2}{*}{} \\
m
\end{tabular} & \begin{tabular}{|l}
$\stackrel{0}{ }$ \\
$i$ \\
\end{tabular} & $\underset{m}{m}$ & 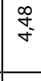 & 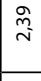 & $\underset{\sim}{\stackrel{f}{\sim}}$ & $\frac{\bar{m}}{m}$ & $\bar{i}$ & $\mid \begin{array}{l}0 \\
\dot{a} \\
\dot{a}\end{array}$ & $\frac{0}{\infty}$ & $\varepsilon$ & 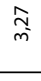 & $\stackrel{\hat{m}}{m}$ \\
\hline & & & ङें & $\underset{\infty}{\tilde{\infty}}$ & $\begin{array}{l}\stackrel{D}{\infty} \\
\dot{J}\end{array}$ & $\frac{0}{6}$ & $\begin{array}{l}\stackrel{0}{0} \\
\stackrel{0}{0}\end{array}$ & ô. & 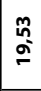 & in & ò & : & 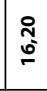 & $\underset{q}{\stackrel{q}{\sigma}}$ & $\varepsilon$ & $\begin{array}{l}\bar{\alpha} \\
\stackrel{\infty}{\simeq}\end{array}$ & 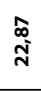 \\
\hline & & 을 & 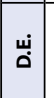 & 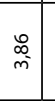 & $\begin{array}{l}\stackrel{n}{m} \\
m\end{array}$ & 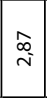 & $\stackrel{\bar{m}}{m}$ & $\underset{i n}{N}$ & $\stackrel{\bar{n}}{\sim}$ & in & 胥 & $\stackrel{\tilde{N}}{\tilde{N}}$ & 竞 & $\mid$\begin{tabular}{l}
7 \\
\multirow{0}{*}{} \\
\hdashline
\end{tabular} & $\varepsilon$ & ${ }_{i}^{\bar{m}}$ & $\begin{array}{l}\stackrel{0}{0} \\
m \\
m\end{array}$ \\
\hline & & 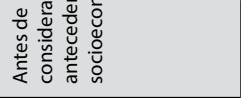 & $\dot{\Xi}$ & $\begin{array}{l}\stackrel{0}{0} \\
\stackrel{2}{=}\end{array}$ & $\begin{array}{l}\frac{a}{\bar{N}} \\
\end{array}$ & 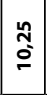 & 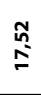 & $\begin{array}{l}\infty \\
\infty \\
0\end{array}$ & . & $\mid \begin{array}{c}n \\
\infty\end{array}$ & $\overline{\bar{q}}$ & 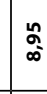 & $\frac{\pi}{\tilde{N}}$ & $\mid \begin{array}{c}\hat{m} \\
\tilde{\sim}\end{array}$ & $\varepsilon$ & $\frac{\infty}{i}$ & $\begin{array}{l}\text { స̃ } \\
\text { సิ }\end{array}$ \\
\hline \multirow{6}{*}{\multicolumn{2}{|c|}{ 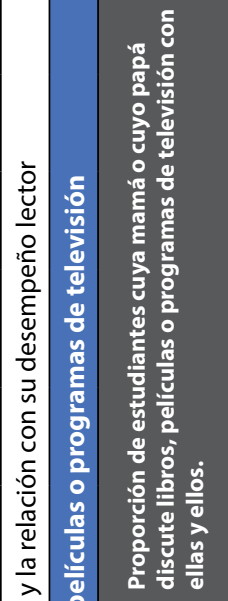 }} & \multirow{2}{*}{ 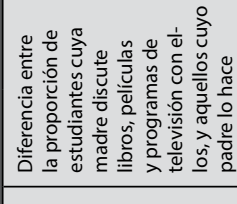 } & 㟧 & $\begin{array}{l}\tilde{z} \\
\vdots \\
0\end{array}$ & $\begin{array}{l}\tilde{0} \\
\tilde{\delta}\end{array}$ & $\mid \begin{array}{c}0 \\
0 \\
0\end{array}$ & $\stackrel{\tilde{0}}{0}$ & $\bar{\delta}_{0}$ & o. & $\tilde{\delta}$ & $\stackrel{\Sigma}{\Xi}$ & $\bar{o}_{0}$ & $\tilde{\tilde{o}}$ & $\mid \begin{array}{l}m \\
0 \\
0\end{array}$ & $\varepsilon$ & : & ó \\
\hline & & & $\ddot{\bar{\Delta}}$ & $\begin{array}{l}\tilde{a} \\
\vdots \\
i \\
i\end{array}$ & $\begin{array}{l}\stackrel{0}{0} \\
\stackrel{i}{i}\end{array}$ & $\mid \begin{array}{l}0 \\
\vdots \\
i\end{array}$ & o̊ & 0 & 草 & 苗 & $\begin{array}{l}n \\
0 \\
o \\
\end{array}$ & $\stackrel{0}{0}$ & $\mid \begin{array}{l}n \\
0 \\
0 \\
\vdots\end{array}$ & $\mid \begin{array}{c}n \\
\bar{i}\end{array}$ & $\varepsilon$ & 立 & $\frac{m}{i}$ \\
\hline & & \multirow{2}{*}{ 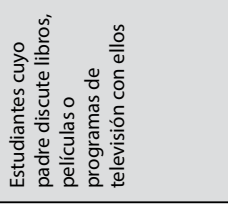 } & मّं & $\begin{array}{l}\tilde{0} \\
0\end{array}$ & $\begin{array}{l}\tilde{O} \\
:\end{array}$ & $\mid \begin{array}{l}\overline{0} \\
0 \\
0\end{array}$ & 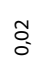 & 官 & 立 & : & $\stackrel{\Xi}{0}$ & $\bar{o}$ & 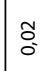 & $\mid \begin{array}{l}m \\
0 \\
0\end{array}$ & $\varepsilon$ & 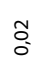 & E. \\
\hline & & & 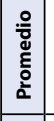 & $\hat{\mathrm{O}}$ & $\begin{array}{l}\stackrel{0}{0} \\
\hat{0}\end{array}$ & $\mid \begin{array}{l}\infty \\
0 \\
o \\
0\end{array}$ & $\hat{\ldots}$ & $\mid \begin{array}{l}\infty \\
\infty \\
\infty\end{array}$ & 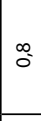 & $\begin{array}{l}\tilde{y} \\
0 \\
0\end{array}$ & 音 & 离 & 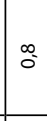 & 啇 & $\varepsilon$ & $\begin{array}{l}n \\
\hat{\sigma} \\
0\end{array}$ & 苟 \\
\hline & & \multirow{2}{*}{ 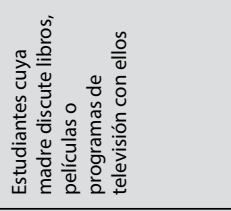 } & मّं & 立 & $\overline{0}$ & $\mid \begin{array}{l}0 \\
0 \\
0\end{array}$ & $\bar{o}_{0}$ & 官 & 0 & 衣 & $\bar{\Delta}$ & $\bar{o}_{0}$ & 立 & 立 & $\varepsilon$ & $\bar{o}_{0}$ & $\bar{o}_{0}$ \\
\hline & & & \begin{tabular}{|c|} 
\\
$\frac{0}{8}$ \\
$\frac{0}{2}$ \\
$\frac{0}{2}$ \\
\end{tabular} & 告 & $\begin{array}{l}\infty \\
\infty \\
\odot\end{array}$ & $\mid \begin{array}{l}0 \\
0 \\
0\end{array}$ & E & $\mid \begin{array}{l}\infty \\
\infty \\
o\end{array}$ & 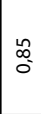 & 商 & $\stackrel{\infty}{\infty}$ & 峁 & $\mid \begin{array}{l}\infty \\
\infty \\
0\end{array}$ & $\mid \begin{array}{l}\hat{N} \\
0 \\
0\end{array}$ & $\varepsilon$ & $\infty_{0}^{\infty}$ & $\stackrel{\infty}{0}$ \\
\hline \multirow{6}{*}{\multicolumn{2}{|c|}{ 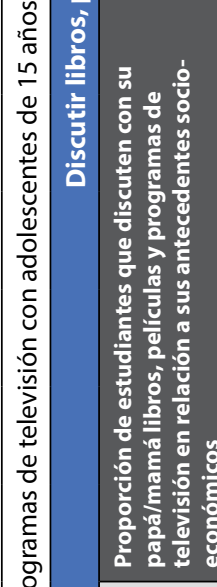 }} & \multirow{2}{*}{ 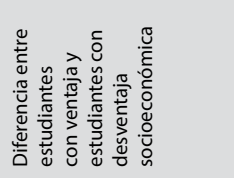 } & щّं & $:$ & $\tilde{O}$ & $\mid \begin{array}{l}0 \\
0 \\
0\end{array}$ & $:$ & : & 官 & : & $\bar{\Delta}$ & s. & 莒 & $\mid \begin{array}{l}n \\
0 \\
0 \\
0\end{array}$ & $\varepsilon$ & $\tilde{O}$ & ¿̊. \\
\hline & & & $\ddot{\bar{\Delta}}$ & $:$ & $\div$ & $\frac{\pi}{0}$ & $\overline{0}$ & $\bar{\sigma}_{0}$ & 0 & $\stackrel{\circ}{0}$ & $\stackrel{0}{0}$ & $\frac{5}{0}$ & $\stackrel{8}{0}$ & $\begin{array}{l}0 \\
0 \\
0\end{array}$ & $\varepsilon$ & $\frac{n}{0}$ & $\frac{N}{0}$ \\
\hline & & \multirow{2}{*}{ 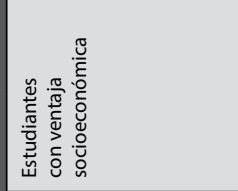 } & घ̈ं & $\bar{o}_{0}$ & $\bar{\delta}$ & $\begin{array}{l}\overline{0} \\
0 \\
0\end{array}$ & $\bar{o}_{0}$ & 立 & : & 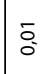 & $\bar{\Delta}$ & $\bar{o}_{0}$ & 立 & 雚 & $\varepsilon$ & $\bar{o}_{0}$ & Бे \\
\hline & & & $\stackrel{\circ}{\frac{0}{2}}$ & $\begin{array}{l}\hat{E} \\
0\end{array}$ & 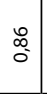 & $\begin{array}{l}: \\
: \\
\circ\end{array}$ & $\underset{\infty}{\infty}$ & $\begin{array}{l}\infty \\
\infty \\
0\end{array}$ & $\begin{array}{l}\infty \\
\infty \\
\infty\end{array}$ & 是 & 总 & $\bar{\Xi}_{0}$ & $\begin{array}{l}\infty \\
\infty \\
\infty\end{array}$ & $\begin{array}{l}0 \\
0 \\
0\end{array}$ & $\varepsilon$ & $\stackrel{\substack{\infty \\
\infty}}{\circ}$ & : \\
\hline & & \multirow{2}{*}{ 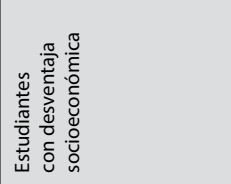 } & घ̈ं & $\begin{array}{l}\tilde{a} \\
0 \\
0\end{array}$ & $\begin{array}{l}\tilde{O} \\
:\end{array}$ & $\mid \begin{array}{l}\overline{0} \\
\overline{0}\end{array}$ & $\bar{o}_{0}$ & 官 & 产 & 衣 & $\bar{\Xi}_{0}$ & $\bar{o}$ & 立 & $\begin{array}{l}m \\
0 \\
0\end{array}$ & $\varepsilon$ & $\bar{o}_{0}$ & $\bar{o}$ \\
\hline & & & 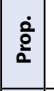 & $\begin{array}{l}\infty \\
: \\
0\end{array}$ & $\begin{array}{l}\stackrel{0}{0} \\
\vdots\end{array}$ & 垈 & R & $\mid \begin{array}{l}\infty \\
\infty \\
0 \\
0\end{array}$ & 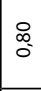 & $\begin{array}{l}\tilde{m} \\
\alpha\end{array}$ & 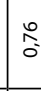 & 売 & $\mid$\begin{tabular}{c}
$\infty$ \\
$\infty$ \\
\hdashline
\end{tabular} & $\mid$\begin{tabular}{c|}
0 \\
$\hat{n}$ \\
0 \\
0
\end{tabular} & $\varepsilon$ & $\hat{N}$ & 萼 \\
\hline & \multirow{2}{*}{\multicolumn{2}{|c|}{ 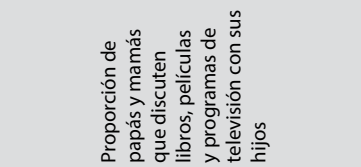 }} & 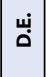 & $\begin{array}{l}\overline{0} \\
\vdots \\
0\end{array}$ & $\bar{o}_{0}$ & $\bar{D}_{0}$ & $\bar{o}_{0}$ & so & : & $\bar{D}_{0}$ & $\bar{\Delta}$ & $\bar{o}_{0}$ & $\bar{\sigma}_{0}$ & $\tilde{\tilde{O}}$ & $\varepsilon$ & $\bar{o}_{0}$ & $\bar{o}$ \\
\hline & & & $\frac{\dot{0}}{\frac{0}{2}}$ & $\begin{array}{l}\Delta \\
\Delta \\
0\end{array}$ & \begin{tabular}{l}
$\tilde{\infty}$ \\
\hdashline \\
\hdashline
\end{tabular} & $\mid \begin{array}{l}0 \\
\\
0\end{array}$ & $\stackrel{0}{\circ}$ & $\mid \begin{array}{c}\infty \\
\infty \\
\infty\end{array}$ & 犃 & $\begin{array}{l}\infty \\
0 \\
0 \\
0\end{array}$ & $\stackrel{\infty}{\infty}$ & ֶू. & $\mid \begin{array}{c}0 \\
\infty \\
0 \\
0\end{array}$ & $\begin{array}{l}0 \\
: \\
0\end{array}$ & $\varepsilon$ & 亦 & Б্ \\
\hline & & & & 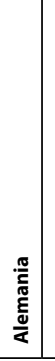 & 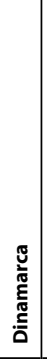 & 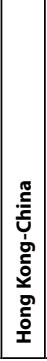 & & & 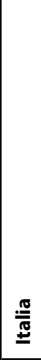 & 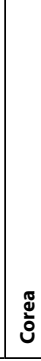 & & 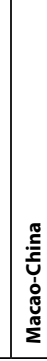 & 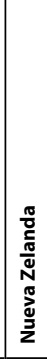 & 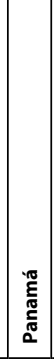 & & 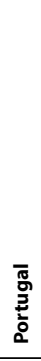 & \\
\hline
\end{tabular}

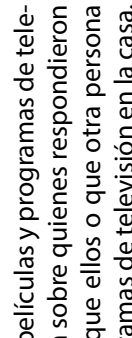

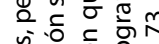

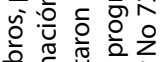

要焉

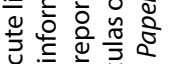

늫

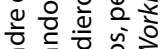

苋馆

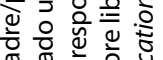

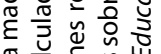

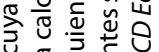

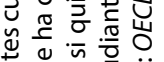

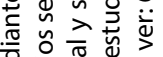

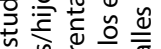

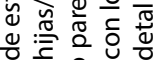

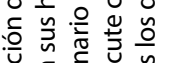

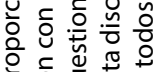

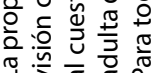

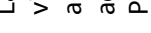

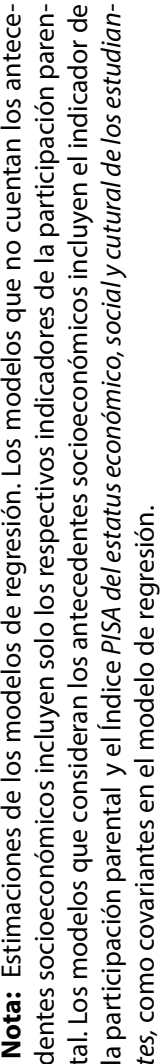

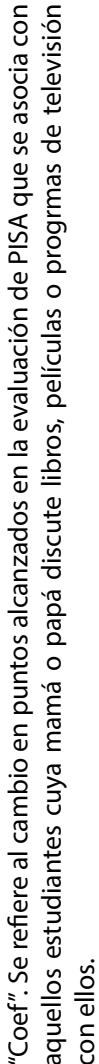




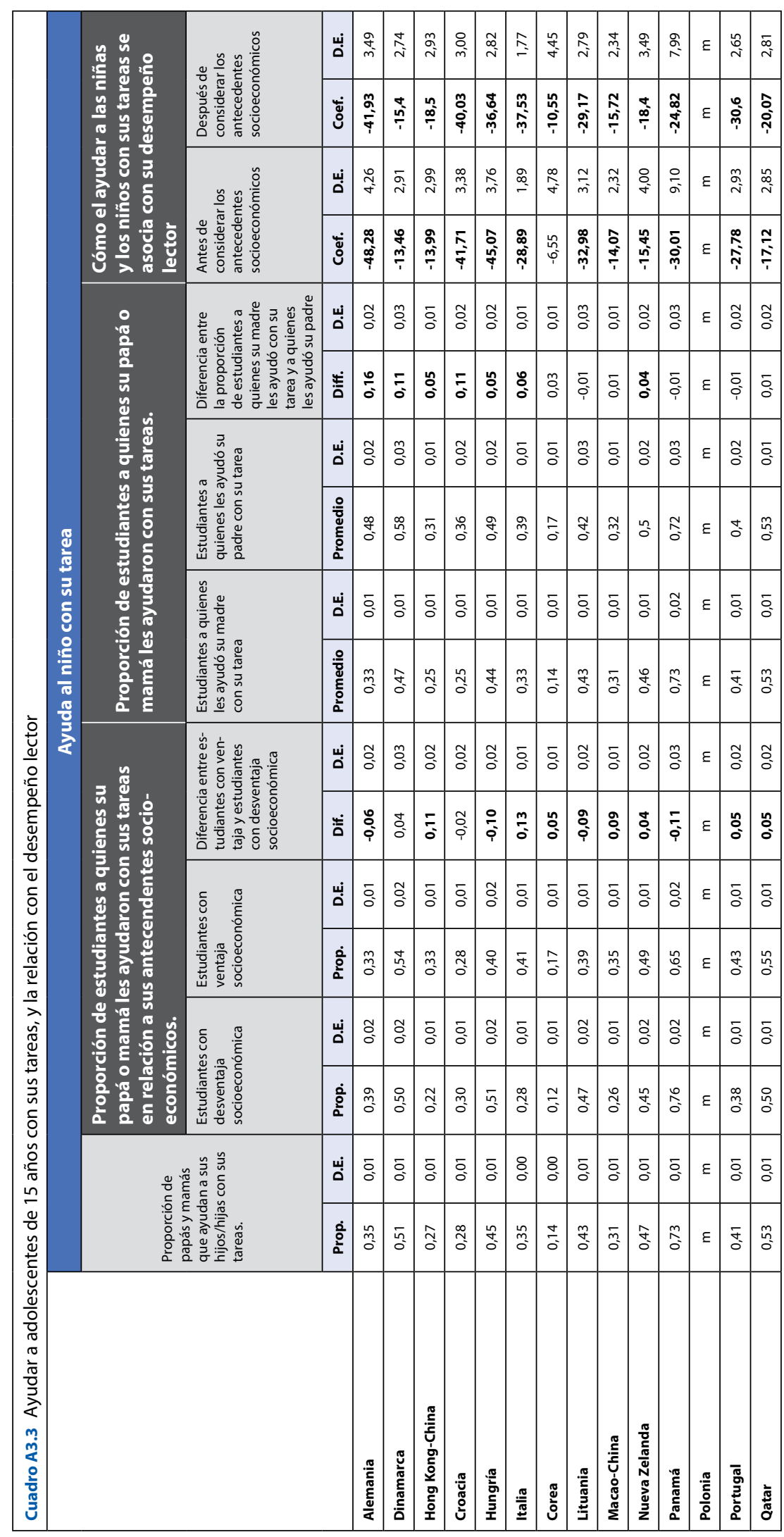

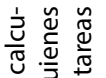

$\frac{\sigma}{5} \frac{\tilde{n}}{n}$

ñ

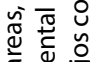

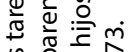

는은 은

ป

ㅇํำ 을

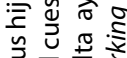

出 $\frac{0}{5} \frac{5}{5}$

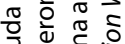

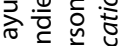

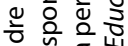

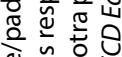

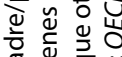

를 흠

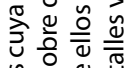

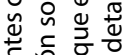

등 은 드응

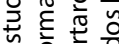

要

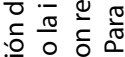

ㅎํ음

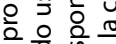

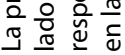

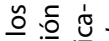

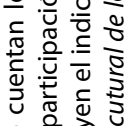

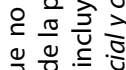

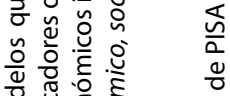

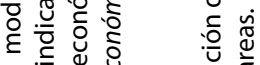

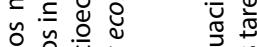

O)

흠

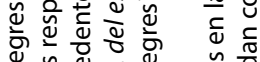

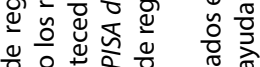

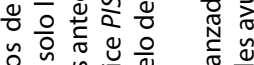

은

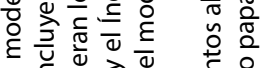

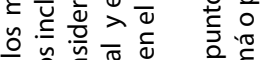

을.

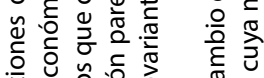

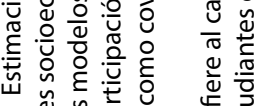

نั

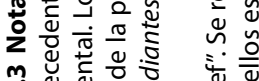

m.

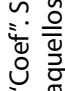




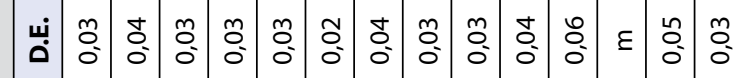

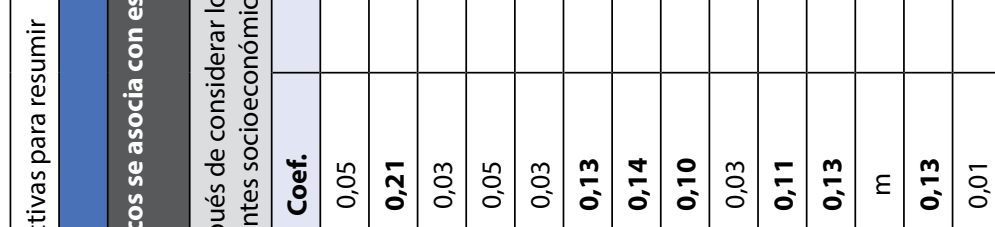
造 ⿺辶寸

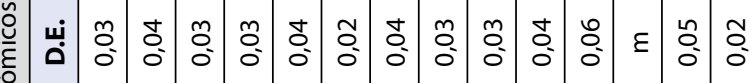
은 웡

응

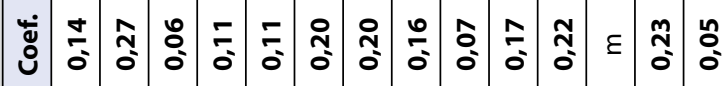
密离

至 ¿

吾

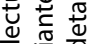

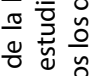

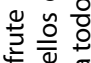

$\frac{0}{\frac{0}{0}} \frac{0}{0}$

¿ ठ 己

过

竞

ฮ

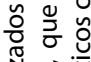

究

ए人

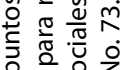

बे

है월

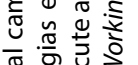

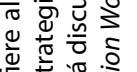

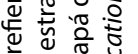

$\backsim$ ํํㅇ

这 气

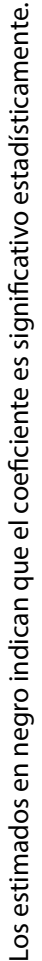

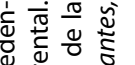

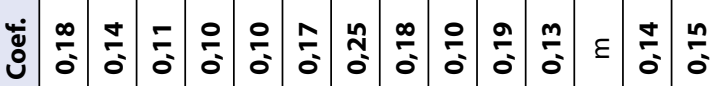

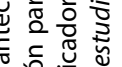

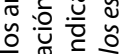

焉

ป

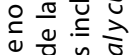

ب்

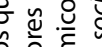

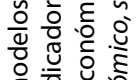

है.

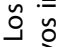

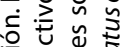

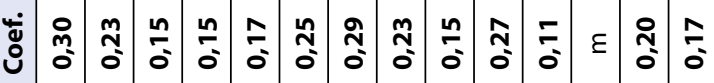

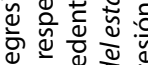

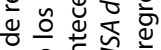

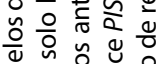

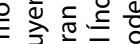

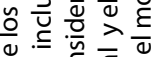

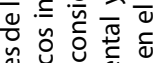

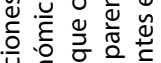

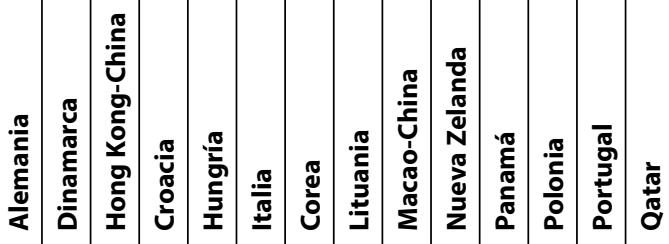

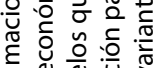

击

i⿱

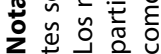




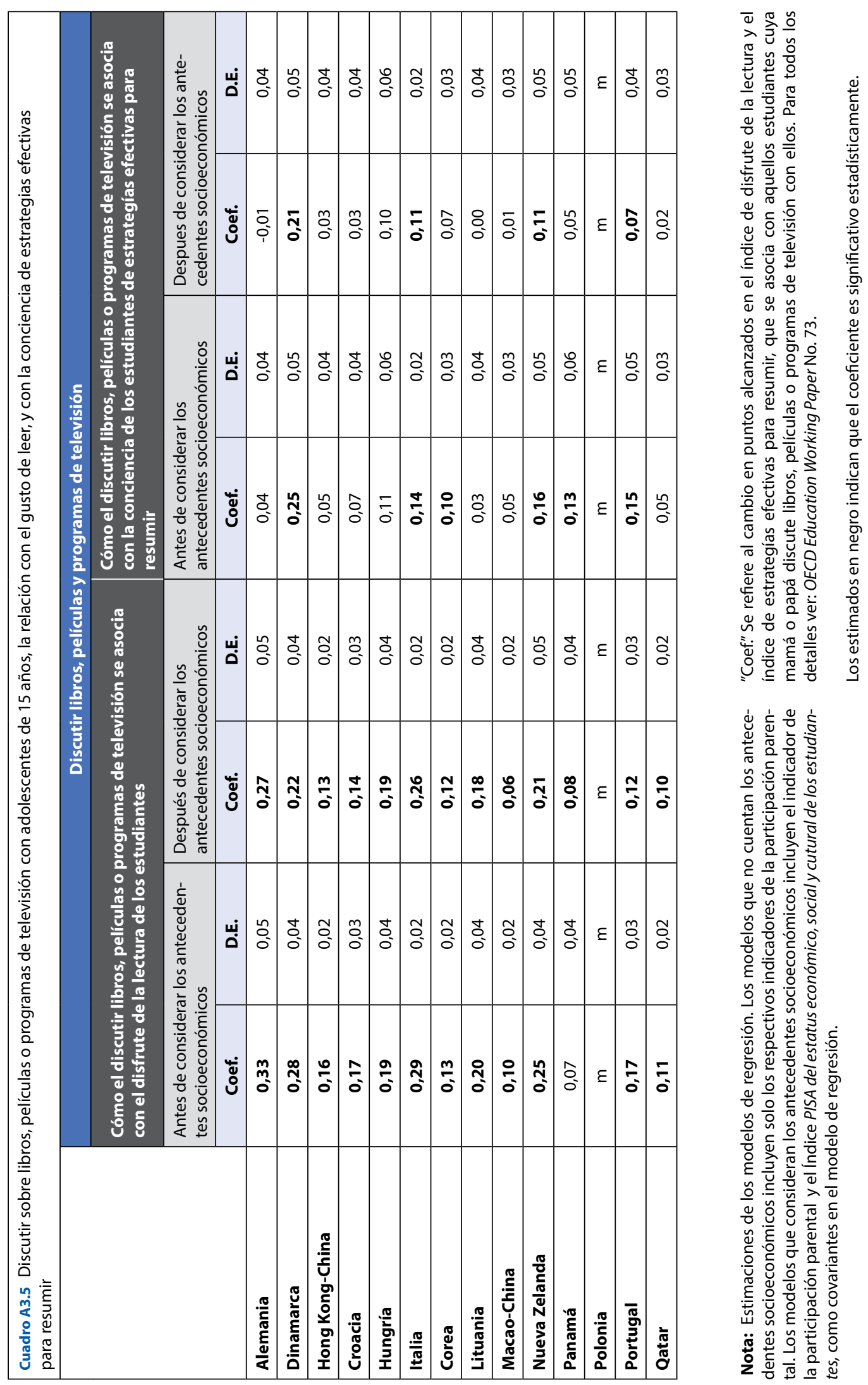



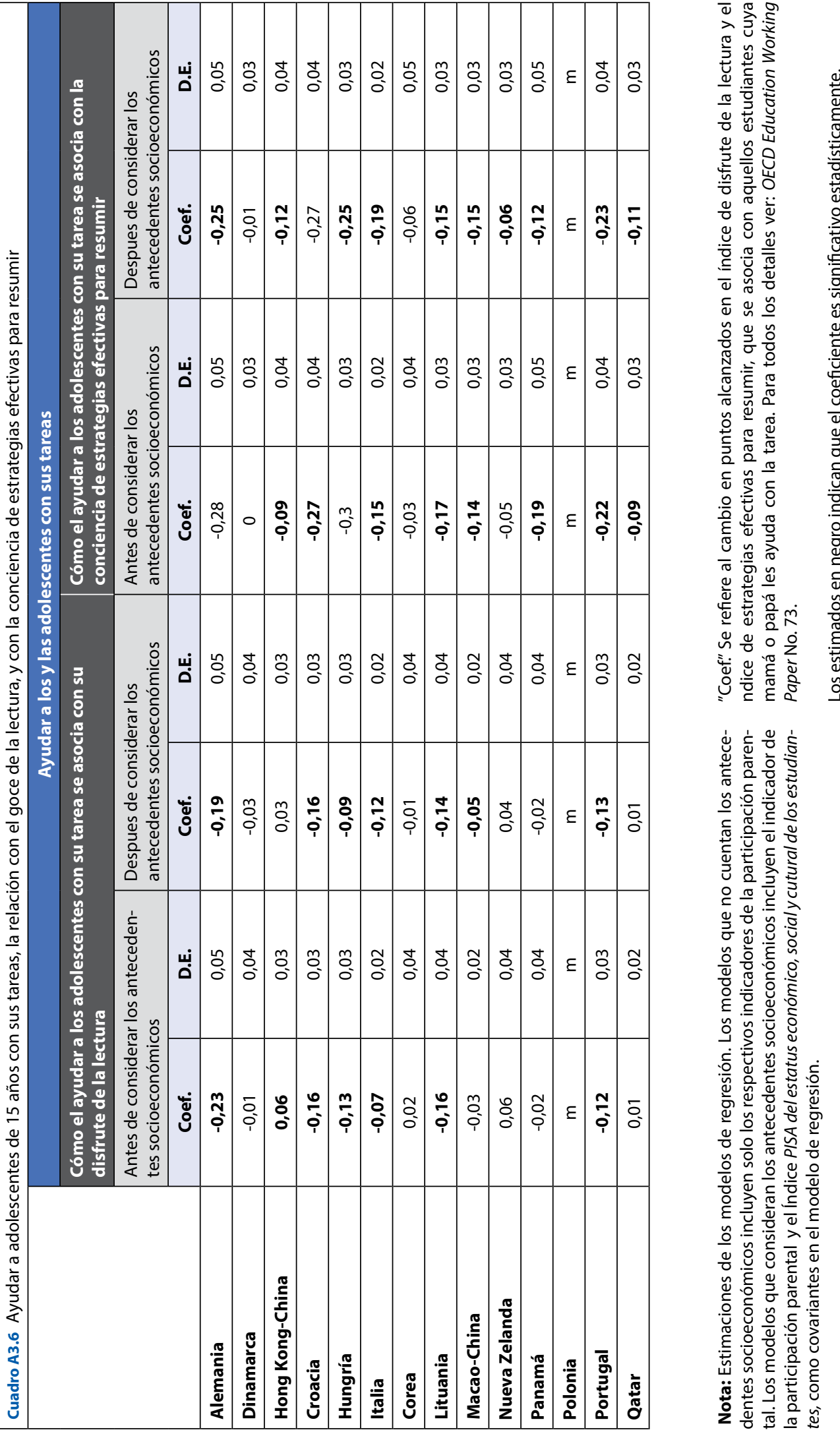


\begin{tabular}{|c|c|c|c|c|c|c|c|c|c|c|c|c|c|c|c|c|c|}
\hline \multirow{4}{*}{\multicolumn{2}{|c|}{ 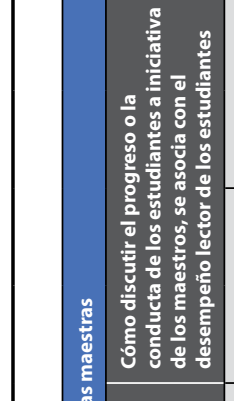 }} & \multirow{2}{*}{ 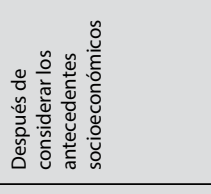 } & 쎰 & $\stackrel{\infty}{\infty}$ & 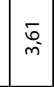 & $\overline{\bar{i}}$ & 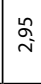 & 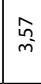 & $\stackrel{a}{-}$ & $\mid \begin{array}{c}\tilde{m} \\
\tilde{m}\end{array}$ & \begin{tabular}{|}
$\stackrel{\infty}{\infty}$ \\
$\sim$ \\
$\sim$
\end{tabular} & $\mid \begin{array}{c}\tilde{N} \\
\stackrel{i}{i}\end{array}$ & $\begin{array}{c}\bar{m} \\
m\end{array}$ & $\mid$\begin{tabular}{c}
$\infty$ \\
$\infty$ \\
\multirow{\leftarrow}{*}{}
\end{tabular} & $\varepsilon$ & 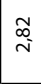 & d্ \\
\hline & & & ङें & 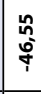 & $\frac{n}{r}$ & $\begin{array}{l}\hat{0} \\
\dot{i} \\
\end{array}$ & ָิ & 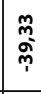 & 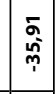 & $\Xi$ & 总 & $\mid \frac{a}{\bar{T}}$ & $\left|\begin{array}{l}n \\
\\
\\
1\end{array}\right|$ & 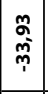 & $\varepsilon$ & 离 & $\stackrel{n}{\frac{n}{7}}$ \\
\hline & & $\underline{\text { o․ }}$ & щேं & $\stackrel{\Delta}{\stackrel{ \pm}{m}}$ & $\mid$\begin{tabular}{l}
2 \\
\multirow{2}{*}{}
\end{tabular} & \begin{tabular}{|l|l} 
\\
d
\end{tabular} & $\stackrel{\infty}{\underset{+}{+}}$ & $\stackrel{\substack{\infty \\
\sim \\
\sim}}{i}$ & $\stackrel{g}{=}$ & 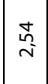 & \begin{tabular}{|}
$\stackrel{a}{\sim}$ \\
$\sim$
\end{tabular} & $\frac{a}{\hat{N}}$ & $\frac{\infty}{m}$ & \begin{tabular}{|l|} 
\\
$\stackrel{+}{+}$
\end{tabular} & $\varepsilon$ & 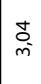 & $\frac{n}{m}$ \\
\hline & & 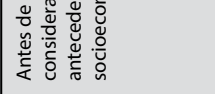 & ङे & ì & $\begin{array}{c}n \\
\hat{n} \\
i \\
\end{array}$ & 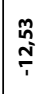 & $\begin{array}{c}m \\
m \\
\frac{m}{T}\end{array}$ & 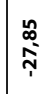 & 奋 & 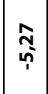 & \begin{tabular}{l}
$\overline{5}$ \\
\hdashline \\
1
\end{tabular} & 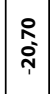 & 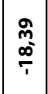 & $\mid \frac{m}{i s}$ & $\varepsilon$ & 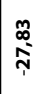 & $\begin{array}{c}0 \\
0 \\
i \\
i\end{array}$ \\
\hline & $\div$ & & 山्ن & 圆 & $\begin{array}{l}\tilde{D} \\
0 \\
0\end{array}$ & 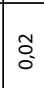 & 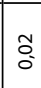 & : & $\bar{o}$ & $\begin{array}{l}0 \\
0 \\
0\end{array}$ & : & $\begin{array}{l}0 \\
0 \\
0\end{array}$ & $\begin{array}{l}0 \\
0 \\
0\end{array}$ & $\mid \begin{array}{l}0 \\
0 \\
0\end{array}$ & $\varepsilon$ & : & s. \\
\hline & 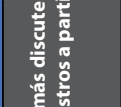 & 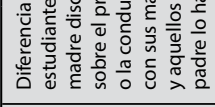 & 㝘 & : & $\begin{array}{l}\tilde{O} \\
0 \\
0\end{array}$ & 草 & $\overline{0}$ & s. & 范 & $\begin{array}{l}\infty \\
0 \\
0 \\
i\end{array}$ & $\begin{array}{l}\hat{0} \\
\dot{i}\end{array}$ & $\begin{array}{l}\mathbf{D} \\
0 \\
0\end{array}$ & $\begin{array}{l}0 \\
0 \\
0\end{array}$ & $\mid \begin{array}{l}\infty \\
0 \\
0\end{array}$ & $\varepsilon$ & : & $\because$ \\
\hline & 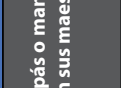 & 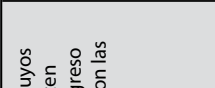 & щேं & :̊ & $\begin{array}{l}\tilde{D} \\
0 \\
0\end{array}$ & : & 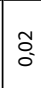 & : & $\begin{array}{l}\bar{\delta} \\
\dot{0} \\
\end{array}$ & $\begin{array}{l}\tilde{a} \\
0 \\
0\end{array}$ & $:$ & \begin{tabular}{|l|}
$\bar{\delta}$ \\
0 \\
0
\end{tabular} & $\begin{array}{l}0 \\
0 \\
0\end{array}$ & \begin{tabular}{|l|}
0 \\
0 \\
0
\end{tabular} & $\varepsilon$ & : & : \\
\hline & 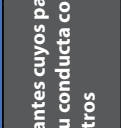 & 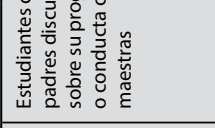 & 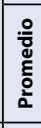 & $\stackrel{\infty}{o}$ & $\begin{array}{l}\Omega \\
0 \\
0\end{array}$ & $\begin{array}{l}\text { g } \\
0\end{array}$ & $\stackrel{t}{0}$ & 商 & $\mid \begin{array}{l}\infty \\
\substack{0 \\
0}\end{array}$ & $\mid \begin{array}{l}N \\
0 \\
0\end{array}$ & \begin{tabular}{|l|}
0 \\
0 \\
0
\end{tabular} & $\mid \begin{array}{l}\overline{0} \\
\\
\end{array}$ & $\mid \begin{array}{l}\stackrel{u}{\hat{n}} \\
0 \\
0\end{array}$ & $\stackrel{\circ}{\circ}$ & $\varepsilon$ & $\stackrel{\circ}{\circ}$ & 壳 \\
\hline 产 & 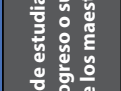 & 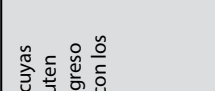 & щேㅁ & $\bar{o}_{0}$ & $\begin{array}{l}\bar{o} \\
0 \\
\end{array}$ & \begin{tabular}{|c}
$\delta$ \\
0 \\
0
\end{tabular} & 衣 & ó & $\bar{\delta}$ & $\begin{array}{l}\overline{0} \\
\dot{0}\end{array}$ & 官 & 玄 & $\begin{array}{l}\overline{0} \\
\dot{0}\end{array}$ & $\begin{array}{l}0 \\
0 \\
0\end{array}$ & $\varepsilon$ & $\tilde{o}_{0}$ & $\tilde{o}_{0}$ \\
\hline '离 & 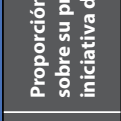 & 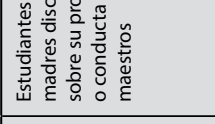 & 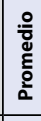 & $\begin{array}{l}\stackrel{0}{0} \\
0 \\
0\end{array}$ & $\hat{O}$ & 目 & o. & $\begin{array}{l}\infty \\
0 \\
o\end{array}$ & 竎 & $\begin{array}{l}2 \\
0 \\
0\end{array}$ & \begin{tabular}{|l|l} 
\\
and \\
0
\end{tabular} & $\mid \begin{array}{l}\hat{n} \\
0\end{array}$ & $\mid \begin{array}{l}m \\
\hat{o} \\
o\end{array}$ & \begin{tabular}{|l|}
$\bar{n}$ \\
no
\end{tabular} & $\varepsilon$ & 芯 & 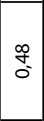 \\
\hline \begin{tabular}{l}
$\bar{\sigma}$ \\
\multicolumn{0}{c}{}
\end{tabular} & & & 㟧 & ¿̊ & $\begin{array}{l}\tilde{O} \\
0 \\
0\end{array}$ & $\mid \begin{array}{l}0 \\
0 \\
0\end{array}$ & $\therefore$ & : & $\begin{array}{l}\bar{\delta} \\
\dot{o}\end{array}$ & $\begin{array}{l}0 \\
0 \\
0\end{array}$ & 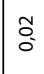 & $\mid \begin{array}{l}0 \\
0 \\
0\end{array}$ & $\begin{array}{l}0 \\
0 \\
0\end{array}$ & $\mid \begin{array}{l}n \\
0 \\
0\end{array}$ & $\varepsilon$ & $\therefore$ & O. \\
\hline 兗 & 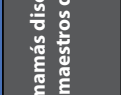 & 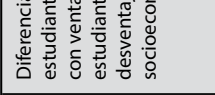 & 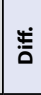 & $\frac{\infty}{i}$ & 音 & \begin{tabular}{|l|}
$\infty$ \\
0 \\
0
\end{tabular} & $\tilde{o}_{i}$ & $\frac{0}{i}$ & $\mid \begin{array}{l}\infty \\
0 \\
0 \\
i\end{array}$ & $\frac{9}{0}$ & $\stackrel{0}{0}$ & $\mid \begin{array}{c}\overline{0} \\
\bar{i}\end{array}$ & $\mid \begin{array}{c}\bar{i} \\
\bar{i}\end{array}$ & $\frac{0}{9}$ & $\varepsilon$ & $\bar{i}$ & : \\
\hline$\vec{n}$ & 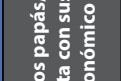 & & щேㅁ & $\bar{o}$ & $\begin{array}{l}\tilde{\sigma} \\
0 \\
0\end{array}$ & $\mid \begin{array}{c}\tilde{a} \\
\vdots \\
0\end{array}$ & : & s. & 家 & $\overline{0}$ & : & $\begin{array}{l}\overline{0} \\
\overline{0}\end{array}$ & $\mid \begin{array}{l}0 \\
0 \\
0\end{array}$ & $\mid \begin{array}{l}0 \\
0 \\
0\end{array}$ & $\varepsilon$ & $\tilde{O}$ & o. \\
\hline$\frac{\widetilde{\sigma}}{\tilde{\xi}}$ & 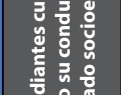 & 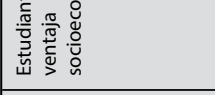 & $\frac{8}{2}$ & m. & $\mid \begin{array}{l}0 \\
0 \\
0 \\
0\end{array}$ & $\mid \begin{array}{l}0 \\
\text { h. } \\
0\end{array}$ & 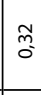 & 商 & f & \begin{tabular}{|l|}
0 \\
\hdashline \\
0
\end{tabular} & ơ & $\mid \begin{array}{l}\hat{n} \\
0\end{array}$ & 望 & f & $\varepsilon$ & in & \%ू. \\
\hline 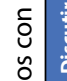 & 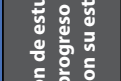 & 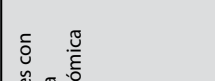 & щேं & : & $\bar{o}$ & \begin{tabular}{|c|}
$\overline{0}$ \\
0 \\
0
\end{tabular} & $\overline{0}_{0}$ & : & $\bar{o}$ & $\bar{o}$ & 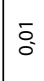 & $\bar{\delta}$ & $\begin{array}{l}\tilde{O} \\
0 \\
0\end{array}$ & $\tilde{O}$ & $\varepsilon$ & $\ddot{O}$ & $\bar{o}$ \\
\hline c & 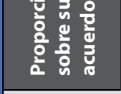 & 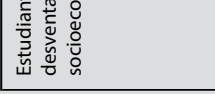 & $\frac{2}{2}$ & $\stackrel{\infty}{0}$ & $\begin{array}{l}0 \\
0 \\
0\end{array}$ & \begin{tabular}{|l|}
$\infty$ \\
0 \\
0 \\
0
\end{tabular} & 旁 & f & 员 & $\begin{array}{l}0 \\
0 \\
0\end{array}$ & $\begin{array}{l}0 \\
\text { hn } \\
0\end{array}$ & 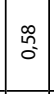 & 志 & $\mid \begin{array}{l}0 \\
0 \\
0\end{array}$ & $\varepsilon$ & \begin{tabular}{|l}
$\infty$ \\
0 \\
0
\end{tabular} & 造 \\
\hline & & $\frac{\pi}{4} \frac{\pi}{0} \overline{0} \frac{\pi}{0}$ & 㟧 & $\bar{D}_{0}$ & $\begin{array}{c}\overline{0} \\
\dot{0}\end{array}$ & \begin{tabular}{|c|}
$\overline{0}$ \\
$\dot{0}$
\end{tabular} & 立 & s. & $\begin{array}{l}\bar{\delta} \\
\dot{0} \\
\end{array}$ & $\bar{o}$ & 官 & \begin{tabular}{|c|}
$\overline{0}$ \\
$\overline{0}$
\end{tabular} & $\bar{o}$ & $\begin{array}{l}\tilde{O} \\
\tilde{0}\end{array}$ & $\varepsilon$ & $\bar{o}$ & s. \\
\hline & & $\begin{array}{l}0 \\
0\end{array}$ & $\frac{0}{2}$ & $\hat{m}$ & $\mid \begin{array}{l}\infty \\
0 \\
0\end{array}$ & 今̂. & \begin{tabular}{|l}
$\tilde{m}$ \\
o.
\end{tabular} & $\begin{array}{l}\infty \\
0 \\
0\end{array}$ & 告 & $\mid \begin{array}{l}\infty \\
0 \\
0\end{array}$ & $\begin{array}{l}\hat{2} \\
\hat{o}\end{array}$ & \begin{tabular}{|l|}
$\hat{o}$ \\
$\hat{o}$ \\
0
\end{tabular} & 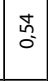 & 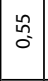 & $\varepsilon$ & : & $\begin{array}{l}\text { ñ } \\
\text { no }\end{array}$ \\
\hline . & & & & 离 & 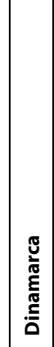 & 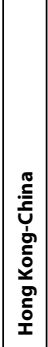 & 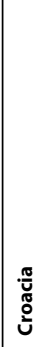 & 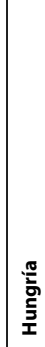 & $\frac{\underline{\underline{m}}}{\underline{\underline{\underline{\underline{S}}}}}$ & ڤัٌ & 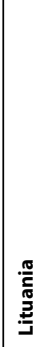 & 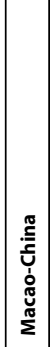 & 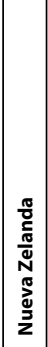 & 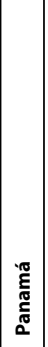 & $\begin{array}{l}\frac{0}{0} \\
\frac{0}{0} \\
\frac{6}{0}\end{array}$ & 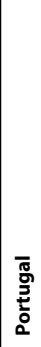 & 童 \\
\hline
\end{tabular}

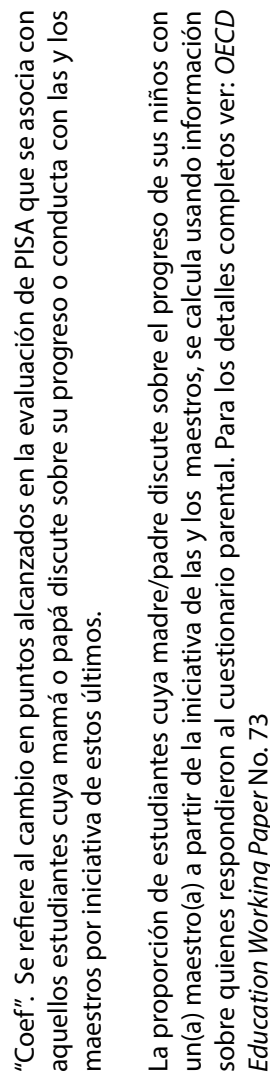

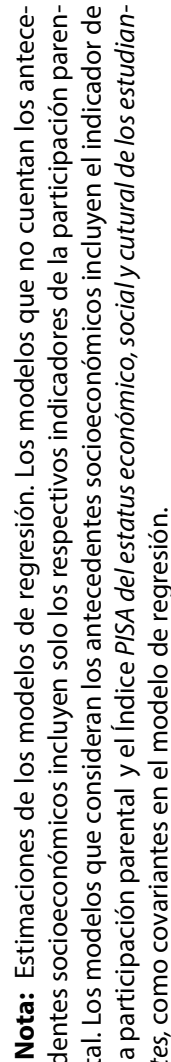




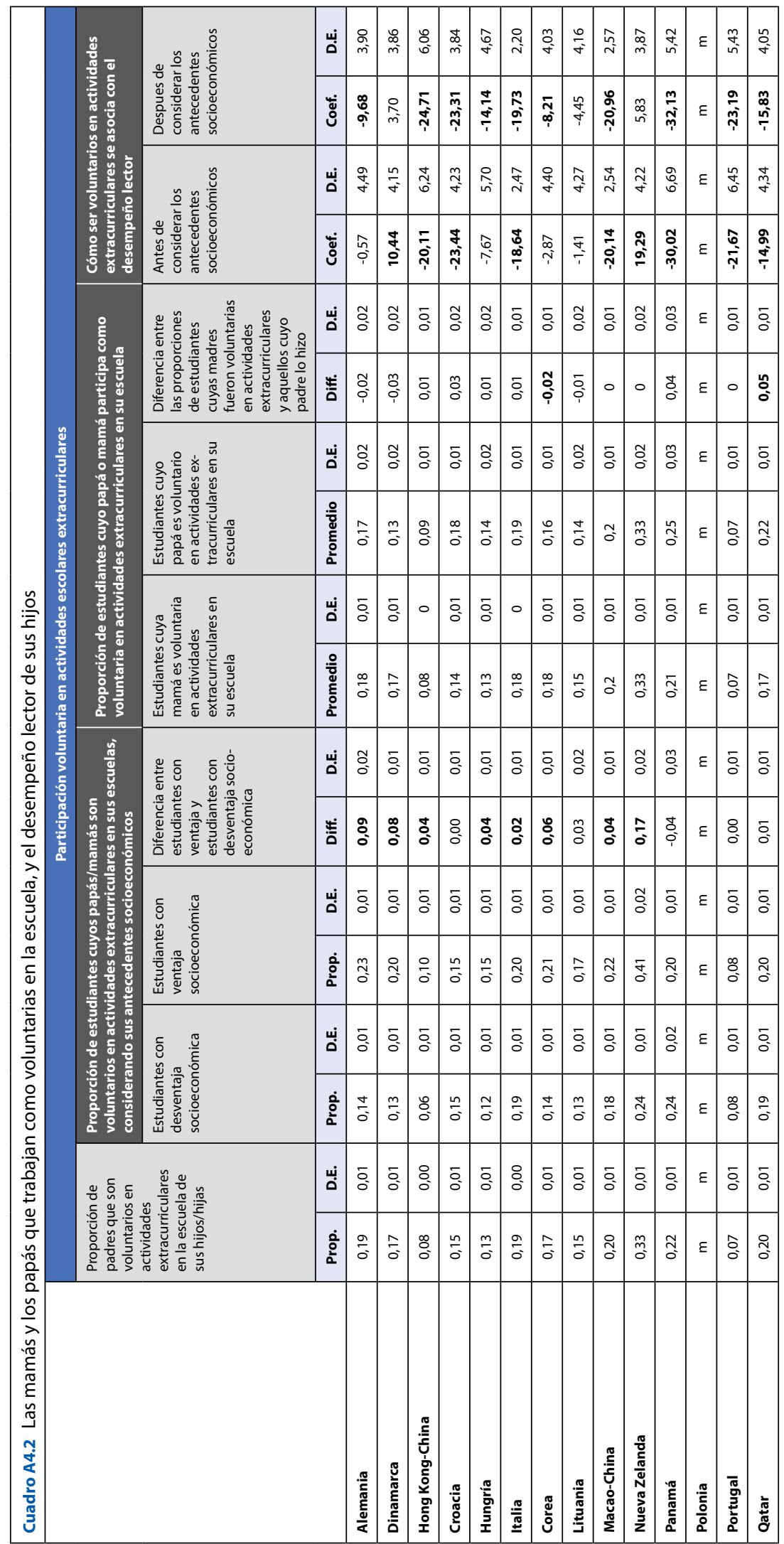

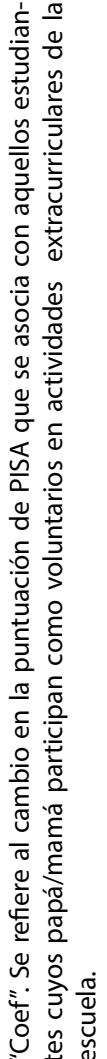

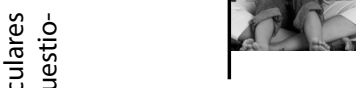

乡ّ山

은 은 읗 气ั

空

बi

을

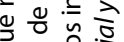

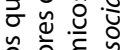

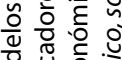

年

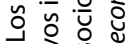

:

흔

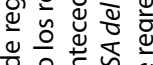

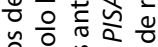

는

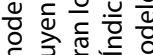

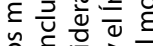

음 $=$

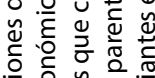

은 응 은

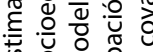

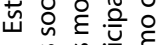

نั

눙

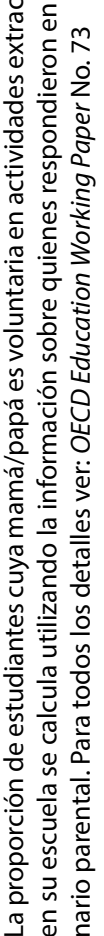




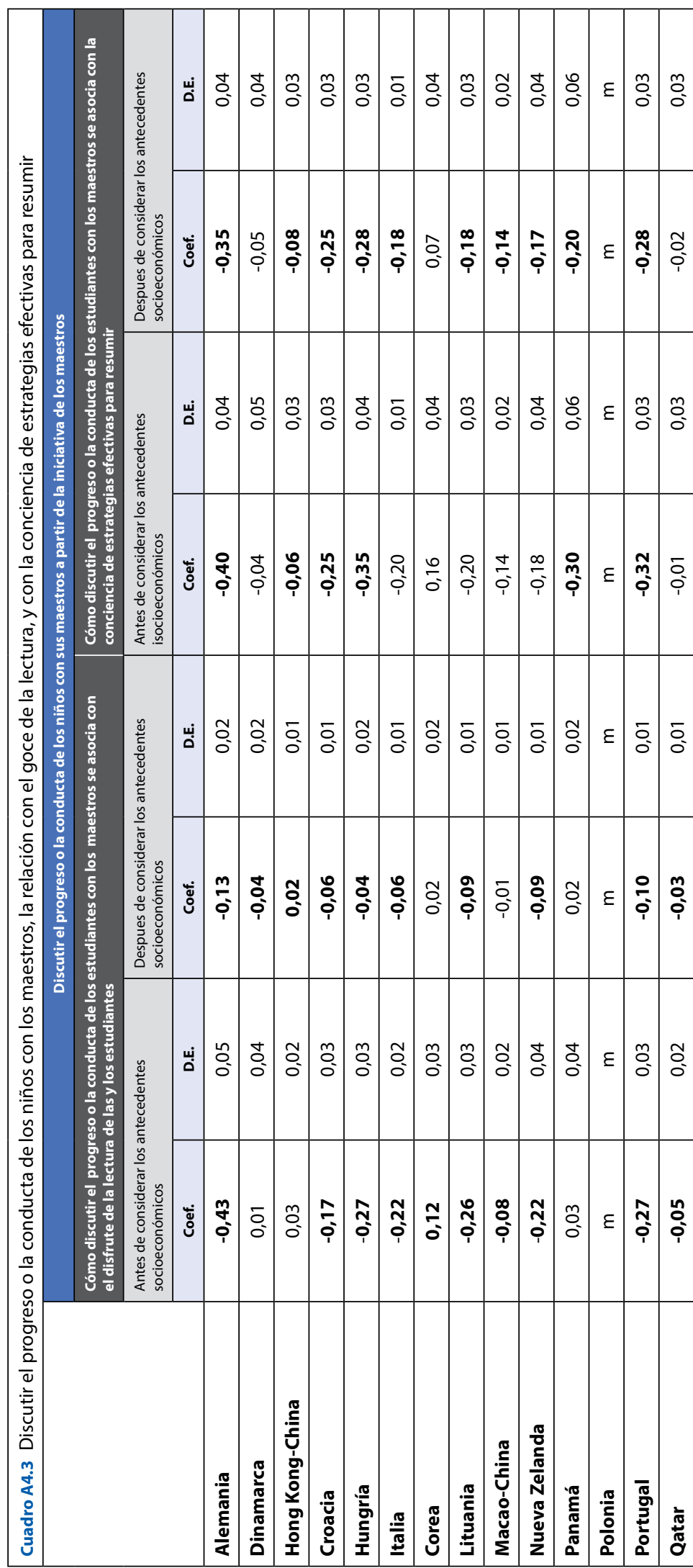

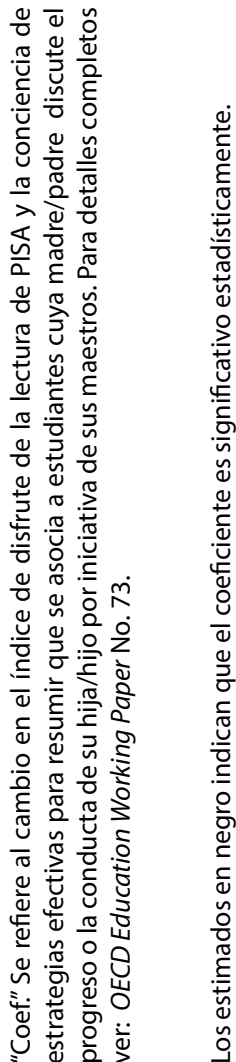

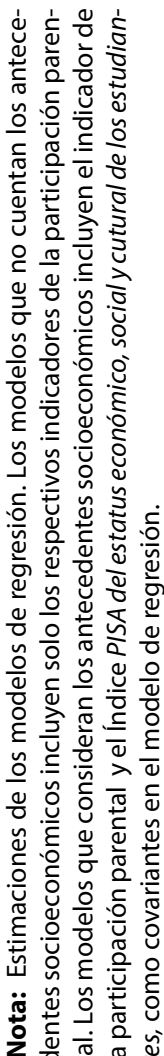




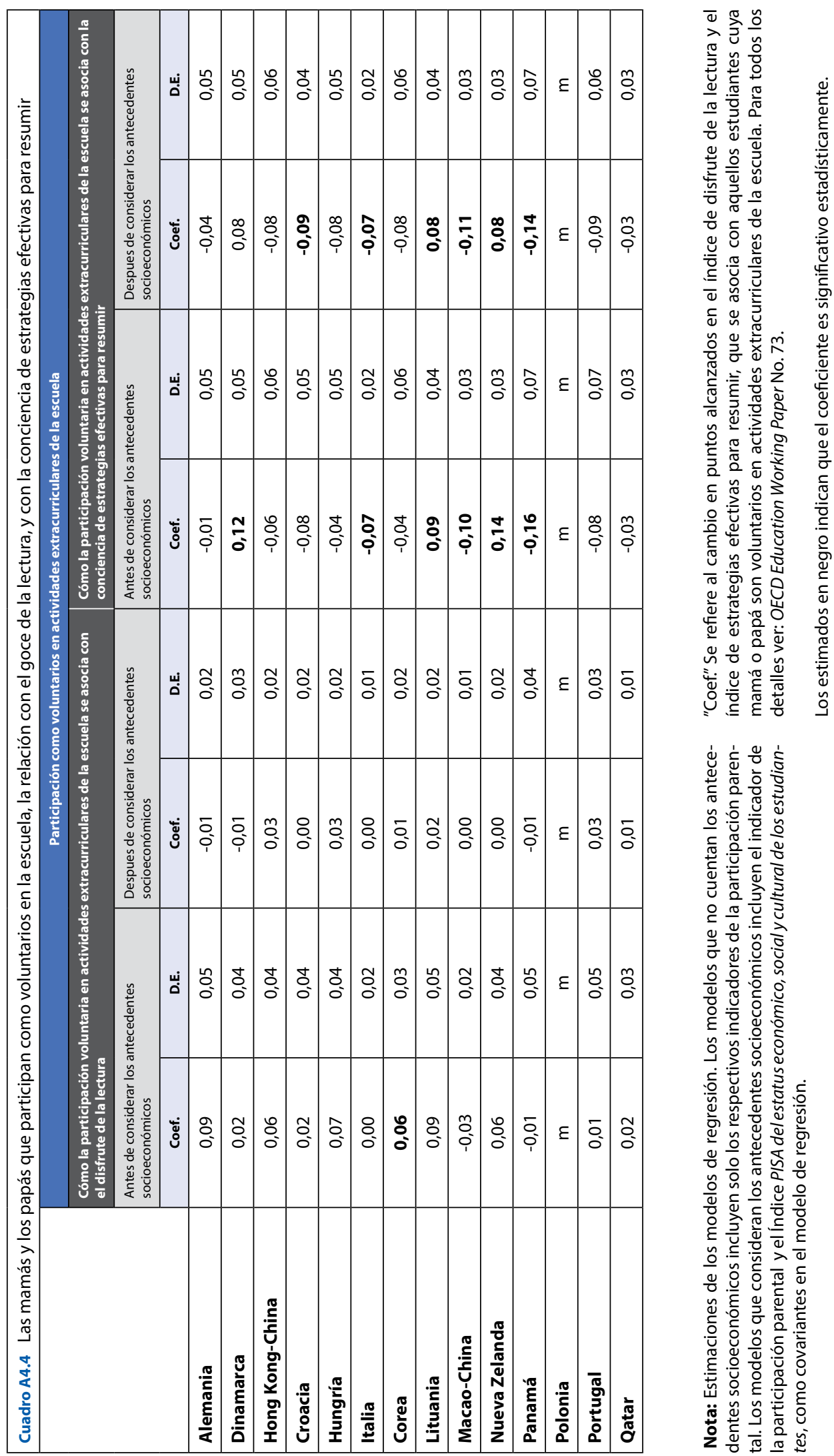




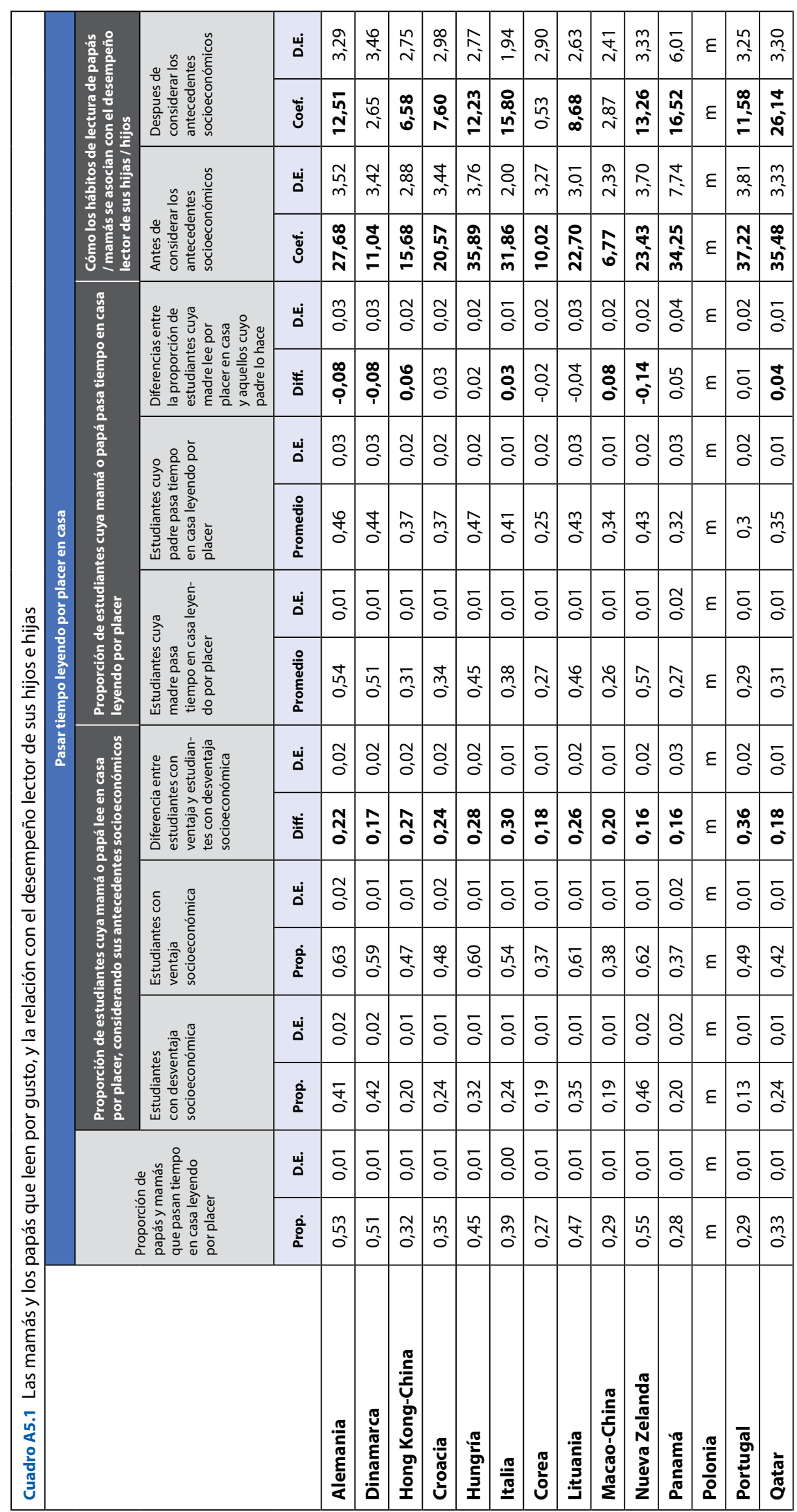

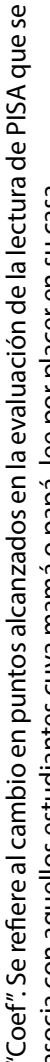

증응

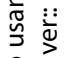

을

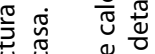

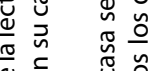

웡

可

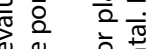

$\frac{10}{2}$

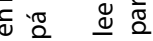

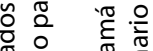

N

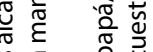

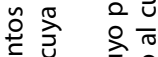

흔

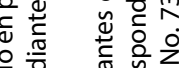

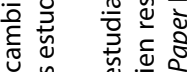

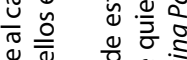

产

这

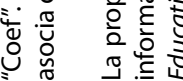

ปั่

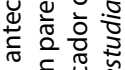

으 은 응 气

동

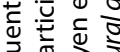

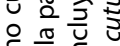

$\frac{a}{2} \frac{0}{0}$

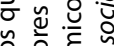

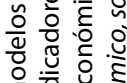

일

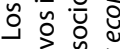

论

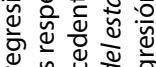

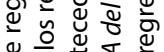

응은

은

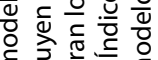

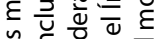

을.

웅 후워

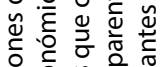

은

है.웡 웡

분

인 


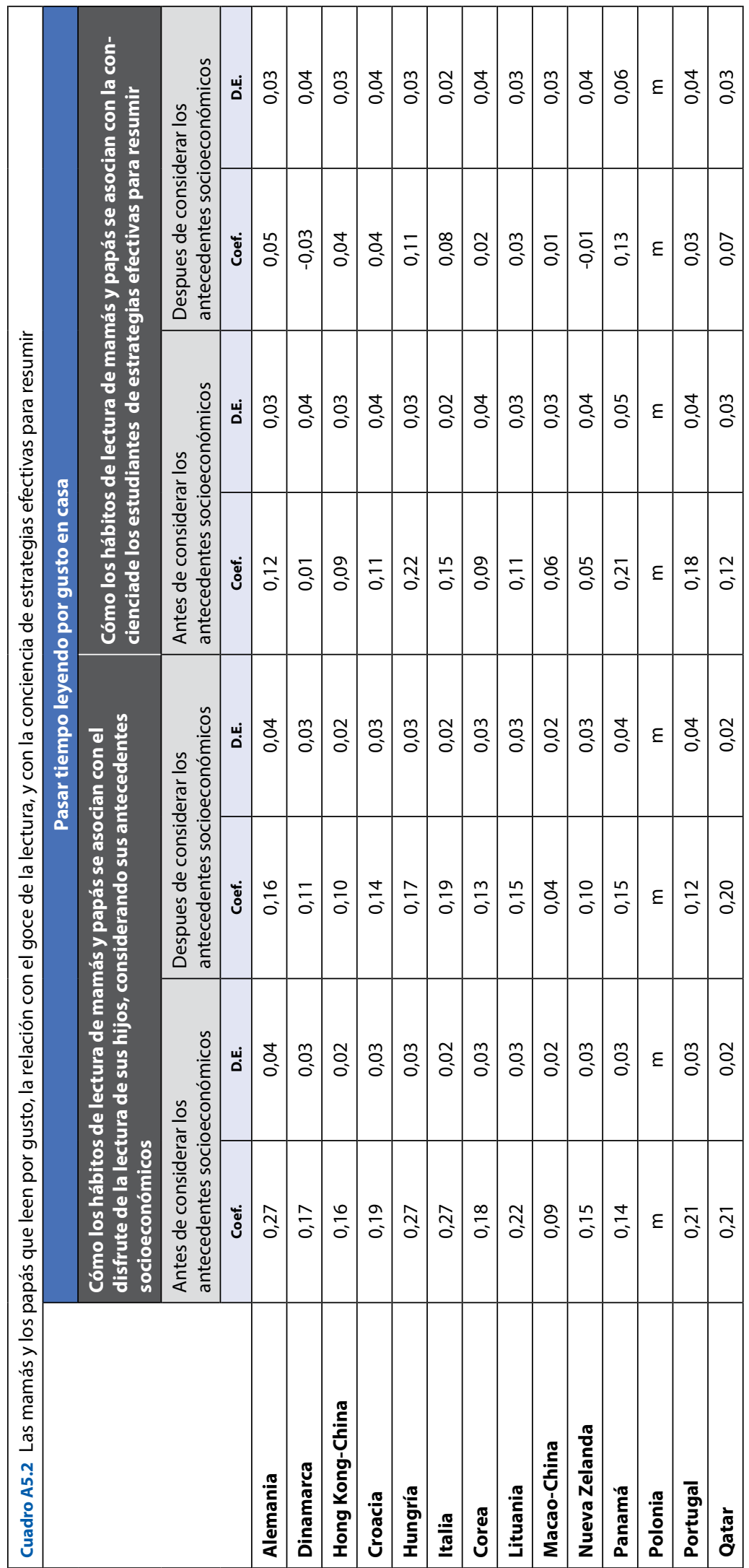

व

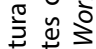

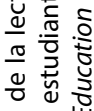

荧呟岂

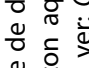

웡

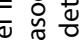

¿

응 음 气ั

N

응 है

金

ปั

을 离

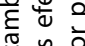

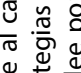

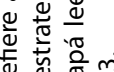

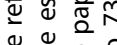

ஸ $\frac{0}{0} \circ$

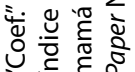

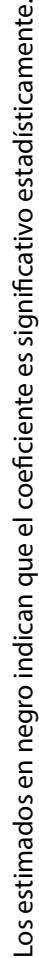

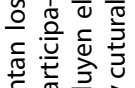

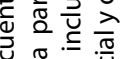

응

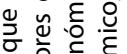

政

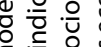

ह.

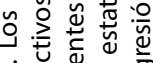

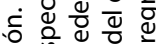

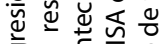

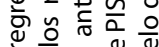

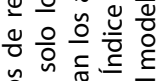

은 $\frac{c}{0} \frac{c}{\omega} \frac{\varepsilon}{\alpha}$

ํㅡㄴ

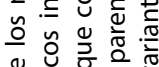

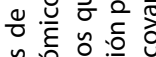

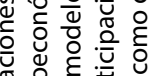

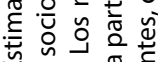

山ै.

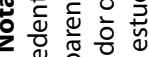

กุ่ 
ORGANIZACIÓN PARA LA COOPERACIÓN Y EL DESARROLLO ECONÓMICOS (OCDE)

La OCDE constituye un foro único en su género, donde los gobiernos trabajan conjuntamente para afrontar los retos económicos, sociales y medioambientales que plantea la globalización. La OCDE está a la vanguardia de los esfuerzos emprendidos para ayudar a los gobiernos a entender y responder a los cambios y preocupaciones del mundo actual, como el gobierno corporativo, la economía de la información y los retos que genera el envejecimiento de la población. La Organización ofrece a los gobiernos un marco en el que pueden comparar sus experiencias políticas, buscar respuestas a problemas comunes, identificar buenas prácticas y trabajar en la coordinación de políticas nacionales e internacionales.

Los países miembros de la OCDE son: Alemania, Australia, Austria, Bélgica, Canadá, Chile, Corea, Dinamarca, Eslovenia, España, Estados Unidos de América, Estonia, Finlandia, Francia, Grecia, Hungría, Irlanda, Islandia, Israel, Italia, Japón, Luxemburgo, México, Noruega, Nueva Zelanda, Países Bajos, Polonia, Portugal, Reino Unido, República Checa, República Eslovaca, Suecia, Suiza y Turquía. La Comisión Europea participa en el trabajo de la OCDE.

Las publicaciones de la OCDE aseguran una amplia difusión de los trabajos de la Organización. Éstos incluyen los resultados de la compilación de estadísticas, los trabajos de investigación sobre temas económicos, sociales y medioambientales, así como las convenciones, directrices y los modelos desarrollados por los países miembros. 


\section{¡Vamos a leer un cuento!}

\section{EL PAPEL DE LOS PAPÁS Y LAS MAMÁS EN LA EDUCACIÓN}

La educación empieza en el hogar. Con la primera palabra que un padre o una madre expresa a su hijo o hija le abre paso al mundo del lenguaje y le lleva al camino de la exploración y el descubrimiento. Cuando la escuela formal comienza, muchos padres creen que su papel como educadores ha terminado. Pero la educación es una responsabilidad compartida y nuevos descubrimientos de PISA muestran que la participación activa de los padres en la educación de sus hijos es fundamental para su éxito a lo largo de su vida escolar, y más allá.

¡Vamos a leer un cuento! no documenta solamente los resultados y análisis de PISA, sino que también ofrece a las madres, a los padres, a los educadores y a los responsables de diseñar políticas públicas recomendaciones para mejorar la participación de los papás y las mamás, y describe los tipos de actividades que se asocian más fuertemente con el mejor desempeño lector. Ofrece abundantes ejemplos de programas que promueven formas efectivas de participación de los padres alrededor del mundo.

Lo más importante es que este informe muestra a los padres que nunca es demasiado temprano -y nunca demasiado tarde- para involucrarse en la educación de sus hijas e hijos. ¡Estar involucrados es la mejor inversión que los padres pueden hacer para el futuro de la siguiente generación!

\section{Contenido}

Capítulo 1. jlnvolúcrate!

Capítulo 2. Lee a tus hijos un cuento

Capítulo 3. Habla con tus hijos sobre el mundo que les rodea

Capítulo 4. Involúcrate en la escuela porque quieres, no porque debes hacerlo

Capítulo 5. Muestra a tus hijos que también valoras la lectura

\section{Consulte esta publicación en línea en: \\ http://dx.doi.org/10.1787/9789264224896-es}

La versión original de esta obra se publicó bajo el título PISA. Let's Read Them a Story! The Parent Factor in Education (ISBN 9789264176195), @ 2012, Organización para la Cooperación y el Desarrollo Económicos (OCDE), París.

Esta traducción se publica por acuerdo con la OCDE. No es una traducción oficial de la OCDE.

www.oecdbookshop.org - Librería en línea de la OCDE www.oecd-ilibrary.org - Biblioteca en línea de la OCDE www.oecd.org/oecddirect - Avisos de nuevas publicaciones de la OCDE 